\title{
Ariel - a window to the origin of life on early Earth?
}

\section{Martin Ferus, ${ }^{*, 1}$ Vojtěch Adam, $\$, 2$ Giuseppe Cassone, $\$, 3$ Svatopluk Civiš, $\$, 1$ Václav} Čuba, ${ }^{\ddagger}, 4$ Elias Chatzitheodoridis, $\$, 5$ Barbora Drtinová, $\$, 4$ Bertrand LeFloch, $\$, 6$ Alan Heays, ${ }^{\ddagger 1}$ Sohan Jheeta, ${ }^{\ddagger}, 7$ Ákos Kereszturi, ${ }^{\ddagger, 8}$ Antonín Knižek, ${ }^{\ddagger 1,9}$ Miroslav Krůs, ${ }^{\ddagger 10}$ Petr Kubelík,, Helmut Lammer, ${ }^{\ddagger, 11}$ Libor Lenža, $\$, 1,2,12$ Lukáš Nejdl, \$, Adam Pastorek, ${ }^{\sharp 1,4}$ Lukáš Petera, ${ }^{\ddagger 1,9}$ Paul Rimmer, ${ }^{\ddagger, 13,14}$ Raffaele Saladino, ${ }^{\ddagger, 15}$ Franz Saija,, 3 Laurenz Sproß, $\$, 11$ Jiří Šponer, $\$, 16,17$ Judit Šponer, $, 16,17$ Zoe Todd,,$\$ 18$ Markéta Vaculovičová, $\$, 2$ Kristýna Zemánková, $\$, 2$ Vladislav Chernov, $\$, 19$

1 J. Heyrovský Institute of Physical Chemistry, Czech Academy of Sciences, Dolejškova 3, CZ 18223, Prague 8, Czech Republic, martin.ferus@jh-inst.cas.cz.

2 Department of Chemistry and Biochemistry, Mendel University in Brno, Zemědělská 1, CZ613 00 Brno, Czech Republic.

3 CNR-IPCF, Viale Ferdinando Stagno d'Alcontres 37, 98158 Messina, Italy.

4 Faculty of nuclear sciences and physical engineering, Czech technical university in Prague, Břehová 78/7, 11519, Prague 1, Czech Republic.

5 National Technical University of Athens, School of Mining and Metallurgical Engineering, 9 Heroon Polytechneiou str.; GR-15780, Zografou, Athens, Greece.

6 CNRS, IPAG, Univ. Grenoble Alpes, 38000, Grenoble, France.

7 Network of Researchers on the Chemical Evolution of Life, Leeds, UK.

8 Konkoly Astronomical Institute, Konkoly-Thege Miklós út 15-17, Budapest, Hungary and European Astrobiology Institute, Strasbourg, France.

9 Charles University in Prague, Faculty of Science, Department of Physical and Macromolecular Chemistry, Albertov 2030, CZ12840, Prague 2, Czech Republic.

10 Institute of Plasma Physics, Czech Academy of Sciences, Za Slovankou 1782/3, 18200 Prague 8, Czech Republic.

11 Space Research Institute, Austrian Academy of Sciences, Schmiedlstr. 6, 8042, Graz, Austria.

12 Valašské Meziřičí Observatory, Vsetínská 941, 75701 Valašské Meziřičí, Czech Republic.

13 University of Cambridge, Cavendish Astrophysics, JJ Thomson Ave, Cambridge CB3 OHE, UK.

14 MRC Laboratory of Molecular Biology, Francis Crick Ave, Cambridge CB2 OQH, UK.

15 University of Tuscia, via San Camillo de Lellis, 01100, Viterbo, Italy.

16 Institute of Biophysics of the Czech Academy of Sciences, Kralovopolská 135, CZ-61265 Brno, Czech Republic.

17 CEITEC - Central European Institute of Technology, Masaryk University, Campus Bohnice, Kamenice 5, 62500 Brno, Czech republic.

18 Harvard-Smithsonian Center for Astrophysics, 60 Garden Street, Cambridge MA, 02138, USA.

19 Voronezh State University, 1 Universitetskaya PI, Voronezh 394018, Russia. Note:

"The authors contributed equally and they are ordered alphabetically.

*Corresponding author:

RNDr. Martin Ferus, Ph.D., E-mail: martin.ferus@jh-inst.cas.cz Tel.: +420 266053204. 
1 Abstract. Is there life beyond Earth? An ideal research program would first ascertain how life on Earth

2 began and then use this as a blueprint for its existence elsewhere. But the origin of life on Earth is still

3 not understood, what then could be the way forward? Upcoming observations of terrestrial exoplanets

4 provide a unique opportunity for answering this fundamental question through the study of other

5 planetary systems. If we are able to see how physical and chemical environments similar to the early

6 Earth evolve we open a window into our own Hadean eon, despite all information from this time being

7 long lost from our planet's geological record. A careful investigation of the chemistry expected on young

8 exoplanets is therefore necessary, and the preparation of reference materials for spectroscopic

9 observations is of paramount importance. In particular, the deduction of chemical markers identifying

10 specific processes and features in exoplanetary environments, ideally "uniquely". For instance, prebiotic

11 feedstock molecules, in the form of aerosols and vapours, could be observed in transmission spectra in

12 the near future whilst their surface deposits could be observed from reflectance spectra. The same

13 detection methods also promise to identify particular intermediates of chemical and physical processes

14 known to be prebiotically plausible. Is Ariel truly able to open a window to the past and answer

15 questions concerning the origin of life on our planet and the universe? In this paper, we discuss aspects

16 of prebiotic chemistry that will help in formulating future observational and data interpretation

17 strategies for the Ariel mission. This paper is intended to open a discussion and motivate future detailed

laboratory studies of prebiotic processes on young exoplanets and their chemical signatures. 
Confidental Paper Concept - Ariel consortium WG Astrobiology and Prebiotic Chemistry

Experimental Astronomy: Special issue for Ariel Phase B

\section{Table of contents}

2

3 Table of contents 3

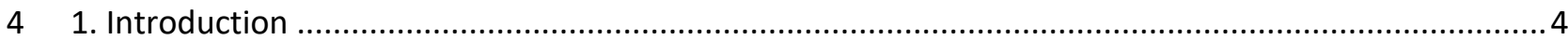

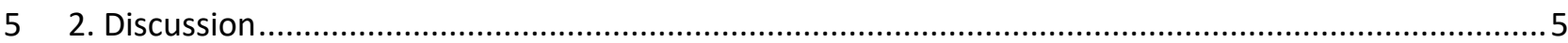

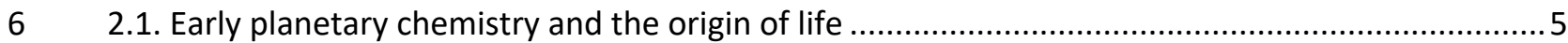

$7 \quad$ 2.1.1. Planetary accretion and impact-driven processes.......................................................... 5

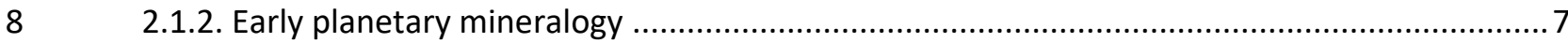

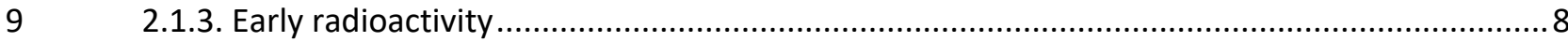

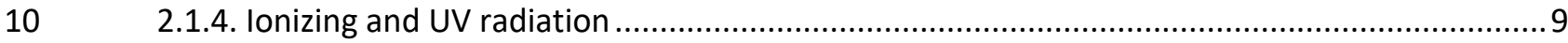

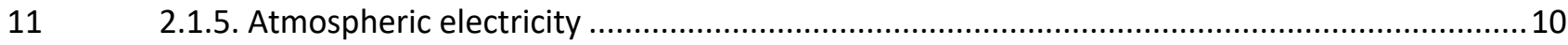

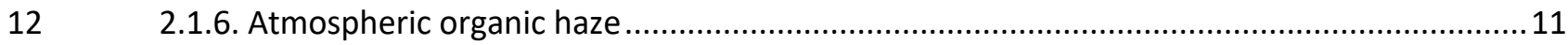

$13 \quad$ 2.1.7. State of the art: Prebiotic synthesis ........................................................................... 11

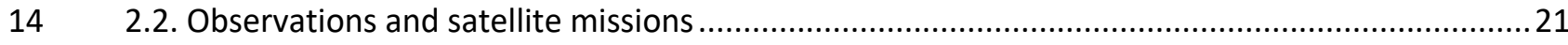

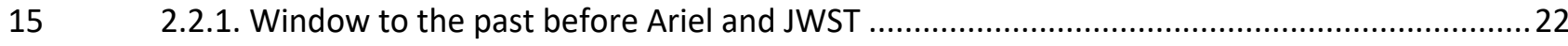

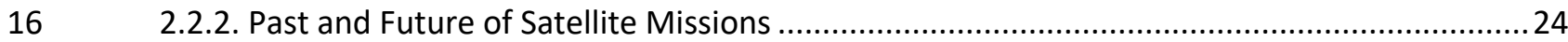

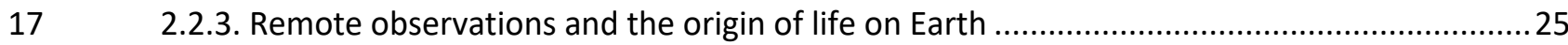

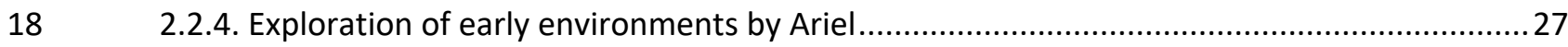

$19 \quad 2.2 .5$. Observation of extreme events and impacts on young worlds........................................2 27

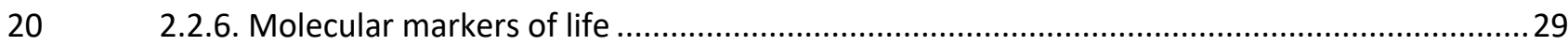

$21 \quad$ 2.2.7. Species related to prebiotic chemistry .............................................................................. 34

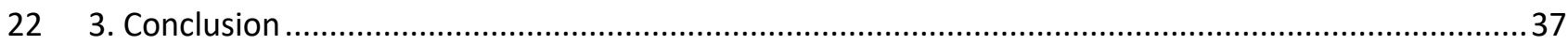

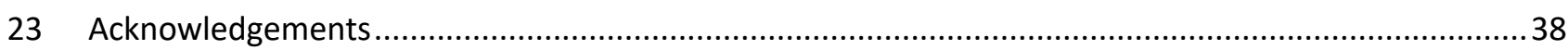

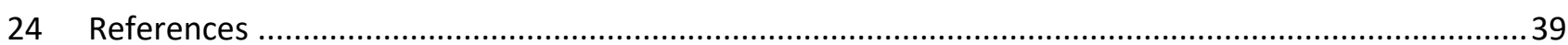

25

26

27 


\section{Introduction}

"Do there exist many worlds or is there but a single world?" This question is attributed to the thirteenthcentury scholar and philosopher Saint Albertus Magnus [1]. Before him, Titus Lucretius Carus, a Roman Epicurean philosopher (c. 98 - c. 53 BC) argues in his poem De Rerum Natura (On the nature of things) that "it is inconceivable that in an infinite universe, it should be only here that a world has formed" [2]. This fundamental question had been asked many times and plenty of scientists, thinkers or curious people still ask it, not only concerning the existence of other worlds but also of other civilizations. Czech poet Jan Neruda, in his famous Cosmic Songs, compared the situation of humankind to small frogs sitting around a single puddle: "What more about this universe? Would you like to be told? Just one more thing, please tell us sir," a frog asked, "Is it true? Do creatures live there just like us? Do frogs exist there too?" ${ }^{1}$ In the same poem, we can find a clue to the answer: "And if we use the spectroscope, their light tells - in addition - that those stars and our Earth, have the same composition." After 150 years, this basic approach is still valid. So far, spectroscopy is the only technique used for studying the composition of distant objects in the Universe. However, technology has changed significantly with its extension to all spectral ranges and adoption of principles and technologies just pioneered or were not known in Neruda's time, and probably resembling magic to the mediaeval philosopher Albertus. "Currently, we are the first generation of scientists able to ultimately prove the existence of alien worlds around distant stars. We are, at the same time, able to study their nature, environment, properties and composition. ${ }^{2 \prime}$

The first exoplanet orbiting a main sequence star was discovered in 1995 [3] by the radial velocity method, and the first observation of an exoplanet atmosphere came in 2002, with the $589.3 \mathrm{~nm}$ sodiumdoublet lines [4]. As of now, over 4000 exoplanets are recognized [5] and the physical and chemical properties of several are tentatively deduced from spectroscopic observations [6]. The two most successful methods for finding exoplanets are the transit [7] and radial velocity [8] methods. The transit algorithm involves observing variation of brightness of a star as the planet passes in front of the host star, while radial velocity measurements track the Doppler shifting of stellar emission lines induced by an orbiting planet. From the transit method, it is possible to obtain the radius of the planet, while the mass of the planet can be determined from the radial velocity method, where the gravitational influence of a planet creates observable shifts in the star's spectral lines [7]. When combined, those methods give the planet's density and a constraint on its interior composition and basic geological properties [9-11]. Transit observations do more than measuring the planetary radius though. By examining how the apparent radius of a planet depends on wavelength, one can measure the absorption spectrum of the planet's atmosphere and analyse it using reference absorption cross-sections for various gas-phase chemical species, clouds, and aerosols [12]. Similar information is obtained from the spectra of planetary emission and reflection $[13,14]$. From observations with sufficiently good resolution, sensitivity and by applying appropriate atmospheric models the chemical composition of the atmosphere can be determined [3, 15]. Additionally, thermal properties [16], surface properties [17], global atmospheric dynamics [18] and cloud properties [19] can all be garnered to a certain extent. Optical and near-infrared interferometry are now offering new possibilities in the search for exoplanets and the characterization of their atmospheres[20], with future prospects at UV wavelengths [21].

\footnotetext{
${ }^{1}$ Translated by D.P. Stern

${ }^{2}$ Noted by Günther Hasinger during Ariel Science, Mission \& Community 2020 Conference.
} 


\section{Discussion}

This paper has been prepared by members of the Ariel consortium working group "Astrobiology and Prebiotic Chemistry." We have selected specific problems closely connected to recent and future research in the fields of prebiotic chemistry, chemical and physical evolution of early terrestrial planetary environments and state-of-the-art exploration of the chemical origins of the first living entities. Exoplanet observations will provide data on the physical and chemical conditions of Earth-like planets in their early evolutionary stages. We expect that relevant chemical evolutionary processes taking place on the distant planets, similar to those which were occurring on the early Earth, will be uncovered by detecting the specific chemical markers. We can confidently say that the chemical composition of a planetary environment is not a static picture: Molecules and their abundances tell us a story about dynamical processes, planetary history and the state of the environment as well as the future destiny of that particular exo-world.

\subsection{Early planetary chemistry and the origin of life}

Contemporary life is a matter of very complex chemistry. However, life's origins are associated with a simple mixture of precursors in a specific environment and undergoing comparatively simple chemical reactions [22]. A first theory on the origin of life from simple precursors (scientific abiogenesis) was proposed by the Russian scientist Alexander Ivanovich Oparin in the 1920's. [23]. The first experiment to support this theory was carried out by Miller and Urey, who demonstrated the formation of aspartic acid, glycine, alanine and butyric acid in a mixture of $\mathrm{CH}_{4}, \mathrm{NH}_{3}, \mathrm{H}_{2}$ and $\mathrm{H}_{2} \mathrm{O}$ exposed to an electric discharge simulating lightning in the primordial atmosphere of the early Earth [24]. However, it should be noted that synthesis of relevant life forming compounds was already known since $19^{\text {th }}$ century, e.g. Strecker synthesis of amino acids, formose reactions leading to sugars explored by Butlerow and, of course, Wohler's synthesis of urea [25]. The main motivation of Miller's pioneering experiments was the exploration of prebiotic synthesis in a simple environment likely similar to the early Earth. Naturally, questions arise: Which environment closely represents the chemistry and physics of the early Earth? Is a mixture of $\mathrm{CH}_{4}, \mathrm{NH}_{3}, \mathrm{H}_{2}$ and $\mathrm{H}_{2} \mathrm{O}$ exposed to electric discharges a realistic model? What does the "Goldilocks chemistry" look like [22]? What sequence of prebiotic reactions in which reactant mixtures gives multiple prebiotic products in good yield without creating too many deleterious side products? Almost 70 years after the Miller experiment, it is still difficult to unite a wide range of experimental and theoretical results, geological evidence and astronomical observations into one picture. Physical and chemical conditions of the Hadean eon as well as the energy sources, starting compounds and intermediates in the origins of prebiotic substances remain unknown. A discussion on important topics related to prebiotic chemistry is given in the following sections. It is assumed that important energetic sources for prebiotic synthesis involve impacts, radiation, electric discharges, heat produced by volcanism and heat in hydrothermal environments of altered impact craters. Minerals and rocks acted as catalysts and provided a reaction environment. Further, deposition of organic feedstock molecules was an important source of starting compounds for prebiotic chemistry, whose major progress is also described in the following pages.

\subsubsection{Planetary accretion and impact-driven processes}

Observational and theoretical studies of solar-type star formation systems in our Galaxy revealed that both our Sun and the circumstellar disk was accreted within a certain unstable regain of the dark molecular cloud due to gravitational collapse of gases and interstellar dust particles. Over tens of millions of years or less, as suggested by recent ALMA observations [25], the material in the protostellar disk accreted into planets. This process occurred in several stages, culminating in the accretion of massive boulders from which the proto-Earth was made [26]. The initial Early Heavy Bombardment 
(EHB) impactor flux decreased after the solidification of the Moon 4.5 Gya, but increased again during the late veneer subsequent to lunar formation and the terrestrial core-closure that occurred prior to 4.4 Gya [27]. The impact flux increased once more during the assumed Late Heavy Bombardment (LHB) $\sim 4-3.85$ Gya [28]. The LHB is a hypothesized time when the Earth was bombarded by asteroid and comet impactors with an increased frequency. The cause of the LHB as suggested by the Nice Model was a restructuring of the outer solar system, prompted by the resonant gravitational interaction of Jupiter with Neptune and other gas giants, and also interacting with populations of asteroids and comets [29-31]. The transient instability of resonance ratios led to a change in Jupiter's orbit and ejection of asteroids and comets from their previously stable orbits towards the centre of the Solar system. Indeed, samples collected during the Apollo missions attributed to impact melting show consistent age to be approximately 3.95 billion years [32],[33]. The age and origin of lunar craters can be ascribed to the LHB as well. The original work of Chyba and Sagan in the 1990s explores the consequences of such high impact activity on the chemical evolution of early Earth [34]. The Earth was probably affected by more than one order of magnitude increase in the frequency of extraterrestrial-body impacts relative to the pre-LHB era [35-37]. At its peak, the LHB highly probably had an influx of $10^{9}$ tons of material per year [38] with typical impact velocities estimated to have increased from $9 \mathrm{~km} \mathrm{~s}^{-1}$ to $21 \mathrm{~km} \mathrm{~s}^{-1}$. Moreover, the ratio of Moon and Earth gravitational cross-sections, approximately 1:17, suggests that about 17 impact basins should have formed on Earth per one lunar basin [39].

Despite this evidence, the existence of the LHB has recently come into question. Debris from the Imbrium impact crater may have reached further sites on the moon, potentially contaminating the samples from the Apollo mission. It has since been suggested that the Apollo samples clustering around 3.95 billion years old may have merely resampled the Imbrium impact crater [40]. In 2012, a study found ages up to 4.2 billion years in the Apollo samples, older than previously known, and suggested that impact formation occurred long before the LHB spike (see extended discussion in [41] and references therein). Suggested modifications to the LHB theory include an extended bombardment period, starting around 4.1-4.2 billion years ago [39],[35], but is not fully supported by evidence of Earth's climate at the time, which was hospitable and had a fairly low temperature [42].

Although the LHB, if it happened, did not induce global ocean evaporation or sterilisation of the Earth [43], it can be assumed that it had a wide influence on planetary chemistry [34, 44-46]. Impact-related processes may have contributed to the delivery [47-50], transformation [51], or even synthesis [52, 53] of biologically-relevant molecules and their precursors on Earth's surface. These expectations are in agreement with more recent findings; for instance, the hydrosphere was probably enriched by water [54] and the atmosphere partly eroded and transformed [55]. Besides water, impactor delivery of volatiles is also expected to have occurred [56], including several reducing gases [46, 57]. In fact, analysis of Ce-anomalies in igneous zircons of crustal origin older than 4.0 Gya reveal that the Hadean continental crust was probably more reduced than its modern counterpart and experienced a progressive oxidation between 4 3.6 Gya [57]. These results indicate a longer persistence of reducing types of atmospheres on the early Earth than previously thought. However, the degree to which the atmosphere was reducing is still uncertain, the exact composition of the reducing mixture remains unknown and the persistence or instability of a particular type of environment on geological time scales is not well understood. Formation of a reducing environment during the Hadean eon is first attributed to impact degassing of reduced substances from impactors and to degassing of $\mathrm{CO}$ - and $\mathrm{H}_{2}$-rich volcanic species [57]. Impact generated atmospheres has been investigated by Kuwahara and Sugita [45], finding the exact molecular concentrations vary widely even for the same impactor composition but, in general, 
impact-produced atmospheres may have been rich in $\mathrm{CH}_{4}$ as on Mars and the ocean-covered Earth and rich in $\mathrm{H}_{2}$ and $\mathrm{CO}$ on the land-covered Venus and super Earths. Other species generated by the degassing of chondritic impactors include $\mathrm{H}_{2} \mathrm{O}, \mathrm{CO}_{2}, \mathrm{~N}_{2}, \mathrm{H}_{2} \mathrm{~S}, \mathrm{NH}_{3}$ and OCS. It is deduced that tens of smaller nonocean-vaporizing impacts will generate significant amounts of $\mathrm{H}_{2}$ and $\mathrm{CO}$ but very little $\mathrm{CH}_{4}$ or $\mathrm{NH}_{3}$ unless catalysts were available to reduce the quenching temperature [58].

Recent investigations provide evidence for impact-induced synthesis of biologically crucial molecules $[53,59-65]$. Moreover, we have studied in detail the possible transformation of atmospheric molecules on early terrestrial planets, such as the formation or decay of formamide and transformations of hydrogen cyanide [66], acetylene [67], methane [68] and carbon monoxide [69],[70]. It should also be noted that abiotic fixation of early Earth's atmospheric $N_{2}$ in the early Archean was not only due to lightning (as it is today) but also due to an increased flux of energetic solar particles, atmospheric shock heating by frequent meteorite impacts, a higher solar ultraviolet radiation and coronal mass ejections related to super flares [71, 72]. Even though some of our work on this topic is focused on the early Earth and origin of life, similar processes are naturally expected to occur in exoplanetary atmospheres [7375]. A goal of ongoing research is to find out whether this chemistry provides distinct gaseous markers that can be observed with facilities such as JWST and Ariel. As an example, take the impact-induced shock-wave reprocessing of a reducing planetary atmosphere dominated by $\mathrm{CO}_{2}, \mathrm{CH}_{4}$ and $\mathrm{N}_{2}$ [76]. Such a shock wave was experimentally simulated in a model planetary atmosphere by dielectric breakdown induced by a terawatt-power laser. Shock-wave chemical reprocessing following the delivery of $3750 \mathrm{~J}$ of energy in 25 laser shots leads to a $5 \%$ yield of $\mathrm{HCN}, 8 \%$ yield of acetylene, $5 \%$ yield of cyanoacetylene and $1 \%$ yield of ammonia. The authors [76] predict that the amount of acetylene produced in earlystage rocky planetary atmospheres with the studied composition would be observable remotely when subjected to a heavy bombardment similar to what happened on the early Earth. This finding has profound implications for exoplanetary observations. If correct, the conjecture that rocky planets with this composition and showing acetylene spectral features are actively experiencing heavy bombardment will provide insight into the formation, chemical composition and evolutionary stage of the observed planetary system.

\subsubsection{Early planetary mineralogy}

During the evolution of planets and planetary systems, the mineral and rock composition changes and the complexity increases as a consequence of different physical and chemical processes [77]. Refractory materials in the interstellar environment contain a limited number of mineral phases, such as diamond, graphite, glass, moissanite ( $\mathrm{SiC}$ ), forsterite, perovskite, rutile and binary metal compounds $[78,79]$. It is postulated that accretion in protoplanetary disks leads to the formation of about 60 mineral phases. Aqueous and thermal alteration results in a mineralogical repertoire of about 250 different minerals. Phyllosilicates are especially important in this aspect, as their occurrence points to aqueous alteration [80], which might happen not only in large planets but also inside small planetesimals if a substantial heat source exists, like $\mathrm{Al}^{26}$ or $\mathrm{Fe}^{60}$ in the case of the Solar System [81]. These isotopes together with accretional heat-melted ice contribute to the weathering of silicates to clays, e.g. phyllosilicates [82], and this mineral group supports the build-up of organics by catalysis [83]. Hazen et al. [84] hypothesized that prebiotic Earth's near-surface environment may have held no more than 420 volumetrically significant mineral species. However, the direct evidence is of course missing because Hadean eon is actually defined as the time before the first rock due to lack of fossil evidences (Acasta Gneiss, 4.004.03 Gya, see [85] and references therein). It is assumed that dominant Hadean mineralizing processes include the evolution of a diverse suite of intrusive and extrusive igneous lithologies; hydrothermal 
alteration over a wide temperature range; diagenesis and low-grade metamorphism in near-surface environments; impact-related processes such as the creation of marginal hydrothermal zones, excavation of deep metamorphosed terrains and the direct shock metamorphism. Post-Hadean processes related to biological activity may be responsible for over 4000 of the more than 4800 observed mineral species. However, impact shock-wave-related processes may have created a similar environment suitable for the prebiotic synthesis under early Earth conditions. Our recent explorations show the importance of asteroid or comet impact shock wave on the formation of prebiotic substances such as cyanides, formamide but also nucleobases, sugars or simple amino acids $[53,59,61-63,65-68$, $70,86-92]$.

Another interesting concept is that of the role of nanoparticles. Sulphur in solution with a wide range of metal ions present on the early Earth might lead to the formation of nanoparticles that are important for proto-metabolisms. The environment on early Earth might have supported synthetic cycles based on the metal ions $\mathrm{Zn}(\mathrm{II}), \mathrm{Cd}(\mathrm{II})$ and thiols, and driven by UV radiation. The resulting nanoparticles were able to mimic the enzyme xanthine oxidase function [93]. This chemistry might have been typical, for example, in hydrothermal vents in impact structures on the early Earth.

\subsubsection{Early radioactivity}

Since its formation, our planet was exposed to cosmic radiation and the radioactive decay of radionuclides present in Earth's crust and mantle. The present day core retains heat obtained from a combination of leftover heat generated during its formation and from radiogenic heating [94, 95]. Nowadays, these two sources result in surface heat loss of 36 to 49 TW [96-100], , of which approximately half is due to radioactivity [101]. According to the estimate of Gando's et al. [101] , there are approximately 4.3 billion particles proceeding from the radioactive decay of ${ }^{238} \mathrm{U}$ and ${ }^{232} \mathrm{Th}$ permeating every square centimetre of the Earth's surface every second. This ubiquitous radioactivity certainly had the potential to influence early abiogenic synthesis and molecular stability. Zagórski et al. discuss the role of Earth's radioactive background in their origin of life theories and note the nuclear chemistry contribution to this multidisciplinary problem is often overlooked $[102,103]$. The evolution of Earth's heat budget especially in the first half of its lifetime has not been resolved yet, but the radioactive activity can be estimated through the exponential decay law [97]. Considering ${ }^{238} \mathrm{U}\left(\tau_{1 / 2}=\right.$ $4.47 \mathrm{Gyr}),{ }^{235} \mathrm{U}\left(\tau_{1 / 2}=0.704 \mathrm{Gyr}\right),{ }^{232} \mathrm{Th}\left(\tau_{1 / 2}=14.0 \mathrm{Gyr}\right)$, and ${ }^{40} \mathrm{~K}\left(\tau_{1 / 2}=1.25 \mathrm{Gyr}\right)$ [104], which constitute the main radioactive isotopes in the mantle, one can find a doubling in activity at $2.5 \mathrm{Gya}$, more than a tripling at $4 \mathrm{Gya}$, and an even stronger increase at earlier times, due to the short-lifetimes of this quartet of isotopes. Therefore, very young terrestrial planets might have strong radiogenic surface emissions. It can also be assumed that ionising radiation is a ubiquitous source of energy for building up the prebiotic inventory in interplanetary space (e.g., in the form of a solar wind) $[105,106]$, interstellar space (e.g., in the form of heavy particles [107]) as well as for the early Earth (e.g., by exposure to radioactive minerals [108]).

Adam et al. [109] recently studied the production rate of formamide influenced by radioactive minerals on the prebiotic Earth. They estimate a formation production rate up to $0.1-0.8 \mathrm{~mol} \cdot \mathrm{km}-2 \cdot \mathrm{yr}-1$. In highly concentrated radioactive mineral deposits (e.g., the Oklo natural reactor in Africa) the production rate could have been 3 orders of magnitude higher, $0.1-1 \mathrm{~mol} \cdot \mathrm{m}-2 \cdot \mathrm{yr}-1$, providing a possible answer to the long-lasting question of the plausible concentration of formamide, or general radiogenic products, in the early environment (see also Z. Adam et al.[110] and Ebisuzaki et al.[111]). 
1 The role of an enhanced background radioactivity in terrestrial prebiotic synthesis, the origin of life and

2 the first metabolic processes is not yet completely understood, being The investigation of radiolysis

3 products observable in planetary spectra and their possible relation to the intensity of radioactive

4 background on exoplanets represent truly a terra incognita in the field of exoplanetary science.

\section{2.1.4. lonizing and UV radiation}

6 The chemical environments of early-stage planets are assumed to be largely influenced by radiation

7 from their young parent stars, which frequently emit orders-of-magnitude greater UV/XUV/X-ray fluxes

8 than main sequence stars $[112,113]$, as well as incoming high energy particle $\left(\mathrm{eg} \mathrm{H}, \mathrm{H}^{+}, \mathrm{D}^{+}, \mathrm{He}, \mathrm{He}^{+}\right)$and cosmic radiation. On the other hand, recent findings highlight the importance of asteroid and cometary impacts, $[34,52,53,92,114]$ and volcanic activity $[59,115]$ for producing dusts, hazes and heavy clouds [116]. Under some conditions, the planetary surface is then shielded from UV light and surface chemistry is more influenced by impact plasmas, shock waves [53], thermochemistry [117] or atmospheric electricity [118],[119]. Nevertheless, UV fluxes influence the upper part of even dusty and cloudy atmospheres, producing hazes with rich photochemistries, with examples being Titan and Venus. A thorough understanding of photochemical reactions on early exoplanets is essential for identifying the more likely variants of prebiotically relevant reactions. It can be assumed that during planetary evolution, when the surface UV flux increases, several prebiotic feedstock molecules such as formamide, formaldehyde, hydrogen cyanide and related compounds (ferrocyanides, tholin deposits, cyanamide, cyanoacetylene or cyanogene) can react upon irradiation to produce biologically relevant molecules. Understanding the chemical environment of early planets is therefore important because it will render possible the identification of the most plausible feedstock molecules. The presence of water both in the atmosphere[120] and on the surface may also significantly affect chemical processes on early planets. It is worth mentioning that enhanced radiolysis by charged particles is expected in the case of slowly rotating or tidally locked exoplanets with weak magnetic fields.

As an example, laboratory experiments [68] demonstrated the UV photocatalytic reduction of $\mathrm{CO}_{2}$ to $\mathrm{CH}_{4}$ in the presence of titanium dioxide or montmorillonite, and possibly other minerals. The transformation of a $\mathrm{CO}_{2}$ atmosphere to one containing $\mathrm{CH}_{4}$ and $\mathrm{CO}$, as well as the purely-photochemical reverse transformation, is then partly possible on terrestrial planets with rich mineral surfaces that are exposed to large UV fluxes and in acidic environments. The current conditions on Mars favour this process and photoreduction may explain the origin and seasonal variation of methane on Mars [68].

In addition to the action of UV light, the ionizing radiation stemming from the presence of radionuclides (decaying radiogenic isotopes eg. ${ }^{235} \mathrm{U},{ }^{230} \mathrm{Th},{ }^{238} \mathrm{U}$ ) and/or cosmic radiation may initiate radiolysis and thus play an important chemical role. The highly reactive intermediates of water radiolysis may react with other compounds present in the environment and rapidly change the chemical speciation of the whole system. Photolysis intermediates behave very similarly. Chemical processes initiated by ionizing and non-ionizing (in particular UV) radiation in aqueous solutions can often be rather difficult to differentiate. In the course of radiolysis, part of the absorbed energy is consumed to form stable products, $\mathrm{H}_{2}$ and $\mathrm{OH}^{-}$, and reactive intermediates that are involved in numerous reactions [121], e.g. $\mathrm{H}$, $\mathrm{OH}, \mathrm{H}_{2}, \mathrm{H}_{2} \mathrm{O}_{2}, \mathrm{H}_{3} \mathrm{O}^{+}, \mathrm{OH}^{-}, \mathrm{HO}_{2}$. The initial radiochemical yields, in units of $10^{-2} \mathrm{eV}^{-1}$, of primary intermediates have been summarized by [122]: $\mathrm{H}(0.62), \mathrm{OH}(5.6), \mathrm{H}_{2}(0.15), \mathrm{e}_{\text {aq }}^{-}(4.78), \mathrm{H}^{+}$aq $(4.78)$. The photolysis of water also yields $\mathrm{OH}$ and $\mathrm{H}$ radicals but through a more streamlined process compared with radiolysis. Hydrated electrons tend to be formed with very low yields at wavelengths longer than $185 \mathrm{~nm}$ [123]. It is well known that $\mathrm{OH}$ radicals play a prominent role among the possible photolysis 
also under $254 \mathrm{~nm}$ irradiation [125]. As the energy of radiation decreases, the probability of formation of ionized states decreases in favor of excited states. However, excited states of water molecules may dissociate to form $\mathrm{OH}$ and $\mathrm{H}$ radicals, and short-wavelength $\mathrm{UV}$ radiation can initiate a chemistry similar to that of ionizing radiation [126].

A recent hypothesis proposes that hydrogen peroxide could have played a significant role in the prebiotic synthetic processes [129], [130]. Radiolysis and photolysis can serve as potential sources of hydrogen peroxide in a primordial environment alongside with the oxygenation of seawater mixed with hydrothermal vent fluids [127], surface reaction of pyrite with water [128], photochemical disproportionation of the superoxide radical, or radiolysis of water in natural nuclear reactors [129].

\subsubsection{Atmospheric electricity}

Lightning directly extends atmospheric chemical variety on short time and spatial scales but also significantly affects the bulk atmospheric composition in the long run. On young planets, impacts and volcanism produce significant amounts of dust and vapours that form dense clouds [131-133]. In such environments, we can assume there is strong lightning activity and its significant contribution to atmospheric plasma chemistry [34,131,134-137]. For example, it has been recently demonstrated via state-of-the-art simulations that a partial formose reaction (i.e., an autocatalytic series of chemical reactions starting from aldehydes and forming relatively complex sugars) is initiated simply by exposing aqueous mixtures of glycolaldehyde to intense electric fields [119].

Electric discharges play an important role in the transformation of atmospheres, particularly by producing a large amount of $\mathrm{HCN}$ from $\mathrm{H}-\mathrm{C}-\mathrm{N}$ bearing species [66]. In their pioneering experiment, Miller and Urey demonstrated the synthesis of amino acids from simple initial mixtures of reduction gases such as $\left(\mathrm{CH}_{4}+\mathrm{NH}_{3}+\mathrm{H}_{2} \mathrm{O}+\mathrm{H}_{2}\right.$ [24]; $\mathrm{CO}+\mathrm{CO}_{2}+\mathrm{N}_{2}+\mathrm{NH}_{3}+\mathrm{H}_{2}+\mathrm{H}_{2} \mathrm{O}$ [138]; or $\mathrm{H}_{2} \mathrm{CO}$ and their various combinations $[139,140]$ ) by exposing these to electric discharges. Following their explorations, Ferus et al. [141] have shown that nucleic acid bases can be synthetized alongside the amino acids in this kind of experiment as well. Also, these investigations show that volcanic lightning can produce large deposits of formamide or tholins. These original ideas have re-emerged in the light of new experiments carried out very recently in several studies showing, for example, that the atmosphere of Titan, the largest moon of Saturn, can produce nucleobases in rich $\mathrm{HCN}$-based discharge chemistry [142, 143].

Energetic processes such as lightning also act as a strong abiotic fixation process for the removal of atmospheric $\mathrm{N}_{2}$. Earth's present thunderstorm lightning fixes 4-6 Tg N/yr [144-148], which sums up to more than 10 mbar N in 10 Myr [73]). Generally, throughout Earth's history, abiotic fixation pathways have occurred via high-temperature reduction or oxidation reactions of $\mathrm{N}_{2}$ to $\mathrm{NH}_{x} / \mathrm{HCN} / \mathrm{NO}_{x}$ depending on the environment's redox state $[73,149-151]$. The resulting compounds are mostly water-soluble

During an electrical discharge like in the Miller-Urey experiment free electrons are generated with a wide energy range 30-60 kV. The high-energy electrons (and extreme-UV photons) undergo inelastic collisions with molecules, resulting in their ionization or decomposition into fragments. These processes starting with reactive species like free radicals and ions are characterized by a non-uniform distribution of reaction intermediates and non-selective chemistry leading to the production of multiple products and may include reaction not available to pure photochemistry [152]. In planetary atmospheres, 
discharge chemistry results in the formation of $\mathrm{CH}_{2} \mathrm{NH}$ and $\mathrm{HCN}$ starting from atmospheres of $\mathrm{CH}_{4}$ and $\mathrm{NH}_{3}$. This could possibly also occur under prebiotic conditions and is considered an important step linking complex biomolecules to $\mathrm{CH}_{4}$ and $\mathrm{NH}_{3}$ [153]. The low-energy Rydberg states of atoms [154], [155], [156], [157]. generated in electric discharges are another important initiator of reactions. Thes Rydberg states are excited by secondary electrons and can emit UV photons upon decay. In turn, the UV photodetachment of hydrocarbon anions (e.g. $\mathrm{C}_{4} \mathrm{H}^{-}$and $\mathrm{C}_{6} \mathrm{H}^{-}$as well as $\mathrm{C}_{3} \mathrm{~N}^{-}$and $\mathrm{C}_{5} \mathrm{~N}^{-}$) can lead to neutral hydrocarbons that further contribute to hydrocarbon chemistry in planetary atmospheres [158].

\subsubsection{Atmospheric organic haze}

Based on models of exoplanetary [159, 160], early Earth's [161, 162] and Titan's atmosphere [163-165], high altitude atmospheric organic haze could play a role in prebiotic synthesis. Such a haze is composed of aerosols, including PAHa, [163] formed from $\mathrm{CH}_{4}$ by UV-driven upper-atmosphere photochemistry [166]. Certain model calculations [167] suggest that exoplanet hazes with anomalously low $\mathrm{CH}_{4} / \mathrm{CO}_{2}$ ratios suggest the presence of biogenic sulphur and, therefore, biogenic activity, however, the necessary observations require high spectral resolution. The Observation of organic hazes might provide a constraint on the thermal budget of a planet, and its apparent habitability [168]. A large variety of possible reactions contribute to the evolution of prebiotic haze layers, and several models [169-172] stand to be supported, confirmed or rejected by Ariel observationsAriel, especially regarding the range of identified atmospheric components. Observation-based aerosol scattering properties could point to the size and spatial concentration of haze grains and their temporal variation, and linked to the planetary albedo $[173,174]$.

\subsubsection{State of the art: Prebiotic synthesis}

We do not know how life on Earth came to be. Prebiotic chemistry, however, tries to explore the likelihood of various abiotic synthesis scenarios. The advent of prebiotic synthesis began in 1953 when Miller and Urey [175], synthesized amino acids in simulated planetary atmospheres, as described above. The synthesis mechanism has not been confirmed but possibly proceeds through Strecker synthesis, whose general mechanism is shown in Figure 1, though other scenarios have been proposed and supported by computations [176].
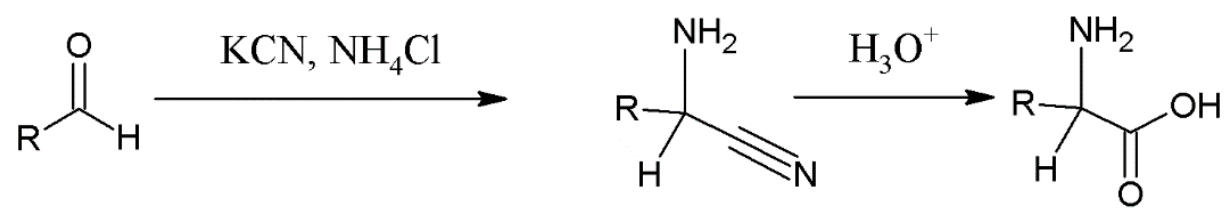

Figure 1. The basic mechanism of Strecker synthesis.

Since 1953, major progress has been made [51, 53, 176-179]. Prebiotic synthesis of nucleobases and nucleotides became more important than ever in the late 1960s when the theory of the RNA world was established by Alexander Rich in the book Horizons in Biochemistry [180-182]. The modern form of this theory follows the discovery of Thomas R. Cech et al. in 1982 [183], that RNA has autocatalytic properties and can replicate itself. Proteins have no such quality and the RNA world theory proposes that RNA must have occurred first and incorporated proteins later. This theory is further supported by the central dogma of molecular biology. postulating (in general) that proteins are synthesized from nucleic acids and not vice versa [184]. In the modern form of this theory [185], RNA structures such as ribozymes are assumed to be the most ancient heritage of the RNA world in modern cells. Ribozymes still exhibit several independent functions. For example, E. Kejnovský concludes in his book that RNA 
world still exists on an independent level in modern cells [185]. However, the structure of this small

The issue of nucleic acids synthesis under prebiotic conditions is usually divided into three separate problems - the synthesis of single components (nucleobases, saccharides and phosphate); the synthesis of nucleotides; origin of nucleosides and the synthesis of the nucleic acid itself from its components (the condensation of nucleotides). Hydrogen cyanide $(\mathrm{HCN})$ and its hydration product, formamide $\left(\mathrm{HCONH}_{2}\right)$, are at the centre of great scientific interest concerning prebiotic synthesis of nucleobases and their components. Many possible mechanisms have been proposed where one of the above-mentioned molecules plays a key role in synthesising life's precursors $[34,51,53,59,63,67,106,107,135,136$, 186-189] . It is noteworthy that HCN can be produced in planetary atmospheres from various mixtures of atmospheric gases under various conditions and with varying yields. Experiments synthesising nucleic acid bases and glycine in a reducing atmosphere containing $\mathrm{CH}_{4}, \mathrm{CO}, \mathrm{N}_{2}$ and $\mathrm{H}_{2} \mathrm{O}$ used a shock-wave simulating an asteroid impact as an energy source. The shock wave generated in this high power laser experiment reaches velocities up to $60 \mathrm{~km} \mathrm{~s}^{-1}$ and with local pressures as high as $3.6 \mathrm{Mbar}$ [190]. When experimentally simulating the conditions of an extraterrestrial body impact [191] it turns out that mixtures containing carbon, hydrogen, oxygen and nitrogen molecular form, e.g. as $\mathrm{CO}_{2}, \mathrm{~N}_{2}, \mathrm{CO}, \mathrm{CH}_{4}$, $\mathrm{NH}_{3}$ or $\mathrm{H}_{2} \mathrm{O}$ reliably and systematically produce $\mathrm{HCN}$ [66]. The yield of $\mathrm{HCN}$ and other reaction products, such as $\mathrm{C}_{2} \mathrm{H}_{2}$ or $\mathrm{C}_{2} \mathrm{H}_{4}$, depends on the initial composition and the conditions the mixture is exposed to [62, 67-69, 192-194]. Similar results can be obtained when an electric discharge (simulating lightning events) is used as an energy source $[186,195]$. Similarly to a lightning or impact event, the pulsed-laser experiment produces a shock is heated to a very high temperature, $\sim 5000 \mathrm{~K}$, and causes XUV photoemission of the medium [196]. The nature of the underlying molecular processes is as-yet unknown but both radical and thermal reactions may influence the dynamics. Theoretical validation is necessary, but a possible reaction mechanism of the $\mathrm{HCN}$-based radical synthesis is shown in Figure 2 . Additionally, formamide-based radical synthesis of nucleic acid bases is also demonstrated in the laboratory [53] and its reaction mechanism, depicted in Figure 3, fully verified by a spectroscopic survey of products and theoretical calculations [114] [193].

The "classical" pathways of prebiotic synthesis, in the absence of high energy chemistry, should also be mentioned. The story of formamide-based biomolecule synthesis begins with Bredereck et al. 1956 [197], which did not, however, have any connection to the origin of life. Formamide was first proposed as the parent molecule of life by Raffaele Saladino and Ernesto Di Mauro in the late 1990s. Their study published in 2001 [198] presents a prebiotically possible 


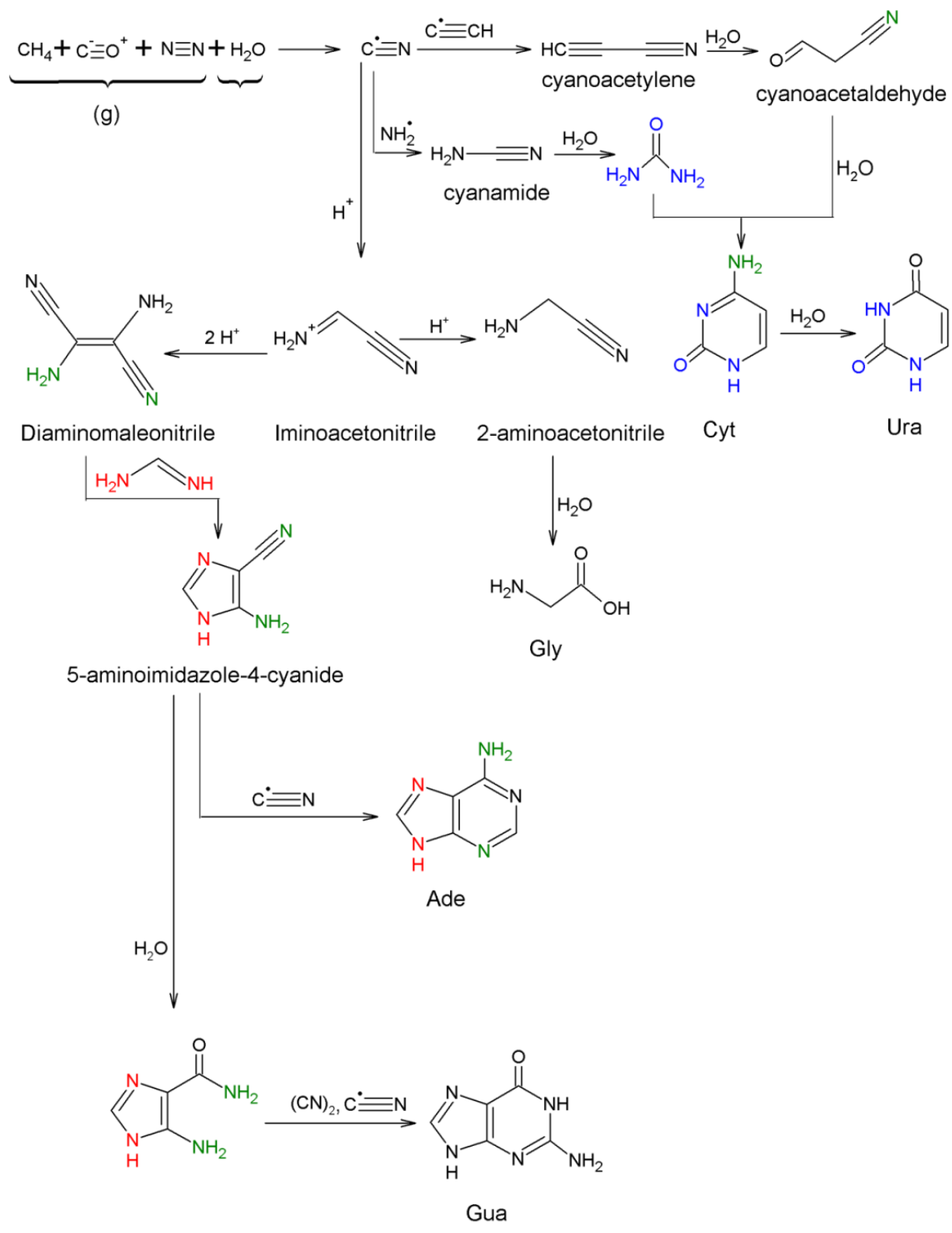

2 Figure 2. HCN-based synthesis of nucleic acid bases in our experiments. The figure was adapted from 3 [68] and published in [199].

4 


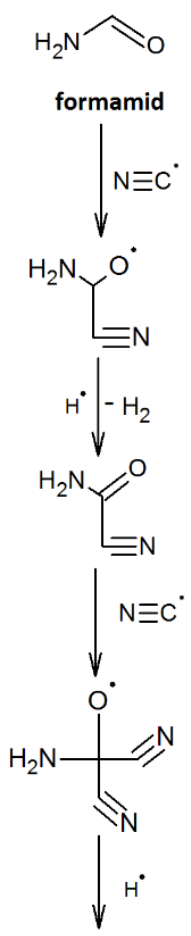<smiles>N#CC(N)(O)C#N</smiles>

$$
\downarrow N \equiv c^{\circ}
$$<smiles>CCC(=[V])C(N)(O)C#N</smiles><smiles>N#CC(=N)C(N)(O)C#N</smiles>

2,3-diaminofumaronitrile HCN tetramer

$$
\text { DAFN }
$$<smiles>N#CC(N)=C(N)C#N</smiles>

2,3-diaminomaleonitrile (HCN tetramer) DAMN<smiles>CCCCCCC</smiles><smiles>N#CC(=N)C(N)C#N</smiles><smiles>CCCNC=O</smiles>

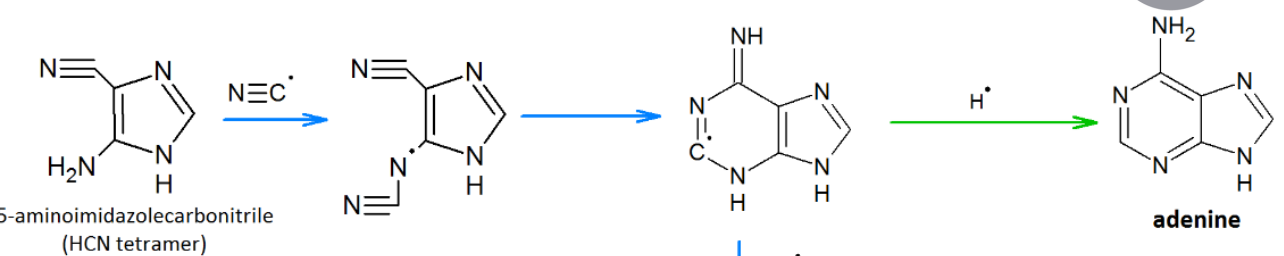
( $\mathrm{HCN}$ tetramer)

$$
\downarrow \mathrm{NH}_{2}
$$

adenine

$$
\text { AICN }
$$<smiles></smiles>

3 Figure 3. Formamide-based radical synthesis of nucleic acid bases in our experiments. The scheme was 4 adapted from[53], [114] and [193]. 


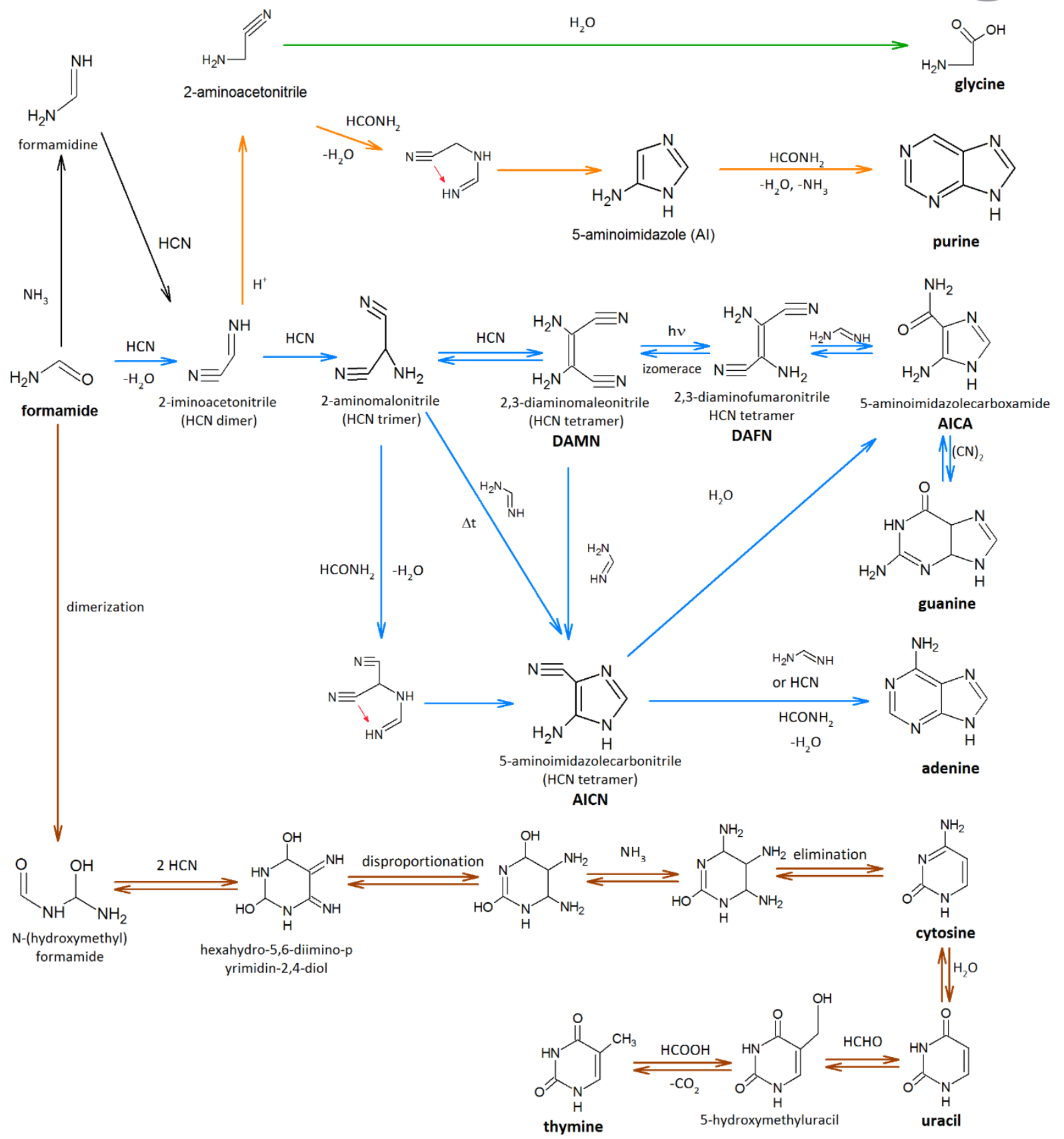

Figure 4. Classical synthesis of nucleic acid bases from formamide in aqueous solution. The figure was adapted from $[199,200]$.

synthesis of adenine, cytosine, purine and $4(3 \mathrm{H})$-pyrimidinone from formamide heated to $160{ }^{\circ} \mathrm{C}$ in the presence of catalysts like silica and alumina. The authors argument that formamide is a more plausible starting molecule than $\mathrm{HCN}$ since it is comprised of all four macrobiogenic elements $\mathrm{H}, \mathrm{N}, \mathrm{C}$ and $\mathrm{O}$, whereas to produce biomolecules from $\mathrm{HCN}$ requires incorporation of oxygen via hydration (to produce formamide) or in a complex radical and ion chemistry [51]. The typical thermal formamide-based synthesis is depicted in Figure 4. This mechanism is also very plausible in post-impact hydrothermal environment with metal-rich water altered minerals containing both original material from the impactor and formamide likely produced in the early planetary environment [201]. 
1

Formic acid, $\mathrm{HCOOH}$, is often overlooked in prebiotic synthesis, even though it was a major product in the famous Miller-Urey experiment. However, formic acid has been observed as a product of simulated extraterrestrial impact into a planetary atmosphere of $\mathrm{H}_{2} \mathrm{O}, \mathrm{SO}_{2}, \mathrm{H}_{2}, \mathrm{CO}$ and $\mathrm{N}_{2}$ [202]. This result indicates that formic acid could have been available in the atmosphere of early Earth for prebiotic synthesis [202].

On another note, in accordance with the Bernal's hypothesis on the role played by minerals in the origin of life [203], the chemo-specificity and regioselectivity of prebiotic chemistry on the primitive Earth was most likely controlled by the catalytic properties of minerals provided by the geochemical scenario [204]. In this context, Ariel is an effective cosmological tool for the identification and selection of real prebiotic probes in exoplanets. From the geochemical point of view, the Hadean was characterized by the serpentinization process producing huge amount of highly concentrated silica solution, the optimal medium for the spontaneous self-assembly of inorganic biomorphs [205]. These supramolecular structures show inorganic membranes with a different internal and external composition. The membrane interior is mainly composed from metal silicates, while ordered aggregates of silica largely prevail outside [206]. The chemo-physical asymmetry of the whole system has relevant consequences for prebiotic chemistry since it generates $\mathrm{pH}$ and electrochemical gradients able to act as a driving-force for the synthesis of biomolecules [207]. Dynamic systems of this type, associated with the intrinsic catalytic effect of silica minerals and metal atoms, are proven to be efficient synthetic factories for the production of a large panel of biomolecules from formamide [208]. Compartmentalisation also works as a regioselective process, favouring the formation of the largest amount of reaction products, including the complete set of nucleobases inside the biomorph structure (Figure 5). Moreover, the capacity of silica minerals to catalyse the oligomerization of nonactivated amino acids to their corresponding peptides has been reported as requiring a low energy [209].

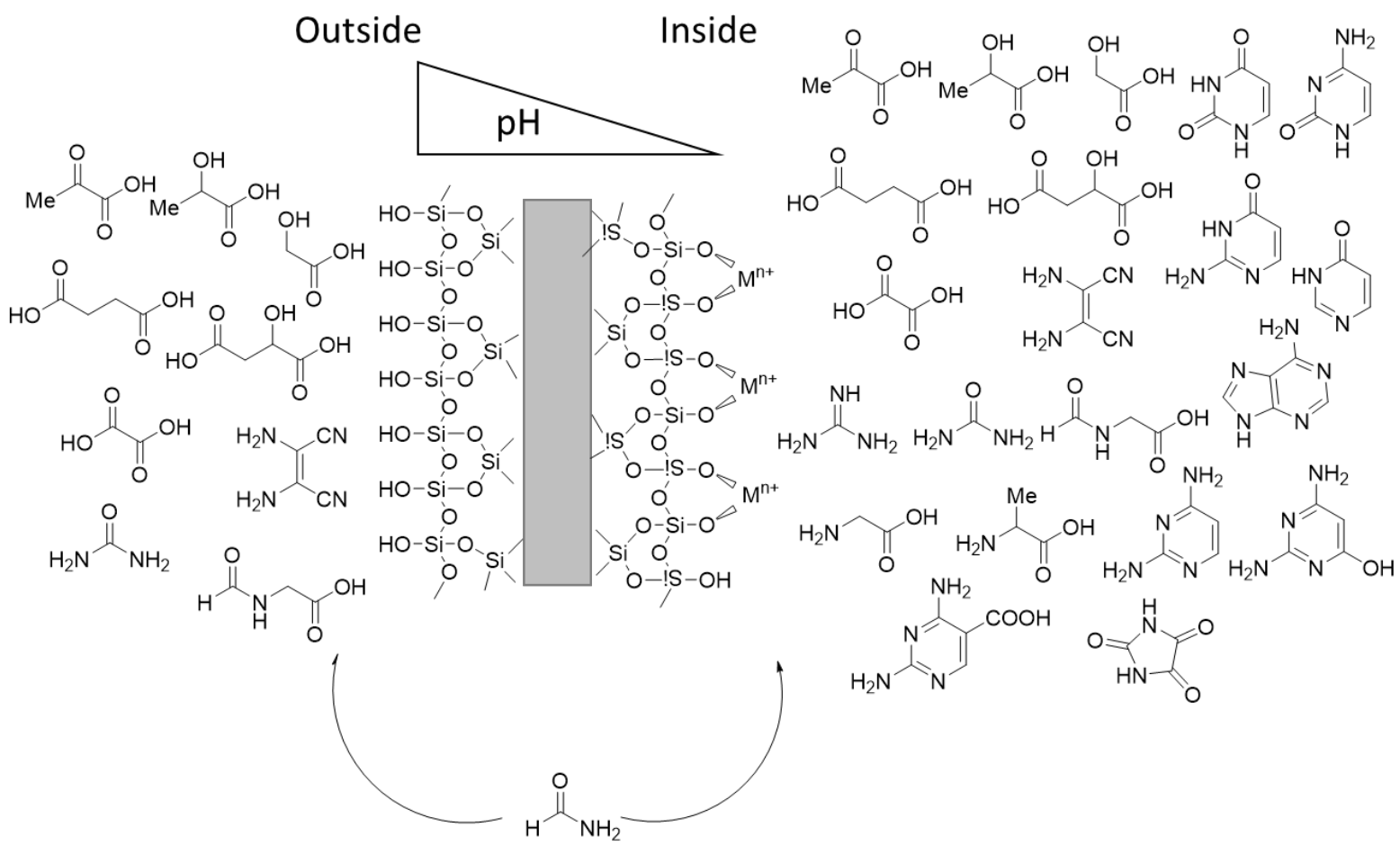


2 Figure 5. Catalytic effect of silica garden in the oligomerization of formamide to biomolecules. A 3 different chemo-selectivity is operative depending on the compartmentalization of the system.

4 Nucleobases and heterocycles largely prevailed in the conditions existing inside the membrane 5 characterized by a lower $\mathrm{pH}$ and the presence of metal silicates.

7 The mechanical stability of membranes during the self-assembly process in mineral vesicles is a critical 8 aspect to be considered in the successive molecular evolution events. Unlike chemical gardens that 9 possess a stable membrane, mineral vesicles are destined to break their membrane once a critical 10 growth dimension is reached. In this way, vesicular biomolecules are expelled into the environment and 11 start further reactions and aggregation processes, acting as a virus-like prebiotic system [210]. Here we 12 see the broader promise of inorganic biomorphs for favouring increased organic-molecule complexity 13 in a prebiotic environment [211]. 


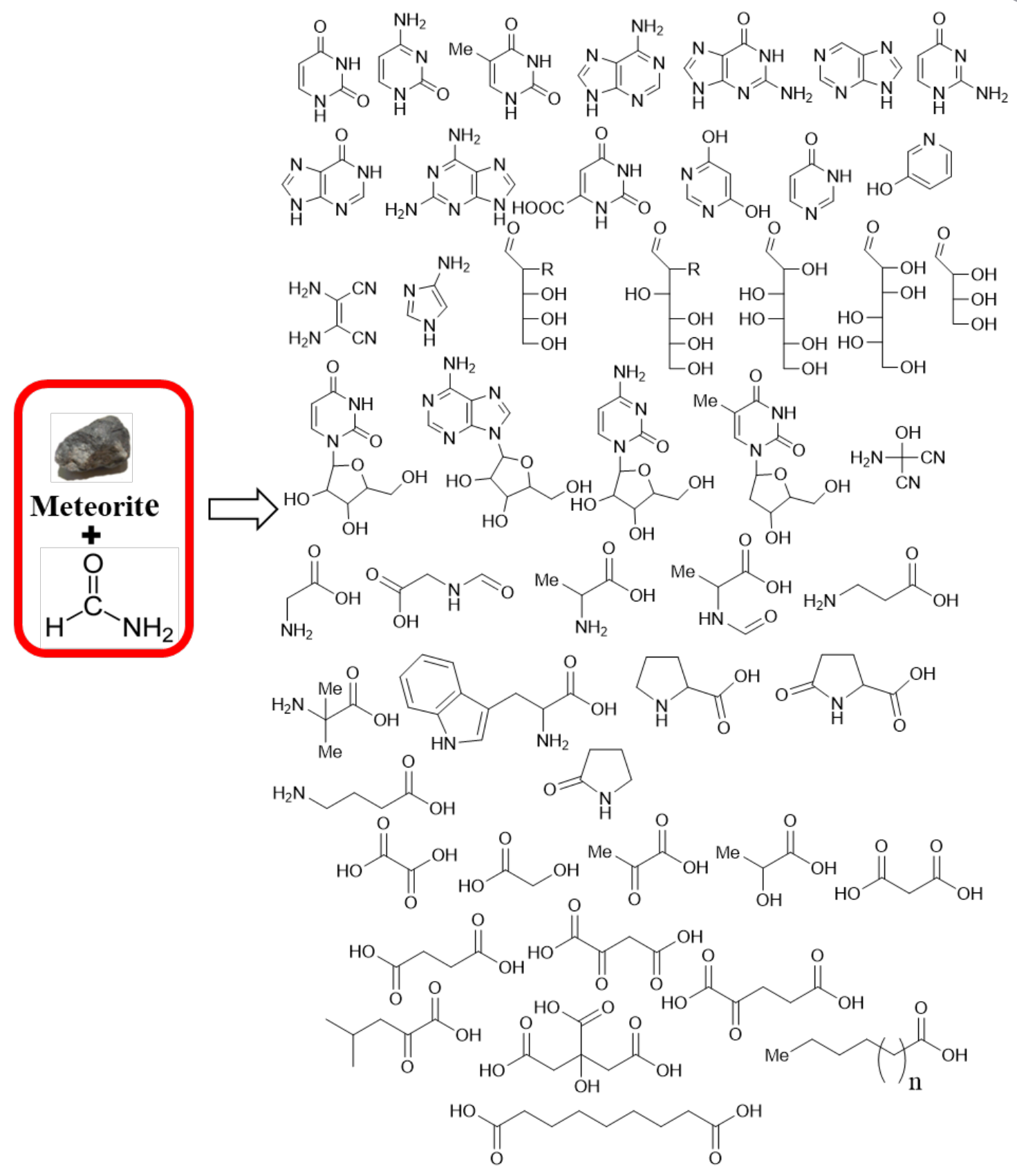

3 Figure 6. The impressive variety of biomolecules that can be synthesized in one-pot conditions during the oligomerization of formamide catalysed by meteorites.

Early experiments successfully studied the reactivity of formamide in the presence of meteorites of different types [212]. Because meteorites have a very complex mineralogical and petrochemical composition, they represent an optimal tool for correlating a variety of synthesisable chemical structures with catalyst complexity. Practically speaking, meteorites have the capacity to catalyse the oligomerization of formamide to an impressive variety of biomolecules, including nucleobases, nucleotides, oligonucleotides, different heterocycles, sugars, amino acids, carboxylic acids and condensing agents such as urea, guanidine and carbodiimide (Figure 6) [106]. In other words, the complete sets of biomolecules potentially involved in the emergence of pre-genetic and pre-metabolic apparatuses are easily synthesized in one-pot conditions via a complex network of mineral-catalysed 
multi-component and click-like reactions [107]. It is reasonable to suggest that reaction mechanisms operative during these transformations are similar to those previously reported for high-energy meteorite impact events, encompassing a unified synthetic pathway characterized by common intermediates, as is the case for the role of diaminomaleonitrile in the contemporary formation of both purine and pyrimidine nucleobases. Irrespective of the cosmological origin and elemental composition of a meteorite, the inventory of biomolecules is always complete and large enough to sustain the first step in synthesising functional macromolecules in the presence of water acting as a diluting medium for formamide, with water from thermal pool being the best environment [213]. As more experiments are performed using different and more common terrestrial minerals (silicates, aluminates, silicoaluminates, borates, carbonates, phosphates, zirconates, and simple metal oxides) the generality of the prebiotic process has become more apparent, with formamide always being transformed into biomolecules in the presence of various energy sources [214]. Moreover, when computationally studying these reactions at the molecular level, it is evident that the mineral surface plays a relevant role in the regio- and stereo-selectivity of the processes [59]. To take an example, the selective interaction between geminal hydroxyl groups in sugars with the surface of chondritic meteorite selectively favours the formation of the biologically-useful adenosine $\beta$-nucleosides stereoisomer during the addition of adenine produced in situ by proton beam irradiation of formamide (Figure 7) [105].

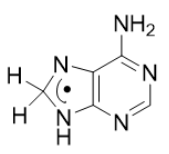<smiles>Nc1ncnc2c1ncn2C1OC(CO)C(O)C1O</smiles>

$\beta$-isomer

Figure 7. Preferential adsorption of ribose on the surface of a meteorite of the chondrite type. The interaction of the vicinal hydroxyl groups with the mineral surface favours the addition of the nucleobase from the beta-side of the molecule to yield biologically useful adenosine $\beta$-nucleoside.

An even more significant regioselective effect has been observed during thermal phosphorylation of nucleosides with common mineral phosphates in the presence of formamide [215]. In this latter case, the $5^{\prime}, 3^{\prime}$-cyclic nucleotide monophosphate was selectively accumulated for longer reaction time [216]. This compound spontaneously reacts through a $\pi-\pi$ supramolecular pillared controlled click-like ringopening process to yield small RNA oligonucleotides in a one-pot manner (Figure 8) [217]. 
A

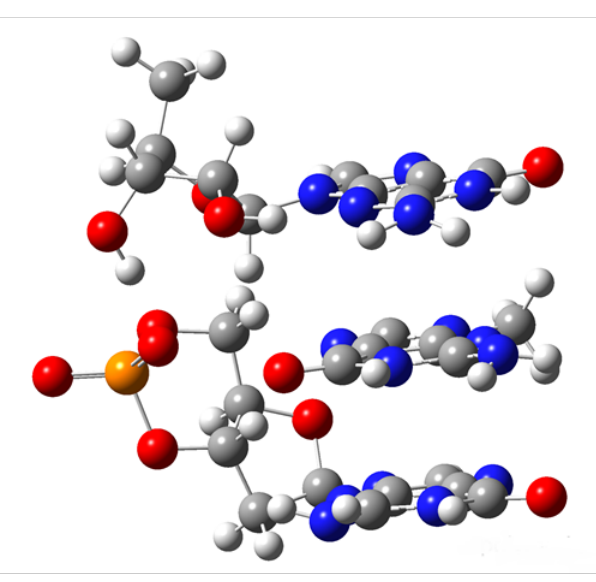

B

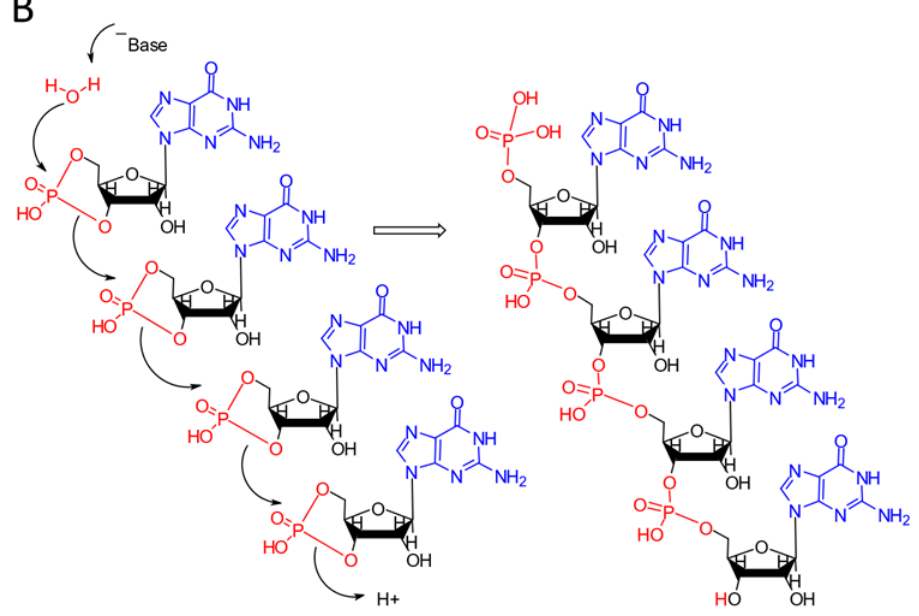

Figure 8. Spontaneous oligomerization of $3^{\prime}, 5^{\prime}$-cyclic adenosine monophosphate. Panel A: Pillared structure. Panel B: click-ring opening polymerization. The reaction activated by a water molecule produces the contemporary formation of several $5^{\prime} 3^{\prime}$-phospho diester bonds.

An even richer source of information is contained in large databases reporting prebiotic chemistry pathways that are most likely operative in specific atmospheric and geochemical scenarios, starting from a large panel of simple chemical precursors $\left(\mathrm{CH}_{4}, \mathrm{COx}, \mathrm{NH}_{3}, \mathrm{H}_{2}, \mathrm{HCN}\right.$, urea, formamide, guanidine, ammonium formate etc). Surfaces and catalysts may have played a significant role in prebiotic synthesis in other ways. For example, meteoritic impactors, aside from delivering organic molecules, alter the impact site and facilitate reprocessing of both impacting and surface minerals. This is already demonstrated in the Nakhla Martian meteorite to occur on Mars, in which a bolide impact shock events melts locally volumes of the meteorite and forms ovoid structures in which hydrothermal waters are circulating, altering the primary minerals and depositing secondary ones, such as clays, while at the same time they sustain habitable microenvironments [218]. Along with the residual heat of the impact, these processes can also catalyse the synthesis of nucleic acid bases, amino acids or urea, similarly with evidence of abiotic amino acid synthesis in iron-rich saponitic clay in basalts from the Atlantis Massif (Mid-Atlantic Ridge) [219] which can be considered to occur on the aforementioned microenvironments on Mars or other planets. Notably, thermolysis of formamide in the presence of meteorites and clays (representing the surface) produces such molecules [201]. The role of clays as catalysts is explored by Pastorek et al. [201] and Saladino et al.[220] and a theory of Alexander Cairns-Smith [221] postulatesError! Bookmark not defined. clays as replication sites facilitating an origin for life.

It is nowadays generally accepted that functions of natural enzymes can be mimicked by various nanoparticles (nanozymes) composed from metal or carbon precursors [222]. The main advantages of nanozymes over natural enzymes include stability, scalability, chemical diversity, and functionality in non-aqueous solvents. The enzymatic activity of inorganic materials is starting to be considered highly important in the context of new theories about the origin of life [223],[224]. Specifically light-activated nanozymes are candidates for these purpose [225]. The experiments conducted by Nejdl et al. [93] prove that light-controlled processes lead to the formation of nanoparticles (quantum dots - QDs) and these QDs exhibit xanthine oxidase (XO)-like activity. Enzymatic reactions in the prebiotic world are still 
unknown. So far, only enzymatic reactions mediated by RNA (ribozymes) are reliably proven. The functions of ribozymes in modern organisms support the hypothesis that life passed through the RNA world before the emergence of proteins or DNA. Moreover, numerous microorganisms are capable of nanoparticle synthesis in order to remove undesired metal species [226].This ability of microorganisms can also support the hypothesis that chemical evolution of life passed through a period of abiotic artificial material (nanozymes). Nejdl et al. [93] suggested that nanozymes could have played an important role in forming the first proto-metabolic networks; this is because nanoparticles are able to concentrate relevant compounds on their surface by forming covalent and/or electrostatic interactions which result in radicals becoming sensitive to both ultraviolet and visible radiation. A frequently stated advantage of radical-based methodologies for molecular formation is that radical reactions are essentially free from solvent effects on their reaction kinetics and, hence, on the reaction products. Radicals also cause polymerizations or bond cleavage [227]. Nejdl et al. [93] hypothesized that all cellular subsystems could have arisen simultaneously through common formamide-based chemistry and the key reaction steps could have been driven by light. Therefore, we may assume that the first protometabolism pathway could be associated with purine catabolism [228] enabled by nanoparticles (nanozymes) like QDs (mimicking XO). All QD precursors (metals ions, sulphur-containing compounds and ammonia) together with formamide are abundant in space. As the Ariel space mission will observe a large number of exoplanetary atmospheres and its main goal is to provide statistical data on thousands of atmospheric compositions it will bring important information necessary for testing and refining origin of life theories such as this one.

Parallel to an astonishing growth in the number of proposed prebiotic pathways, the last decade witnessed an unprecedented step forward in computationally modelling these processes. This has enabled an elaborate "in silico" approach to studying the origin of informational polymers. A great advantage of computations complementary to experiments is the provision of information on particular selected molecules and chemical reactions, whereas prebiotic chemistry experiments always work with complex mixtures that are challenging to interpret. The contribution of computational chemistry might be instrumental for experimentalists, where theory supplements experimental information with atomiclevel insight into structural aspects, electronic-structure changes, energetics, spectroscopic properties and dynamical behaviour of the studied systems [59].

Recently, the extraterrestrial synthesis of organic feedstock molecules of prebiotic relevance became a hot topic in computational chemistry related to the origin of life. Major developments include the application of high-level quantum-chemical calculations for interpreting rotational spectra observed by radioastronomy [229]. In addition, the last few years witnessed a significant step forward in understanding the chemical mechanisms leading to the synthesis of simple organic molecules in interstellar space. In this topic, a special emphasis is placed on ion-molecule [230] and radical-assisted chemical processes [53] and accretion-driven chemical synthesis [92] among other processes.

\subsection{Observations and satellite missions}

The previous section of this paper provides a review of selected important topics related to prebiotic chemistry. What observational strategy should be adopted when searching for evidence of ongoing prebiotic processes on distant exoplanets? Based on recent results, only a combination of indirect evidence can serve as a proof. To determine whether life-connected processes are taking place on a planet it is necessary to estimate the occurrence likelihood of physical processes that are friendly to prebiotic chemistry (e.g., impacts, UV radiation, electric discharges, hydrothermal and volcanic activity), of a plausible chemical environment (very likely a reducing atmosphere with a surface rich in deposits of parent compounds), and the observation of chemical markers of complicated prebiotic chemistry reaction networks. 
1 2.2.1. Window to the past before Ariel and JWST

2 In 1995, the Hubble Space Telescope captured images of four newly discovered protoplanetary disks

3 around young stars in the Orion nebula, located 1500 light-years from our system. Gas and dust disks,

4 long suspected by astronomers to be an early stage of planetary formation, were then directly observed

5 in the visible spectral range. The exploration of chemical environment and processes occurring in star-

6 and planet-forming regions is important for understanding its potential relevance in seeding prebiotic

7 chemistry on planets and perhaps leading to origins of life. In connection with extraterrestrial delivery

8 of volatile compounds to the atmosphere and hydrosphere, exogenous delivery of organic compounds

9 must also be questioned.

10 In the past decades, many organic molecules have been detected throughout the Universe. A list of 11 examples important to prebiotic chemistry is shown in Table 1. The simplest $\mathrm{C}-\mathrm{C}$ bond is represented by the $\mathrm{C} 2$ radical, the simplest $\mathrm{C}-\mathrm{H}$ bond by the $\mathrm{CH}$ radical and similarly $\mathrm{CO}$ and $\cdot \mathrm{CN}$ are shown. This table does not serve as a list of all molecules observed in space, some containing more atoms, whose number 14 is far greater.

23 Table 1. Selected important molecules related to prebiotic chemistry detected in space so far. We note that in case of an important prebiotic substance, aminoacid glycine, the detection is still debated.

\begin{tabular}{|c|c|c|c|c|c|}
\hline Compound & Name & $\begin{array}{c}\text { Year of } \\
\text { detection }\end{array}$ & Compound & Name & $\begin{array}{c}\text { Year of } \\
\text { detection }\end{array}$ \\
\hline$\cdot C_{2}$ & $\mathrm{C}_{2}$ radical & 1995 & $\mathrm{NH}_{2} \mathrm{CN}$ & Cyanamide & 1975 \\
\hline$\cdot \mathrm{CH}$ & $\begin{array}{c}\mathrm{CH} \\
\text { radical }\end{array}$ & 1941 & $\mathrm{C}_{2} \mathrm{H}_{4}$ & Ethene & 1981 \\
\hline$\cdot \mathrm{CN}$ & $\begin{array}{c}\mathrm{CN} \\
\text { radical }\end{array}$ & 1941 & $\mathrm{HCONH}_{2}$ & Formamide & 1989 \\
\hline $\mathrm{CO}$ & $\begin{array}{c}\text { Carbon } \\
\text { monoxide }\end{array}$ & 1970 & $\mathrm{CH}_{3} \mathrm{CHO}$ & Acetaldehyde & 1997 \\
\hline
\end{tabular}


Confidental Paper Concept - Ariel consortium WG Astrobiology and Prebiotic Chemistry Experimental Astronomy: Special issue for Ariel Phase B

\begin{tabular}{|c|c|c|c|c|c|}
\hline $\mathrm{HCN}$ & $\begin{array}{c}\text { Hydrogen } \\
\text { cyanide }\end{array}$ & 1971 & $\mathrm{HOCH}_{2}-\mathrm{CHO}$ & Glycolaldehyde & 2006 \\
\hline $\mathrm{C}_{2} \mathrm{H}_{2}$ & Acetylene & 1976 & $\mathrm{CO}\left(\mathrm{NH}_{2}\right)$ & Urea & 2014 \\
\hline HNCO & $\begin{array}{l}\text { Isocyanic } \\
\text { acid }\end{array}$ & 1984 & $\mathrm{C}_{2} \mathrm{H}_{5} \mathrm{OH}$ & Ethanol & 1975 \\
\hline $\mathrm{NH}_{3}$ & Ammonia & 1984 & $\left(\mathrm{CH}_{3}\right)_{2} \mathrm{CO}$ & Acetone & 1984 \\
\hline$\cdot \mathrm{CH}_{3}$ & $\begin{array}{l}\text { Methyl } \\
\text { radical }\end{array}$ & 1991 & $\left(\mathrm{CH}_{2} \mathrm{OH}\right)_{2}$ & Ethylene glycol & 2002 \\
\hline $\mathrm{HCOOH}$ & $\begin{array}{c}\text { Formic } \\
\text { acid }\end{array}$ & 1971 & $\begin{array}{l}\mathrm{NH}_{2}-\mathrm{CH}_{2-} \\
\mathrm{COOH}\end{array}$ & Glycine & $\begin{array}{l}2003 \\
(2016)\end{array}$ \\
\hline
\end{tabular}

1

There is now ample evidence that complex organic molecules are already present in the earliest stages of stellar formation [231]. In 2013, Kahane et al. [232] have reported the first detection of formamide towards the binary protostellar system IRAS 16293-2422 located in Rho Ophiuchi star-forming region approximately 457 light-years away, which consists of at least two stellar embryos, A and B, 700 A.U. apart and which may be similar to the Sun and Solar system progenitors. As noted in chapters describing prebiotic chemistry, formamide $\left(\mathrm{HCONH}_{2}\right)$ represents a complex organic molecule (by astrochemical standards) which is potentially important to prebiotic chemistry as many proposed scenarios stem from formamide as a starting compound. Systematic studies [233-237] show that formamide is also present in a wide range of environments and physical conditions throughout the Galaxy and that it can be abundant towards the formation sites of solar-type stars [238], especially those which contain oxygenbearing organics in their protostellar envelopes. The formamide formation mechanism in interstellar space is still debated and there are many studies attempting to explain its origin. Other prebiotic substances detected in protostellar surroundings involve cyanopolyynes [239], glycolaldehyde [240], phosphorus-bearing molecular species [241], formaldehyde and many other molecules [242]. We note that formaldehyde, which was recently identified as important molecule in prebiotic chemistry, is far more abundant than formamide in space [91]. Large observatories continue to unveil the chemical richness of star forming regions at centimetre and millimetre wavelengths, as shown for example on the detections of organics such as methanol and formic acid in the disks of young stars [243]. These spectral regions are well suited for space observations due to their relative transparency with regards to Earth's atmospheric absorption. The Herschel Space Mission (now defunct) has revealed large amounts of water in protostellar regions and in the protoplanetary disks surrounding young stars and has improved our understanding of the formation and transport of water from clouds to protostars, disks and planets [243]. Life on Earth is carbon-based and requires water; if life on other planets shares those properties, it is of paramount importance to understand if and how the necessary organics and water came to be available on a planet. Understanding the chemical environment in star- and planet-forming regions, and determining the inheritance of this chemistry to planets, can help constrain the potential habitability of exo-worlds and better inform which targets should receive priority. The tools for detecting the biosignals of life may also come in the form of radio-telescopes [244]. The largest ground-based telescope, the Square Kilometre Array (SKA), is still under construction with only small sections currently 
operational. However, when this facility eventually becomes fully operational (probably around 2027),

it will have a resolution surpassing anything that is currently available by many orders of magnitude.

Alongside remote observations, important insights into the history of our Solar system and beyond are possible through the analysis of meteors and, more importantly, meteorites [245, 246]. It has been proposed that interstellar meteors offer a unique opportunity to probe extrasolar systems [247]. Unfortunately, such direct observations are very sporadic. Only occasional asteroids such as the 'Oumuamua (see [248] and references therein) or sporadic meteors probably created by extrasolar bodies [245, 246] have been recorded. So far, there are over 1000 observed meteoritic falls, but the precise origin (i.e., the orbital trajectory) has been calculated only for about 30 of them [249-251] and none of them can be linked to extrasolar origin. Even though the number of meteorites with "known lineage" is so low, meteorite science has become very important to prebiotic chemistry during the recent two decades. For instance, nucleobases of extra-terrestrial origin were discovered in the Murchinson meteorite [50], extraterrestrial amino acids were found in the Paris meteorite [49] and recently, extraterrestrial organic matter was also discovered buried within volcanic sediment from over 3.3 Gya [252]. These lines of evidence suggest that chemical inheritance from interstellar space to star forming regions can be relevant for the chemistry of a planet. Moreover, the remarkable catalytic activity of meteorites has been described in literature in relation to prebiotic synthesis [92, 106, 178, $201,252]$. Finally, direct exploration of the comet 67P/Churyumov-Gerasimenko revealed that its ancient material harbours a wide range of organic substances important for prebiotic chemistry [253, 254].

\subsubsection{Past and Future of Satellite Missions}

Since the discovery of the first exoplanet, several satellite missions have been dedicated to or used for the detection and observation of other exo-worlds. Most notably, the Hubble Space telescope launched in 1990: Although originally constructed as a multipurpose optical telescope, it recently discovered water vapour on super Earth K2-18b [255]. Another satellite, the Spitzer Space Telescope, an infrared telescope launched in 2003, successfully mapped the atmospheric circulation of the gas giant HD 189733b (e.g. [256]). CoRoT (Convection, Rotation et Transits planétaires), launched in 2006, was designed for sensitive detection of transiting super Earth exoplanets and asteroseismology [257]. In the course of its operation, the telescope widely broadened the exoplanet classification. The Kepler space telescope [258], extended as the K2 mission, was originally launched in 2009. It has, by photometric monitoring of main sequence stars, discovered 2662 exoplanets of which 30 are potentially habitable. The telescope made its final observation in autumn 2018. Gaia[259], launched 2013 and designed to map our galaxy, provides, due to its all-sky survey of the stellar position, brightness and motion, a large dataset to search for exoplanets. TESS [260] (Transiting Exoplanet Survey Satellite launched in 2018 with the ambition of discovering many Earth-sized planets and has recently discovered its first Earth-size planet, TOI $700 \mathrm{~d}$ orbiting a red dwarf star in a habitable zone. CHEOPS [261] (CHaracterising ExOPlanet Satellite, launched in 2019, is a precise photometric observatory, which will the characterize mass and size distributions of exoplanets. The planned James Webb Telescope [262] (JWST), scheduled to launch in 2021, will observe at least 28 unique exoplanet targets, 9 of them smaller than 2 Earth radii. Another planned satellite, PLATO [263], is scheduled for 2026. Plato will observe transits and discover and characterize rocky extrasolar planets around yellow dwarf stars.

The Ariel telescope, currently under construction, will be a powerful tool in the exploration of exoworlds. The satellite should launch in 2028 onboard the Ariane 6-2 rocket to the $L 2$ libration centre. 
Ariel's off-axis $1.1 \times 0.7 \mathrm{~m}$ Cassegrain telescope will observe about 1000 exoplanets using two advanced infrared spectrometers: NIRSpec (NIR spectrometer), which covers a range from $9090 \mathrm{~cm}^{-1}(1.95 \mu \mathrm{m})$ to $5128 \mathrm{~cm}^{-1}\left(1.1 \mu \mathrm{m}\right.$ ) with a resolving power or $\mathrm{R}=15$ (i.e., resolution from $568 \mathrm{~cm}^{-1}$ to $\left.320 \mathrm{~cm}^{-1}\right)$, and AIRS (Ariel infrared spectrometer), which has two channels, AIRSO with operating range from $5128 \mathrm{~cm}^{-1}(1.95$ $\mu \mathrm{m}$ ) to $2564 \mathrm{~cm}^{-1}\left(3.9 \mu \mathrm{m}\right.$ ) with $\mathrm{R}=100$ (i.e., resolution from $50 \mathrm{~cm}^{-1}$ to $25 \mathrm{~cm}^{-1}$ ), and AIRS1 from 2564 $\mathrm{cm}^{-1}(3.9 \mu \mathrm{m})$ to $1282 \mathrm{~cm}^{-1}(7.8 \mu \mathrm{m})$ with $\mathrm{R}=30$ (i.e., reaching a resolution of $83 \mathrm{~cm}^{-1}$ to $\left.41 \mathrm{~cm}^{-1}\right)$. More specific technical details of the mission have been described in [1] and references therein. The upcoming large spectral survey of exoplanets by Ariel and other telescopes offers a unique opportunity to extend our knowledge both on the spatial and temporal evolution of planets.

Several missions are planned beyond the Ariel satellite and the James Webb telescope. For instance, HabEx [264] (Habitable Exoplanet Observatory) which should be able to detect atmospheric gases that are possibly indicative of biological activity, such as oxygen and ozone, planned for 2035) or the LUVOIR telescope concept [265] (Large Ultraviolet Optical Infrared Surveyor, intended to launch in late 2030s).

\subsubsection{Remote observations and the origin of life on Earth}

Direct geologic records revealing the chemical conditions on Earth and its evolution during the Hadean eon (>4 Gya) and early bombardment are very sporadic. However, this era probably played a crucial role in the evolution of Earth and its life. Studies of ancient zircons and supracrustal rocks from the Jack Hills in Australia indicate an environment "cold enough" to allow for the existence of liquid water oceans by zircons show that the Hadean continental crust was probably more reduced than its modern counterpart [57], i.e., the atmosphere likely contained a portion of simple molecular gases [57, 177] such as $\mathrm{CH}_{4}, \mathrm{NH}_{3}, \mathrm{PH}_{3}, \mathrm{H}_{2}, \mathrm{HCN}, \mathrm{CO}, \mathrm{SO}_{2}, \mathrm{HCl}, \mathrm{H}_{2} \mathrm{~S}, \mathrm{HCOOH}, \mathrm{HCHO}$ including reducing substances in notable amounts. These simple gases have spectral signatures in the wavelength range of Ariel and this telescope may then provide detailed data on the similarity of young planets to Earth as it observes around 1000 exoplanets from gas giants to rocky super Earths (and probably the most interesting terrestrial size planets as well) in the hot to temperate zones around F to M stars[268]. The final target list is still being updated and revised.

These findings may be connected to the emergence of the first living organisms, whose ages are estimated via $^{13} \mathrm{C}$ isotope fractionation measurements in carbon inclusions in rocks and minerals $3.8 \mathrm{Gya}$ [269], 3.95 Gya [270] and 4.1 Gya [271] by claiming that the deficiency might be attributed to organisms. Putative findings of fossilized microorganisms in ferruginous sedimentary rocks are dated to $3.77 \mathrm{Gya}$ and possibly 4.28 Gya $[270,272]$.

Due to the limited rock record and physical evidence on Earth, the mystery surrounding climate and chemical conditions on the early Earth are lost to us forever. However, hope remains in exoplanet observations, since given enough data on the early evolutionary state of rocky planets we may be able to deduce the probable state of the early Earth. Indeed, Ariel observations of rocky planets with conditions and evolutionary stages similar to early Earth may render the need for geological records, that are so difficult to come by, less vital, and understanding the chemical and physical conditions of these planets may ultimately help unravel the mystery of the origin of life on Earth. This leap hinges on a fundamental question: Why should a hypothetic origin of life on a far-away exoplanet be similar to what occurred on Earth? And, why should all possible large and complex life forms require oxygen to breathe? The assumption of Earth-like biochemistry for alien life might be inaccurate but is surely a useful starting point for observations. Even if the basic premise of an Earth-similar origin of life turns 
out to be wrong, to follow the development of our own biochemistry will certainly lead to knowledge that is likely applicable in the future [273]. The naive Earth-similarity approach may help unravel the mystery of our own origin or at least will help understand which features of mineralogy, geochemistry, radiation environment and atmospheric chemistry/physics were important to allow the origin of life on early Earth and similar-conditioned exoplanets, which is in the end helpful for the question on the second Earth, ie. "Earth 2.0," or eta-Earth value, the mean number per star of rocky planets with between 1 and 1.5-2 Earth-radii that reside in the optimistic habitable zone (HZ) of their host star [275, 276]. By providing increased knowledge of the history of young planets, we can better understand how Earth's own history unfolded; the appearance and physical conditions on young exoplanets can inform and constrain conditions on Earth that may have been essential to the origins of life [68]. Creating life in the laboratory with no information about the conditions that may have been available on the early Earth leaves scientists with an overwhelming set of possibilities. In reality, such an approach would surely be nearly intractable. Instead, by using the constraints from geochemistry and observations of processes occurring on young planets, we can narrow down the appropriate avenues of origin-of-line study and attempt a determination of whether life is common or uncommon [73]. Observational missions such as Ariel will help assess the likelihood of the necessary life-forming conditions coinciding in one place.

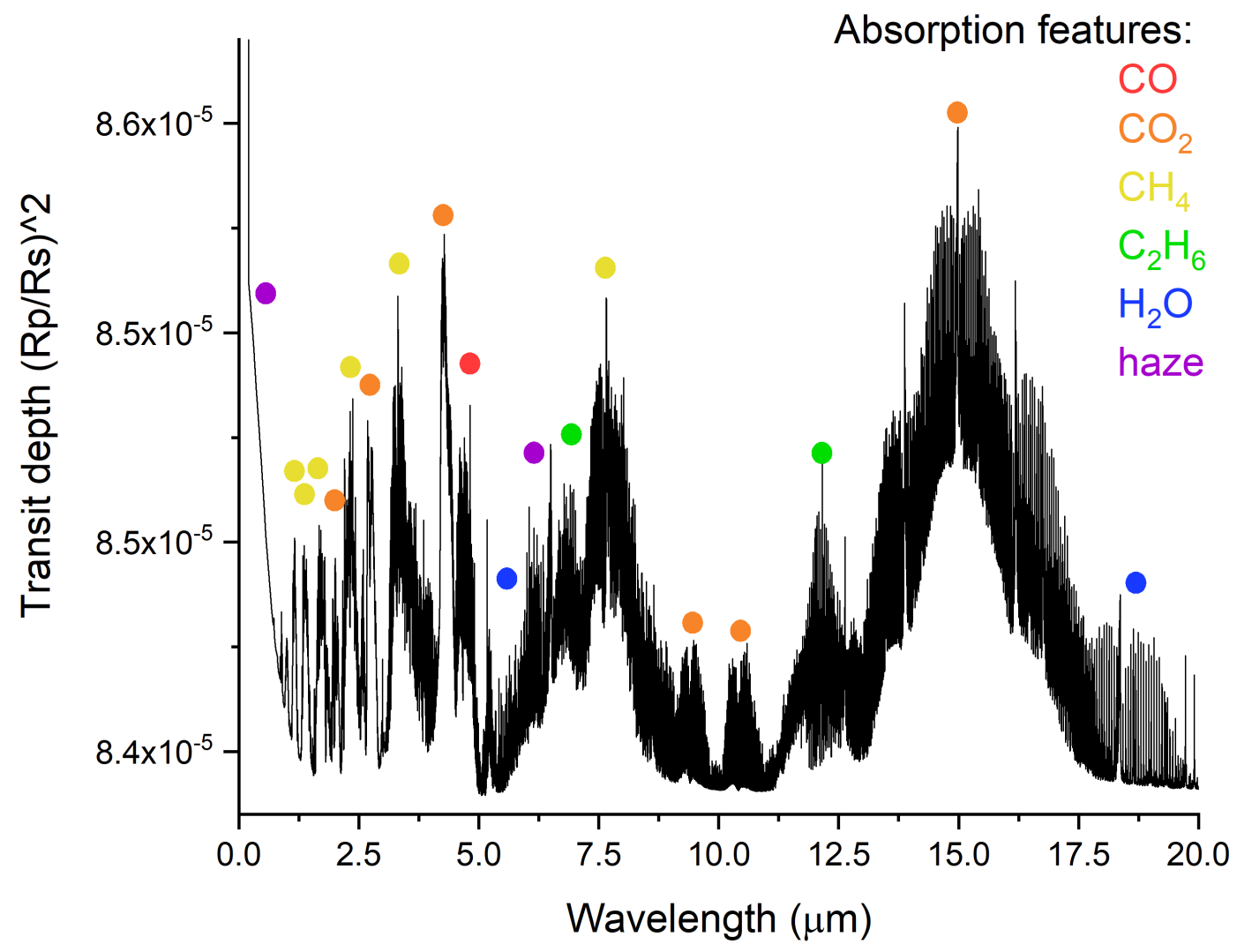

Figure 9: A modelled transit spectrum of a hypothetical Archean Earth under an Archean Sun. The planet in this model has a 1 bar nitrogen atmosphere with $2 \% \mathrm{CO}_{2}$ and $0.32 \% \mathrm{CH}_{4}$ causing the formation of a thin haze. The figure was compiled from data in Arney et al. [168]. 


\subsubsection{Exploration of early environments by Ariel}

2 The Ariel mission will observe a large number of exoplanetary atmospheres and its main goal is to provide statistical data on an unprecedented sample of exoplanets. For small and low mass exoplanets, observations by Ariel will help to understand how fast these planets accreted mass during the lifetime of their protoplanetary disk, which has implications for the atmospheric composition of the planets. When planets first form in the disk, they may accrete a primordial atmosphere, containing mainly $\mathrm{H} 2 / \mathrm{He}$. In the case of Earth, the primordial atmosphere was lost and replaced by a secondary atmosphere containing gases like $\mathrm{N}_{2}, \mathrm{CO}_{2}, \mathrm{CO}, \mathrm{CH}_{4}$, together with $\mathrm{NH}_{3}, \mathrm{PH}_{3}, \mathrm{H}_{2}, \mathrm{HCN}, \mathrm{SO}_{2}, \mathrm{HCl}, \mathrm{H}_{2} \mathrm{~S}$, $\mathrm{HCOOH}, \mathrm{HCHO}$ etc., as mentioned above. Recent studies show that terrestrial planets that grow beyond $75 \%$ of Earth's mass at the time when their disk dissipates will never get rid of their accumulated primordial atmosphere [274]. It is found from modelling present-day atmospheric noble gas isotope ratios of ${ }^{36} \mathrm{Ar} /{ }^{38} \mathrm{Ar},{ }^{20} \mathrm{Ne} /{ }^{22} \mathrm{Ne}$ and ${ }^{36} \mathrm{Ar} /{ }^{22} \mathrm{Ne}$, that the proto-Earth most likely had $53 \%-58 \%$ of its present mass and could lose its tiny captured primordial $\mathrm{H}_{2} /$ He-dominated atmosphere during a few Myr after disk evaporation [274]. This finding indicates that rocky planets need to accrete more than about $60 \%$ of the present Earth mass during their disks lifetime in order to later evolve into potential Earth-like habitats. With the contribution of Ariel, we will have a much improved statistical picture of how frequently small or low mass planets retain their primordial atmospheres and therefore would not be good candidates for Earth-like habitability. This in turn will let us estimate the fraction of rocky planets that should evolve with secondary $\mathrm{CO}_{2}$ - or $\mathrm{N}_{2}-\mathrm{O}_{2}$ - dominated atmospheres that can be further investigated [72] as possible habitable targets.

Atmospheric models of exoplanets and early Earth adopt input conditions according to the most recent findings. Large progress in this field and related to habitable planets can be found in studies published by Kaltenegger, Glenn, Lunine and Herbst et al. $[275,276]$ A recent example is the simulated transmission spectrum of Arney et al. [168] shown in Figure 9. The spectrum shows a transition spectrum of the Archean Earth irradiated by an Archean Sun. Molecules such as $\mathrm{CO}_{2}, \mathrm{CO}$, water, methane and acetylene are key absorbers, as well as a hydrocarbon haze making the atmosphere opaque to UV radiation. Ariel observations will be able to observe transit spectra of exoplanets, which can be used to provide comparisons to models. It is possible that Ariel observations will reveal more complicated spectra, with features that may be able to provide more information. Will Ariel observe a spectrum similar to Figure 9 ? Or perhaps a more complicated spectrum providing more information? The processes related to observable spectral features are discussed in the following chapters for molecules related to prebiotic synthesis.

\subsubsection{Observation of extreme events and impacts on young worlds}

While in most cases atmospheric spectral features are moderately difficult to decode, high-complexity target chemicals may be distinctly observable during unusual events, some of which are expected to emerge during the continuous monitoring of 1000 targets. Such events, including impact ejection [277], asteroid disruption [278], and dust cloud expansion [279], might provide information about these events where they alter the transit colour depth or present specific absorption features.

So far, extraterrestrial impact events have been directly observed on the Moon [280], Mars [281] and Jupiter [282], i.e. on Solar system bodies. A prominent example is the July 1994 collision between Jupiter and the comet P/Shoemaker-Levy 9 [283], leaving two traces in its atmosphere from fragments $D$ and $G$ [284] that the comet had split into earlier in 1992. A similar event on Jupiter was again captured in 2009 by the Hubble Space telescope [285] indicating that such events might be sufficiently frequent to 
observe multiple events occurring on the same exoplanet. On the other hand, detector sensitivity remains a major technical issue for exoplanetary observations. For instance, it has been estimated that an impact the size of the Chicxulub event 65 Mya ago viewed from 10 light-years distance would exhibit an absolute magnitude of 20.9 and be barely detectable even assuming $100 \%$ emissivity [286].

However, an area of attention in a future of increased spectroscopic resolution and instrument sensitivity, as well as when lock-on telescopes for long-term observation of a single exoplanet are devised, is the atmospheric-entry and impact of meteors on large to giant exoplanets [287]. This might constitute a novel area of research that could be applied to all kinds of exoplanets, with or without an atmosphere. The probability of observing such large impacts or collision events from Solar-type and Solar-age exosystems is low in an evolved state. On the other hand, explosions, collisions or large impact events are more likely to be observed in especially young exoplanet systems or those experiencing orbital instabilities. Mathematic models suggest that the first few hundred million years of terrestrial planet formation is dominated by giant impacts that collectively influence the growth, composition, and habitability of any forming planets [288]. In these cases, the detection of extrasolar impacts from recorded emission spectra would give an idea of whether our solar system is typical, what is the elemental composition of extrasolar rocky bodies, and the frequency of these impacts. Large-scale impact events could reveal lower atmospheric layers or produce intense plasma flashes due to the interaction of the bolide and exoplanet atmosphere or surface (when the atmosphere is thin or absent). Such an event captured with a high-angular-resolution telescope and ultrasensitive spectrometer might allow us to infer compositions of both atmosphere and meteor in a combined observation. This process might even be possible now for non-transiting exoplanets, whose orbits are not obscured by their star.

Although Ariel's spectrometers do not cover all wavelengths present in plasma emission, it can work in synergy with other spectrometers, such as the $45 \mathrm{~cm}$ telescope of the Twinkle satellite [289], which covers the visible $(0.4-1.0 \mu \mathrm{m})$ and band $(1.3-4.5 \mu \mathrm{m})$ bands. The wavelength range of Twinkle's spectrometer can be increased through modifying its gratings and extended deeper into the UV, reaching $0.2 \mu \mathrm{m}$. Similarly, the James Webb Space Telescope NIRSpec $(0.6-5.3 \mu \mathrm{m})$ and MIRI $(5-30 \mu \mathrm{m})$ could also be candidate instruments for synergy with Ariel. Ariel observations could permit the selection of the interesting targets for other instruments to focus on and lock on to them.

The events listed in Table 2 might provide an opportunity for indirectly observing material from planet or impactor interiors, or in related processes, from other than the atmosphere of exoplanets. For example, the occurrence of crystallized olivine and pyroxene minerals point to high melting temperatures, while phyllosilicates might indicate liquid water inside disrupting bodies, even small ones, and is of astrobiological relevance. If these are ejected to the atmosphere, they might be detectable in a transit. 
1 Table 2: Summary of rare but expected extreme events.

\begin{tabular}{|c|c|c|c|}
\hline Event & Realisation, consequence & $\begin{array}{l}\text { Observational } \\
\text { possibility }\end{array}$ & Ideal targets \\
\hline $\begin{array}{l}\text { Impact driven } \\
\text { ejecta cloud }\end{array}$ & $\begin{array}{l}\text { Increased solid dust } \\
\text { occurrence around the } \\
\text { exoplanet with wide grain } \\
\text { size range, for gaseous } \\
\text { planets increased gas } \\
\text { absorption }\end{array}$ & $\begin{array}{l}\text { Increase of scattering } \\
\text { or intensity of spectral } \\
\text { features, possibly } \\
\text { observable asymmetry } \\
\text { during transit }\end{array}$ & $\begin{array}{c}\text { Young, rocky planets } \\
\text { with unsettled system } \\
\text { configuration and } \\
\text { many impacting } \\
\text { objects }\end{array}$ \\
\hline $\begin{array}{l}\text { Super-volcanic } \\
\text { eruption driven } \\
\text { aerosol cloud }\end{array}$ & $\begin{array}{l}\text { Increase of atmospheric } \\
\text { dust load }\end{array}$ & $\begin{array}{l}\text { Increased dust } \\
\text { absorption and } \\
\text { scattering }\end{array}$ & $\begin{array}{c}\text { Near-start rocky } \\
\text { planets with intensive } \\
\text { tidal heating }\end{array}$ \\
\hline $\begin{array}{l}\text { Disruption of } \\
\text { asteroid, comet }\end{array}$ & $\begin{array}{l}\text { Release of fresh dust/ice } \\
\text { and their gradual } \\
\text { distribution along the orbit } \\
\text { around the star }\end{array}$ & $\begin{array}{l}\text { Increased dust } \\
\text { absorption ad } \\
\text { scattering, not directly } \\
\text { at the target } \\
\text { exoplanet transit }\end{array}$ & $\begin{array}{l}\text { Tidally disrupted or } \\
\text { collided bodies } \\
\text { moderately close to } \\
\text { the star }\end{array}$ \\
\hline $\begin{array}{l}\text { Disruption of } \\
\text { satellite of the } \\
\text { exoplanet }\end{array}$ & $\begin{array}{l}\text { Release of fresh dust/ice } \\
\text { and their gradual } \\
\text { distribution (ring } \\
\text { formation) around the } \\
\text { exoplanet }\end{array}$ & $\begin{array}{l}\text { Increased dust } \\
\text { absorption ad } \\
\text { scattering }\end{array}$ & $\begin{array}{l}\text { Exoplanets with } \\
\text { satellites }\end{array}$ \\
\hline Asteroid impact & $\begin{array}{l}\text { Impact ejecta in the } \\
\text { atmosphere, local residual } \\
\text { heat, local chemical } \\
\text { transformation of the } \\
\text { atmosphere }\end{array}$ & $\begin{array}{c}\text { Formation of } \\
\text { atmospheric markers } \\
\text { - HCN, acetylene, } \\
\text { maybe carbonyl } \\
\text { sulphide, carbon } \\
\text { disulphide and } \\
\text { phosphine }\end{array}$ & $\begin{array}{l}\text { Planets experiencing } \\
\text { significant impact } \\
\text { bombardment } \\
\text { activity. }\end{array}$ \\
\hline
\end{tabular}

3 We conclude that, despite the current technical difficulties, impact events might not be such a rare 4 occasion when the candidates are in a chronological phase similar to early Earth during the Late Heavy 5 Bombardment (LHB). Probing large-diameter exoplanets will also increase the possibility of capturing 6 such an event even today, because of higher spectral contrast.

7 2.2.6. Molecular markers of life

8 In the search for extant life on another planet, exoplanets are classified according to their similarity with

9 Earth. Twenty-seven of them are listed in Table 3 but all are already older than the Earth at the time its 10 earliest known living structure. The existence of life on other worlds could be tentatively inferred from 11 a combination of potential biomarkers. Table 4 contains a list of molecules that are connected to life on 12 Earth to some extent. A very comprehensive discussion of such molecules has been recently published 13 by Schwieterman et al. [290] . Many of the listed species can be produced abiotically so the presence of 14 biosignature molecules in exoplanetary atmospheres does not prove, in most cases, the existence of life exists. Their detection is therefore a necessary but not sufficient condition for constraining the presence 
1 of life. Nonetheless, it is valuable to search for biosignature molecules as they provide information

2 about chemistry on the planet, biotic or not, and further inform our understanding of possible

3 conditions on the early Earth.

4 Table 3: A list of selected potentially habitable exoplanets that are more likely to be rocky and maintain

5 liquid surface water. Listed planetary properties include mass and radius (relative to Earth), orbital

6 period in days, semimajor axis (in astronomical units, AU), stellar flux (relative to the Solar flux), distance

7 from the Solar system (in light years), equilibrium temperature (in Kelvin, K) and properties of the host

8 star, such as spectral type, age (in billions of years, Gyr) and effective temperature (K). The equilibrium

9 temperature of the planet ( $\mathrm{T}_{\text {eq }}$ ) represents the surface temperature assuming the absence of an

10 atmosphere and albedo of 0.3. Earth Similarity Index (ESI) represents relates to the stellar flux and

11 planetary mass, and/or radius (Earth $=1.0$ ). Planets more similar to Earth are not necessarily more

12 habitable, since the ESI does not consider all factors necessary for habitability. *Minimum mass 


\begin{tabular}{|c|c|c|c|c|c|c|c|c|c|c|c|c|c|}
\hline \multicolumn{3}{|c|}{ Basic information } & \multicolumn{8}{|c|}{ Planetary characteristic } & \multicolumn{3}{|c|}{ Stellar characteristic } \\
\hline Name & Year & Method & $\begin{array}{l}\text { Mass } \\
{\left[\mathrm{M}_{\mathrm{e}}\right]}\end{array}$ & $\begin{array}{c}\text { Radius } \\
{\left[\mathrm{R}_{\mathrm{e}}\right]}\end{array}$ & $\begin{array}{l}\text { Flux } \\
{\left[\mathrm{S}_{\mathrm{e}}\right]}\end{array}$ & $\mathrm{T}_{\text {eq }}[\mathrm{K}]$ & $\begin{array}{l}\text { Period } \\
\text { [days] }\end{array}$ & $\begin{array}{l}\text { Semimajor } \\
\text { axis [AU] }\end{array}$ & $\begin{array}{c}\text { Distance } \\
{[\mathrm{ly}]}\end{array}$ & ESI[291] & $\begin{array}{l}\text { Spectral } \\
\text { type }\end{array}$ & $\begin{array}{c}\text { Age } \\
{[\mathrm{Gyr}]}\end{array}$ & $\begin{array}{c}\text { Star Eff. } \\
\text { Temperature } \\
{[\mathrm{K}]}\end{array}$ \\
\hline $\begin{array}{l}\text { Teegarden's } \\
\text { star b }\end{array}$ & 2019 & RV & $1.05[292]$ & - & $1.15[292]$ & $267[291]$ & $4.9[292]$ & $0.025[292]$ & $12[291]$ & 0.93 & M7.0 & & 20 \\
\hline $\begin{array}{l}\text { Teegarden's } \\
\text { star c }\end{array}$ & 2019 & RV & $1.11[292]$ & - & $0.37[292]$ & $202[291]$ & $11.4[292]$ & $0.044[292]$ & $12[291]$ & 0.69 & $\mathrm{~V}[292]$ & & 29 \\
\hline $\begin{array}{l}\text { TRAPPIST - } 1 \\
\text { d }\end{array}$ & 2016 & $\mathrm{~T}$ & $0.41[293]$ & $0.77[293]$ & $1.14[293]$ & $267[291]$ & $4.0[293]$ & $0.021[293]$ & $41[291]$ & 0.89 & & & \\
\hline $\begin{array}{l}\text { TRAPPIST - } 1 \\
\mathrm{e}\end{array}$ & 2016 & $\mathrm{~T}$ & $0.62[293]$ & $0.92[293]$ & $0.66[293]$ & $233[291]$ & $6.1[293]$ & $0.028[293]$ & $41[291]$ & 0.87 & M8 & & \\
\hline $\begin{array}{l}\text { TRAPPIST - } 1 \\
\mathrm{f}\end{array}$ & 2016 & $\mathrm{~T}$ & $0.68[293]$ & $1.04[293]$ & $0.38[293]$ & $203[291]$ & $9.2[293]$ & $0.037[293]$ & $41[291]$ & 0.70 & V[294] & $7.6[295]$ & $2559[293]$ \\
\hline $\begin{array}{l}\text { TRAPPIST - } 1 \\
\mathrm{~g}\end{array}$ & 2016 & $\mathrm{~T}$ & $1.34[293]$ & $1.13[293]$ & $0.25[293]$ & $184[291]$ & $12.4[293]$ & $0.045[293]$ & $41[291]$ & 0.59 & & & \\
\hline GJ $1061 \mathrm{c}$ & 2019 & RV & $1.75[291]$ & - & $1.35[291]$ & $275[291]$ & $6.7[291]$ & $0.035[291]$ & $12[291]$ & 0.88 & M5.5 & & 29 \\
\hline GJ $1061 \mathrm{~d}$ & 2019 & $\mathrm{RV}$ & $1.68[291]$ & - & $0.57[291]$ & $221[291]$ & $13[291]$ & $0.052[291]$ & $12[291]$ & 0.80 & V[296] & & 29. \\
\hline GJ $667 \mathrm{C} \mathrm{c}$ & 2011 & RV & $3.81[297]$ & - & $1.33[291]$ & $274[291]$ & $28.1[297]$ & $0.125[297]$ & $22[291]$ & 0.78 & & & \\
\hline GJ $667 \mathrm{C} \mathrm{e}$ & 2013 & RV & $2.54[297]$ & - & $0.46[297]$ & $210[291]$ & $62.2[297]$ & $0.213[297]$ & $22[291]$ & 0.71 & $\begin{array}{l}\text { M1.5 } \\
\text { V } 297]\end{array}$ & $>2[297]$ & $3350[297]$ \\
\hline GJ $667 \mathrm{C} \mathrm{f}$ & 2013 & RV & $2.54[297]$ & - & $0.85[297]$ & $245[291]$ & $39.0[297]$ & $0.156[297]$ & $22[291]$ & 0.87 & & & \\
\hline Kepler 186 f & 2014 & $\mathrm{~T}$ & - & $1.17[298]$ & $0.30[298]$ & $182[291]$ & $129.9[298]$ & $0.432[298]$ & $561[291]$ & 0.58 & $\begin{array}{c}\text { M1 } \\
\text { V[298] }\end{array}$ & $4.0[298]$ & $3755[298]$ \\
\hline Wolf $1061 \mathrm{c}$ & 2015 & RV & $3.41[299]$ & - & $1.30[299]$ & $275[291]$ & $17.9[299]$ & $0.089[299]$ & $14[291]$ & 0.79 & $\begin{array}{l}\text { M3.5 } \\
\text { V[299] }\end{array}$ & - & $3342[299]$ \\
\hline Tau Ceti e & 2017 & RV & $3.93[300]$ & - & $1.61[291]$ & $285[291]$ & $162.9[300]$ & $0.538[300]$ & $12[291]$ & 0.74 & G8 V[301] & $5.8[302]$ & $5375[303]$ \\
\hline Proxima Cent $b$ & 2016 & RV & $1.27[304]$ & - & $0.65[304]$ & $227[291]$ & $11.2[304]$ & $0.049[304]$ & $4.2[291]$ & 0.87 & $\begin{array}{l}\text { M5.5 } \\
\text { V[304] }\end{array}$ & $4.8[305]$ & $3050[304]$ \\
\hline Kepler - $62 \mathrm{f}$ & 2013 & $\mathrm{~T}$ & - & $1.41[306]$ & $0.46[307]$ & $205[291]$ & $267.3[306]$ & $0.718[306]$ & $1200[291]$ & 0.69 & K2 V[306] & $2.3[308]$ & $4967[308]$ \\
\hline Kepler - 442 b & 2015 & $\mathrm{~T}$ & - & $1.34[298]$ & $0.66[298]$ & $235[291]$ & $112.3[298]$ & $0.409[298]$ & $1115[291]$ & 0.85 & $\begin{array}{l}\mathrm{K} \text { ? V } \\
\text { [309] }\end{array}$ & $2.9[298]$ & $4402[298]$ \\
\hline Kepler - 1229 b & 2016 & $\mathrm{~T}$ & - & $1.34[310]$ & $1.20[311]$ & $213[291]$ & $86.8[310]$ & $0.300[310]$ & $769[291]$ & 0.73 & $\mathrm{M} ? \mathrm{~V}[312]$ & $3.7[308]$ & $3784[308]$ \\
\hline $\mathrm{K} 2-72 \mathrm{e}$ & 2016 & $\mathrm{~T}$ & - & $1.29[313]$ & $1.11[313]$ & $261[291]$ & $24.2[313]$ & $0.106[313]$ & $217[291]$ & 0.90 & M? V[314] & - & $3360[313]$ \\
\hline GJ 273 b & 2017 & RV & $2.89[299]$ & - & $1.06[299]$ & $266[291]$ & $18.6[299]$ & $0.091[299]$ & $12[291]$ & 0.84 & M3.5[299] & - & $3382[299]$ \\
\hline
\end{tabular}


Confidental Revision of the Paper - Ariel consortium WG Astrobiology and Prebiotic Chemistry

Experimental Astronomy: Special issue for Ariel Phase B

https://link.springer.com/journal/10686, the deadline for submission September 14, 2020

\begin{tabular}{|c|c|c|c|c|c|c|c|c|c|c|c|c|c|}
\hline GJ 3323 b & 2017 & $\mathrm{RV}$ & $2.02[299]$ & - & $2.58[299]$ & $265[291]$ & $5.4[299]$ & $0.033[299]$ & $17[291]$ & 0.90 & M4[299] & - & 3159 [299] \\
\hline Kepler 1410 b & 2016 & $\mathrm{~T}$ & - & $1.78[308]$ & $1.06[310]$ & $274[291]$ & $60.8[310]$ & $0.254[310]$ & $1196[291]$ & 0.78 & K7[315] & $4.1[308]$ & 4092 [308] \\
\hline Kepler 1512 b & 2016 & $\mathrm{~T}$ & - & $1.18[308]$ & $1.60[310]$ & $322[310]$ & $20.3[308]$ & $0.131[308]$ & $528[316]$ & - & $\mathrm{K} 5[316]$ & $1.8[308]$ & $4372[308]$ \\
\hline Kepler 560 b & 2016 & $\mathrm{~T}$ & - & $1.47[310]$ & $1.18[310]$ & $298[310]$ & $18.4[310]$ & $0.089[310]$ & $286[310]$ & - & M3[317] & $4.1[298]$ & $3556[298]$ \\
\hline TOI-700 d & 2020 & $\mathrm{~T}$ & $1.25 *[318]$ & $1.037[318]$ & - & $417[318]$ & $10.0[318]$ & $0.068[318]$ & $101[318]$ & - & $\begin{array}{c}\text { M2 } \\
\text { V[318] }\end{array}$ & $1.5[318]$ & $3461[318]$ \\
\hline Kepler 296 e & 2014 & $\mathrm{~T}$ & - & $1.53[319]$ & $1.41[319]$ & $337[320]$ & $34.1[319]$ & $0.169[319]$ & $737[291]$ & 0.80 & $\begin{array}{c}\mathrm{M} 2 \\
\mathrm{~V}[321]\end{array}$ & $4.2[319]$ & 3572 [319] \\
\hline Kepler 438 b & 2015 & $\mathrm{~T}$ & - & $1.12[298]$ & $1.40[298]$ & - & $35.2[298]$ & $0.166[298]$ & $472[322]$ & - & M1[322] & $4.4[298]$ & 3748 [298] \\
\hline Earth & - & - & 1 & 1 & 1 & $255[291]$ & 365.3 & 1 & - & 1.00 & $\begin{array}{c}\mathrm{G} 2 \\
\mathrm{~V}[323]\end{array}$ & 4.54 & 5772 \\
\hline
\end{tabular}


1 Table 4: An example list of molecules potentially indicating existence of life on exoplanets. It is clear that

2 any 'marker' alone cannot serve as direct evidence of life on particular exoplanet and very careful

3 assessment will be needed in context of planet type, its chemistry and history [324], [290].

\begin{tabular}{ccc}
\hline Molecule & Connection to life & Controversy \\
\hline Oxygen $\left(\mathrm{O}_{2}\right)$ & $\begin{array}{c}\text { Created by photosynthesis in plants } \\
\text { and algae. }\end{array}$ & $\begin{array}{c}\text { Created by photolysis of } \mathrm{H}_{2} \mathrm{O}[325] . \\
\text { Ozone }\left(\mathrm{O}_{3}\right)\end{array}$ \\
$\begin{array}{c}\text { Ozone layer protects planetary } \\
\text { surface from UV radiation, thus } \\
\text { shielding life. }\end{array}$ & $\begin{array}{c}\text { Ozone can be formed by the abiotic } \\
\text { Chapman mechanism [326] from oxygen, } \\
\text { which can be created by photosynthesis } \\
\text { (see above); harmful for life as we know it } \\
\text { on Earth. }\end{array}$
\end{tabular}

On Earth, $\mathrm{N}_{2} \mathrm{O}, 64 \%$ of $\mathrm{N}_{2} \mathrm{O}$ is thought to be produced naturally and $36 \%$ by human activity[327].

One possible mechanism of denitrification is performed by

Paracoccus denitrificans. The reaction route is shown in Eq. 3.

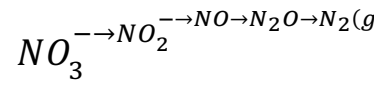

$\mathrm{NO}_{3}{ }^{-}$is reduced to $\mathrm{NO}_{2}^{-}$by means of a membrane $\mathrm{NO}_{3}$ reductase enzyme. Reduction of $\mathrm{NO}_{2}{ }^{-}$is mediated by cytochrome $\mathrm{cd} 1$

Nitrous oxide $\left(\mathrm{N}_{2} \mathrm{O}\right)$

Nitric oxide (NO)

Ammonia $\left(\mathrm{NH}_{3}\right)$ soluble periplasmic nitrite reductase. Then, NO is reduced to $\mathrm{N}_{2} \mathrm{O}$ by a membrane $\mathrm{NO}$ reductase. It is interesting that this reductase bears structural resemblance to oxidases, from which some hypothesize that NO could have been a metabolic predecessor of $\mathrm{O}_{2}$ in some bacteria. Last, $\mathrm{N}_{2} \mathrm{O}$ can be reduced by an $\mathrm{N}_{2} \mathrm{O}$ reductase to $\mathrm{N}_{2}$. This reductase is a soluble periplasmic enzyme [328].

One possible route of production of $\mathrm{NO}$ is as for $\mathrm{N}_{2} \mathrm{O}$ above [329]. It should be noted that NO is an intermediate, not product.

$$
\text { Waste product from fish }
$$
metabolism and from decomposition of organic matter

[332].
Abiotic routes of $\mathrm{N}_{2} \mathrm{O}$ formation have been proposed, for example on Pluto and Triton [329],. It should be noted that $\mathrm{N}_{2} \mathrm{O}$ is a major ozone-depleting substance and counters the formation of an ozone layer [330].

Can be formed by lightning [331].

Ammonia is found aplenty in the solar system [333], where it must have been created abiotically. 


$\begin{array}{cc}\text { Methane } & \text { In combination with oxygen } \\ \left(\mathrm{CH}_{4}\right) & \text { considered a biomarker. Produced } \\ \text { by livestock. }\end{array}$

Carbon Produced in photorespiration, dioxide $\left(\mathrm{CO}_{2}\right) \quad$ burning of organic matter, etc.

Carbon Produced by non-ideal burning of monoxide organic matter, in low quantities by

Methanethiol $\left(\mathrm{CH}_{3} \mathrm{SH}\right)$

\section{Methyl \\ chloride \\ $\left(\mathrm{CH}_{3} \mathrm{Cl}\right)$}

Water $\left(\mathrm{H}_{2} \mathrm{O}\right)$

Phosphane

$\left(\mathrm{PH}_{3}\right)$

$$
\text { organisms. }
$$

Partly released from the decomposition of organic matter. Some bacteria decompose methionine and produce methanethiol [336].

Can be a biomarker in terrestrial planets around $\mathrm{M}$ type stars [337]. Most abundant chlorine compound in Earth's atmosphere, produced by bacteria and trees (mangroves)[338]

Necessary for terrestrial life.

Convenient source of phosphorus for abiotic chemistry. Produced by bacteria [339].
Can be produced abiotically, e.g. by methanogenesis [68] or serpentinization [334].

Product of volcanism, almost omnipresent in the universe.

Abundant in the universe, volcanic gas, produced by photochemical reactions in the troposphere [335].

Not a viable biomarker. Present in natural gas.

\section{Viability as biomarker around other types of stars has not been explored.}
Present at the time of the accretion of Earth.
Not all atmospheric sources characterised, abiotic routes possible [340].

\section{2.2.7. Species related to prebiotic chemistry}

3 The Ariel mission will select a number of molecules as its prime observational focus. If these molecules

4 are observed in the atmospheres of young terrestrial planets, they may help uncover the mechanisms of prebiotic synthesis and give hints towards a preferred scenario of prebiotic synthesis on early Earth.

6 Namely, molecules such as acetylene, carbon disulphide or hydrogen cyanide are expected to be 7 common atmospheric constituents and therefore observable directly in Ariel transmission spectra.

8 Based on astrochemical studies and analyses of interplanetary matter, it is expected that simple 9 molecules sError! Bookmark not defined.uch as $\mathrm{H}_{2}, \mathrm{CO}, \mathrm{CH}_{4}$, and $\mathrm{NH}_{3}$ [56] or $\mathrm{CO}_{2}, \mathrm{H}_{2} \mathrm{O}, \mathrm{HCN}, \mathrm{H}_{2} \mathrm{CO}$, $10 \mathrm{CH}_{3} \mathrm{OH}$, and maybe also $\mathrm{HCONH}_{2}$ [341], together with more complex species such as polymers (tholins 11 [342]), various organic compounds and also biomolecules themselves [34, 47, 133, 343] can be observed 12 on young exoplanets. Experimental results[24, 138, 189, 344] as well as theoretical predictions [34] 13 show that reducing, relatively reactive atmospheres are probably more efficient for the synthesis of 14 biomolecules [47]. However, it should be noted that several papers report the formation of biologically 15 important molecules under neutral $\left(\mathrm{N}_{2}, \mathrm{CO}_{2}, \mathrm{H}_{2} \mathrm{O}\right)$ conditions $[65,177,345]$. If possible, reflectance 
spectra may even reveal the accumulation of species on the surface, such as glyceraldehyde or glycolaldehyde, products of Fischer-Tropsch synthesis and intermediates in several of the proposed reaction mechanisms mentioned above. Although it is not the primary objective of Ariel to measure reflectance spectra, nor is it certain that any of these products, apart from acetylene and HCN, will be produced in sufficient amounts to be observable it is certainly worthwhile to search for their spectral imprints.

Spectral data for some relatively-complex molecules that are important for interpreting Ariel observations are missing from spectroscopy databases, e.g., ExoMol [346]. It will be an important task to record high resolution laboratory spectra of species related to prebiotic chemistry in the wavelength range of Ariel and provide their molecular parameters for spectral simulation of their fingerprints as gas-phase atmospheric species, as atmospheric aerosols, or in surface deposits etc., as indicated in Table 5. An example laboratory spectrum is shown in Figure 10 with the operational range of Ariel telescope indicated by grey rectangles. The upper trace (a) shows a high-resolution spectrum of isocyanic acid (HNCO) [90], which is both a precursor and decomposition product of the crucial prebiotic molecule formamide. Any organic material undergoing, for instance, thermal decomposition typically produces similar products. Trace (b) in Figure 10 is the spectrum of a gas mixture produced by burning organic matter. The most important of Ariel's spectrometers for biomarker analysis will be AIRS channel 0 , with most molecular bands in the range of AIRS1 coinciding strong water absorption, while NIRspec operates in the overtone range where bands are very weak. Another an important region for molecular fingerprinting lies longwards of $7.8 \mu \mathrm{m}$ and is outside Ariel's spectral range.

Table 5: A list of species that are potential reactants, intermediates or products of prebiotic processes and which could be found either on planetary surfaces or in planetary atmospheres.

\begin{tabular}{|c|c|c|c|}
\hline Compound & $\begin{array}{l}\text { Importance } \\
\text { for prebiotic } \\
\text { chemistry }\end{array}$ & $\begin{array}{c}\text { State } \\
\text { (at } 298 \mathrm{~K} \text { ) }\end{array}$ & Expected detection \\
\hline Formamide & $\begin{array}{c}\text { Reactant, } \\
\text { intermediate }\end{array}$ & Liquid & Surface accumulation maybe hazes \\
\hline Cyanopolyynes & $\begin{array}{l}\text { Starting } \\
\text { compounds }\end{array}$ & Volatile & Aerosols \\
\hline Formaldehyde & Reactant & Solid volatile & Deposits, solutions, gas phase \\
\hline Glycolaldehyde & Intermediate & Solid & Surface accumulation \\
\hline Glyceraldehyde & Intermediate & Solid & Surface accumulation \\
\hline Cyanamide & Intermediate & Solid & Surface accumulation \\
\hline Acetaldehyde & Intermediate & $\begin{array}{l}\text { Liquid, close to boiling } \\
\text { point }\end{array}$ & Surface accumulation, gas phase \\
\hline Cyanoacetylene & Intermediate & Liquid & Surface accumulation, gas phase \\
\hline Formic Acid & $\begin{array}{l}\text { Starting } \\
\text { compound }\end{array}$ & Liquid, volatile & Surface or atmospheric presence \\
\hline Tholins & Side products & Varied, mostly liquid & Aerosols, icy bodies in space \\
\hline Methanol & Intermediate & Liquid & Surface accumulation, gas phase \\
\hline Ethanol & Intermediate & Liquid & Surface accumulation, gas phase \\
\hline Acetone & Intermediate & Liquid & Surface accumulation, gas phase \\
\hline
\end{tabular}




\begin{tabular}{|c|c|c|c|}
\hline Urea & $\begin{array}{l}\text { Intermediate, } \\
\text { product }\end{array}$ & Solid & Surface accumulation \\
\hline Diaminomaleonitrile & Intermediate & Solid & Surface accumulation \\
\hline Carbodiimide & Intermediate & Varied & Surface accumulation, gas phase \\
\hline Cyanoacetaldehyde & Intermediate & Solid & Surface accumulation \\
\hline Iminoacetoitrile & Intermediate & Close to boiling point & Surface accumulation, gas phase \\
\hline $\mathrm{C}_{2}$ & Reactant & Gas phase & Plasma \\
\hline$\cdot \mathrm{CH}$ & Reactant & Gas phase & Plasma \\
\hline$\cdot \mathrm{CN}$ & Reactant & Gas phase & Plasma \\
\hline $\mathrm{CO}$ & Reactant & Gas phase & Plasma, Gas phase \\
\hline $\mathrm{HCN}$ & Reactant & Gas phase & Gas phase \\
\hline $\mathrm{C}_{2} \mathrm{H}_{2}$ & Reactant & Gas phase & Gas phase \\
\hline HNCO & Reactant & $\begin{array}{l}\text { Liquid, close to boiling } \\
\text { point }\end{array}$ & Gas phase, surface accumulation \\
\hline $\mathrm{NH}_{3}$ & Reactant & Gas phase & Gas phase \\
\hline$\cdot \mathrm{CH}_{3}$ & Reactant & Gas phase & Plasma \\
\hline Cyanamide $\left(\mathrm{NH}_{2} \mathrm{CN}\right)$ & Reactant & Solid & Surface accumulation \\
\hline $\mathrm{C}_{2} \mathrm{H}_{4}$ & $\begin{array}{l}\text { Intermediate, } \\
\text { product }\end{array}$ & Gas phase & Gas phase \\
\hline Ethylene glycol & $\begin{array}{l}\text { Intermediate } \\
\text { Product, }\end{array}$ & Liquid & Surface accumulation \\
\hline Glycine & $\begin{array}{c}\text { simplest } \\
\text { amino acid }\end{array}$ & Solid & Surface accumulation \\
\hline Ferrocyanides & $\begin{array}{c}\text { Feedstock } \\
\text { deposits } \\
\text { release HCN }\end{array}$ & Solid & Surface accumulation \\
\hline
\end{tabular}

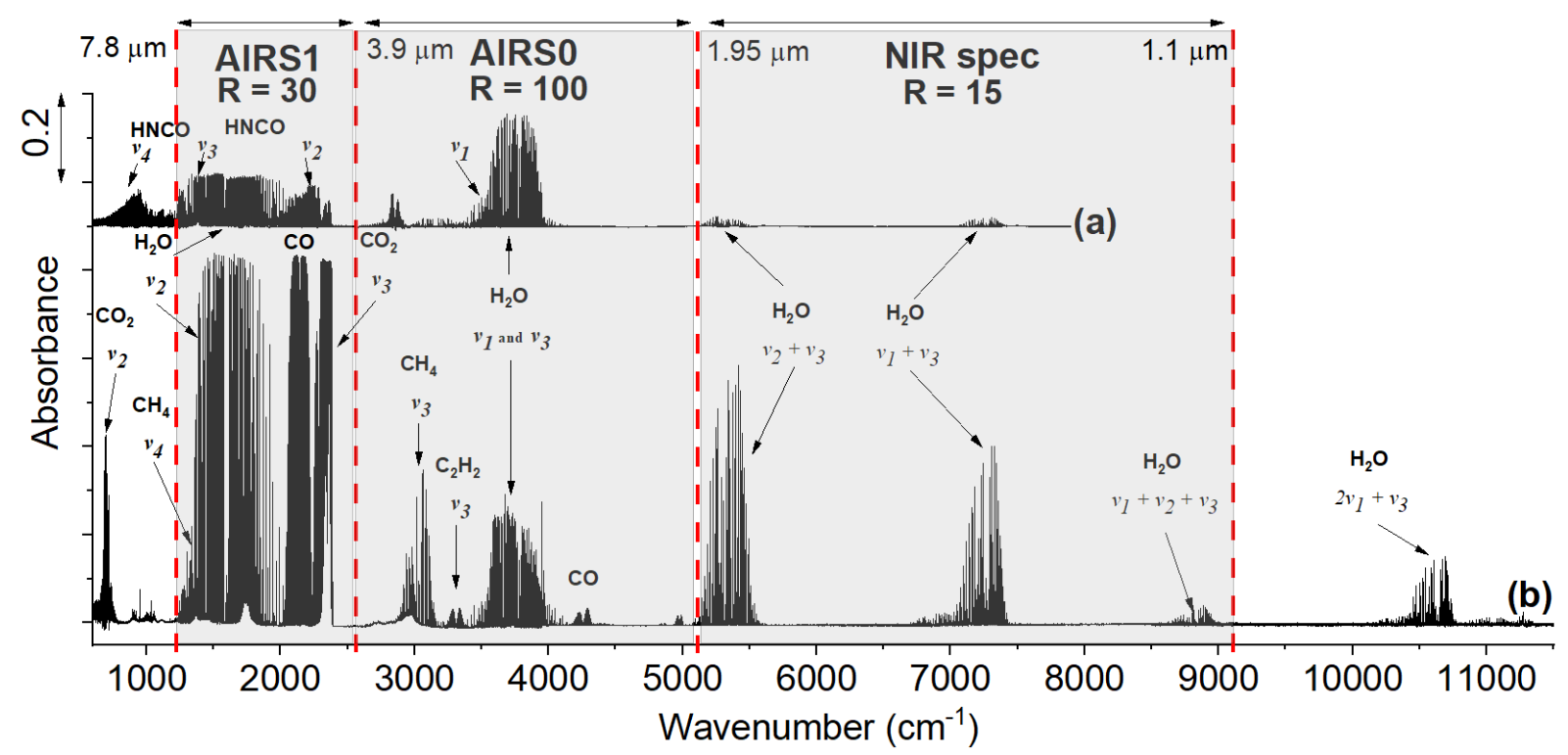


Figure 10. Spectra measured in the laboratory using a high-resolution Fourier-transform spectrometer in comparison with the operational ranges of Ariel spectrometers NIR Spec and AIRS 0 and 1. Spectrum

3 (a) shows an example of the prebiotically important compound HNCO. The spectrum also contains 4 traces of water and $\mathrm{CO}_{2}$. Spectrum (b) is a mixture produced by thermal decomposition of organic matter (a sample of dried leaves). The main dominant spectral bands belong to $\mathrm{CH}_{4}, \mathrm{CO}_{2}, \mathrm{CO}, \mathrm{C}_{2} \mathrm{H}_{2}, \mathrm{C}_{2} \mathrm{H}_{4}$ (around $1000 \mathrm{~cm}^{-1}$, not assigned in the picture for clarity) and $\mathrm{CH}_{3} \mathrm{OH}$ (around $1033 \mathrm{~cm}^{-1}$, not assigned in the picture for clarity). The absorbance of the spectrum in the interval $9000-11500 \mathrm{~cm}^{-1}$ is multiplied by a factor of 20 due to very low intensity of the overtones appearing in this spectral range.

\section{3. Conclusion}

10 The era of detailed exoplanet observations is arriving. Telescopes under construction (such as Ariel) will observe the markers of chemical activity on exo-worlds and a surge of information about exoplanetary chemistry can be expected. Some intriguing prospects are the potential discovery of an Earth analogue or even life beyond the solar system. However, that turns out, detailed observations of exoplanetary chemistry will give us new insight into the history of planet Earth and the origin of its life. For information on the latter we are currently limited to the post-Hadean rock record and indirect evidence of atmospheric processes, but with the upcoming exoplanet spectroscopes we hope to observe early Earth analogues as they evolve in real time. Figure 11 summaries the prebiotically-relevant processes we may observe on exoplanets and are discussed in this paper. Understanding the characteristics of these phenomena is paramount for charting the origin of life on Earth and its potential elsewhere.

How best to gather the necessary detailed information about life-supporting processes from exoplanetary spectra? The strategy outlined here is to look for exotic chemical markers of dynamic processes and trace these to their source of energy, whether impactors, lightning, a strong UV flux, or something else. We provide a chemical and observational overview of molecular species that have a bearing on dynamic processes, prebiotic atmospheric chemistry or emergence of life, and may be detected by Ariel.

Space- and ground-based observatories have already answered many fundamental questions concerning the physical and chemical conditions of star and planet formation. Detailed insights have also followed from the sampling of meteorites, exploration of comets and asteroids, and sparse discoveries of very-old Earth minerals and rocks. However, it is complicated to unite this diverse but incomplete data set into a simple picture of how the hostile early Hadean world evolved through the Moon-forming event, later veneer, late heavy bombardment and transitioned into a warm Archean ocean planet harbouring life. The upcoming large spectral survey of exoplanets will extend our knowledge not only on the spatial, but also in temporal evolution of planets. We believe that Ariel will be a powerful tool aiding this endeavour. 


\section{Exo-Hadean Planet}

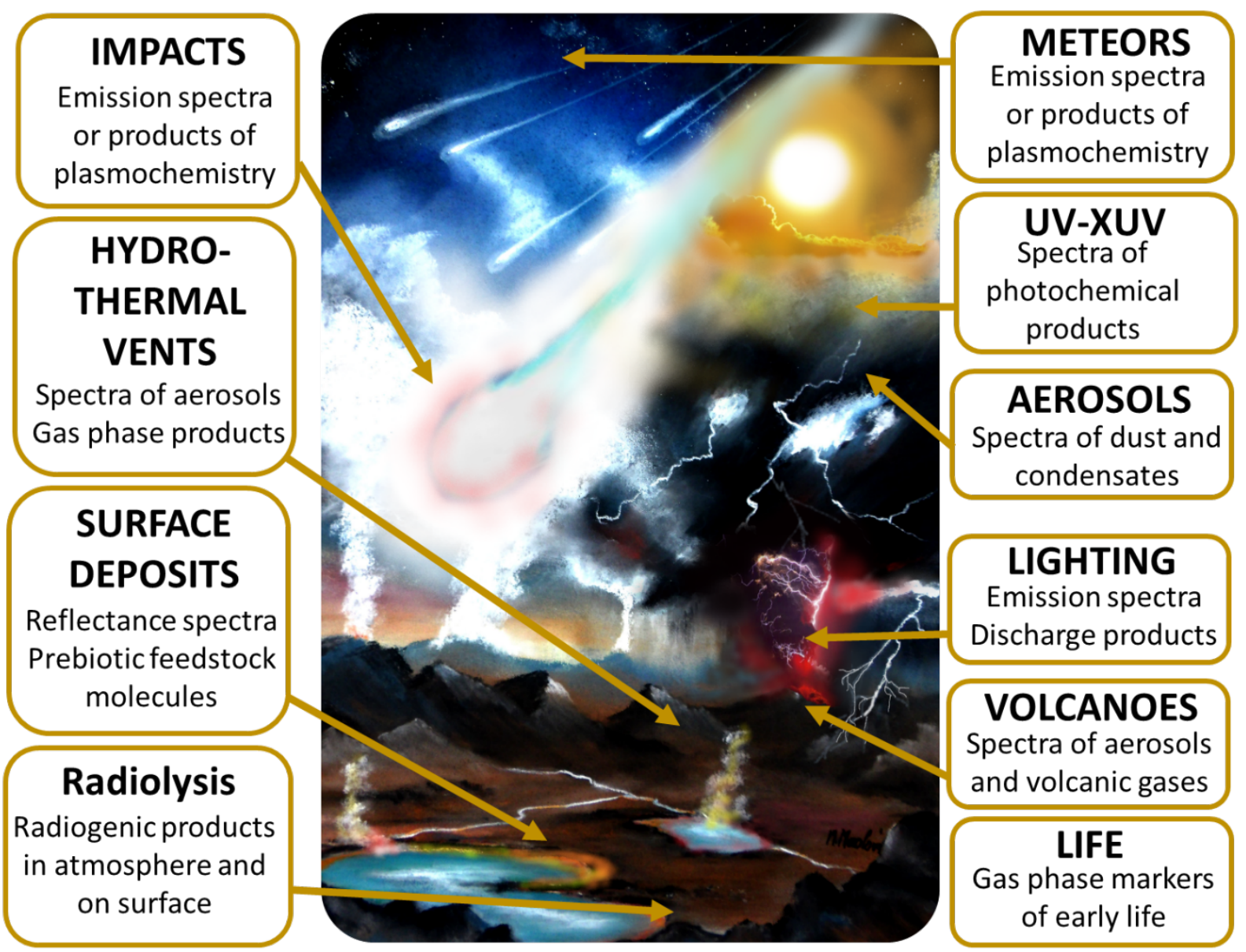

Figure 11. An overview of the main driving forces of prebiotic chemistry and their indicators in planetary spectra.

\section{Acknowledgements}

Martin Ferus acknowledges grant no. 19-03314S of the Czech Science Foundation. Laboratory of high resolution spectroscopy acknowledges ERDF/ESF "Centre of Advanced Applied Sciences" (No. CZ.02.1.01/0.0/0.0/16_019/0000778). Antonín Knížek acknowledges support from grant GAUK 16742. A. Kereszturi acknowledges the support of GINOP-2.3.2-15-2016-00003 from NKFIH. V. Čuba and B. Drtinová acknowledge support from MPO TRIO no. FV30139. Lukáš Nejdl acknowledges the support of Grant Agency of Mendel University in Brno IGA MENDELU 2019_TP_009. Vladislav Chernov and Petr Kubelík acknowledge support from the joint RFBR projects (research projects no 20-10591J and no. 1952-26006, correspondingly). Special thanks go to Antonín Knížek for comprehensive consolidation of the paper and to Alan Heays for his careful language review of the text. 
Confidental Revision of the Paper - Ariel consortium WG Astrobiology and Prebiotic Chemistry

Experimental Astronomy: Special issue for Ariel Phase B

https://link.springer.com/journal/10686, the deadline for submission September 14, 2020

\section{References}

2 1. Bless, R.C.: Discovering the Cosmos. University Science Books,U.S. (2013)

3 2. Sedley, D.: Lucretius. In: Zalta, E.N. (ed.) Stanford Encyclopedia of Philosophy. Metaphysics Research Lab, Center for the Study of Language and Information, Stanford University, Stanford, CA 94035 (2018)

3. Mayor, M., Queloz, D.: A Jupiter-mass companion to a solar-type star. Nature. 378, 355-359 (1995). https://doi.org/10.1038/378355a0

4. Charbonneau, D., Brown, T.M., Noyes, R.W., Gilliland, R.L.: Detection of an extrasolar planet atmosphere. Astrophys. J. 568, 377-384 (2002). https://doi.org/10.1086/338770

5. exoplanet.eu.

6. Deming, L.D., Seager, S.: Illusion and reality in the atmospheres of exoplanets. J. Geophys. Res. 122, 53-75 (2017). https://doi.org/10.1002/2016JE005155

7. Mandel, K., Agol, E.: Analytic light curves for planetary transit searches. Astrophys. J. 580, L171-L175 (2002). https://doi.org/10.1086/345520

8. Udry, S., Fischer, D., Queloz, D.: A decade of radial-velocity discoveries in the exoplanet domain. Protostars Planets V. 951, 685-699 (2007)

9. Seager, S., Kuchner, M., Hier-Majumder, C.A., Militzer, B.: Mass-radius relationships for solid exoplanets. Astrophys. J. 669, 1279-1297 (2007). https://doi.org/10.1086/521346

10. Dressing, C.D., Charbonneau, D., Dumusque, X., Gettel, S., Pepe, F., Cameron, A.C., Latham, D.W., Molinari, E., Udry, S., Affer, L., Bonomo, A.S., Buchhave, L.A., Cosentino, R., Figueira, P., Fiorenzano, A.F.M., Harutyunyan, A., Haywood, R.D., Johnson, J.A., Lopez-Morales, M., Lovis, C., Malavolta, L., Mayor, M., Micela, G., Motalebi, F., Nascimbeni, V., Phillips, D.F., Piotto, G., Pollacco, D., Queloz, D., Rice, K., Sasselov, D., Segransan, D., Sozzetti, A., Szentgyorgyi, A., Watson, C.: The mass of Kepler-93b and the composition of terrestrial planets. Astrophys. J. 800, (2015). https://doi.org/10.1088/0004-637X/800/2/135

11. Zeng, L., Sasselov, D.: A Detailed Model Grid for Solid Planets from 0.1 through 100 Earth Masses. Publ. Astron. Soc. PACIFIC. 125, 227-239 (2013). https://doi.org/10.1086/669163

12. Fortney, J.J., Shabram, M., Showman, A.P., Lian, Y., Freedman, R.S., Marley, M.S., Lewis, N.K.: Transmission spectra of three-dimensional hot Jupiter model atmospheres. Astrophys. J. 709, 1396-1406 (2010). https://doi.org/10.1088/0004-637X/709/2/1396

13. Swain, M.R., Tinetti, G., Vasisht, G., Deroo, P., Griffith, C., Bouwman, J., Chen, P., Yung, Y., Burrows, A., Brown, L.R., Matthews, J., Rowe, J.F., Kuschnig, R., Angerhausen, D.: Water, methane and carbon dioxide present in the dayside spectrum of the exoplanet HD 209458b. Astrophys. J. 704, 1616-1621 (2009). https://doi.org/10.1088/0004-637X/704/2/1616

14. Brogi, M., Snellen, I.A.G., de Kok, R.J., Albrecht, S., Birkby, J.L., de Mooij, E.J.W.: DETECTION OF MOLECULAR ABSORPTION IN THE DAYSIDE OF EXOPLANET 51 PEGASI b? Astrophys. J. 767, (2013). https://doi.org/10.1088/0004-637X/767/1/27

15. Greene, T.P., Line, M.R., Montero, C., Fortney, J.J., Lustig-Yaeger, J., Luther, K.: CHARACTERIZING TRANSITING EXOPLANET ATMOSPHERES WITH JWST. Astrophys. J. 817, (2016). https://doi.org/10.3847/0004-637X/817/1/17

16. Charbonneau, D., Allen, L.E., Megeath, S.T., Torres, G., Alonso, R., Brown, T.M., Gilliland, R.L., 
Confidental Revision of the Paper - Ariel consortium WG Astrobiology and Prebiotic Chemistry

Experimental Astronomy: Special issue for Ariel Phase B

https://link.springer.com/journal/10686, the deadline for submission September 14, 2020

Latham, D.W., Mandushev, G., O'Donovan, F.T., Sozzetti, A.: Detection of thermal emission from an extrasolar planet. Astrophys. J. 626, 523-529 (2005). https://doi.org/10.1086/429991

17. Demory, B.O. et al.: A map of the large day-night temperature gradient of a super-Earth exoplanet. Nature. 7141, 207-209 (2016)

18. Knutson, H.A., Charbonneau, D., Allen, L.E., Fortney, J.J., Agol, E., Cowan, N.B., Showman, A.P., Cooper, C.S., Megeath, S.T.: A map of the day-night contrast of the extrasolar planet HD 189733b. Nature. 447, 183-186 (2007). https://doi.org/10.1038/nature05782

19. Sing, D.K., Wakeford, H.R., Showman, A.P., Nikolov, N., Fortney, J.J., Burrows, A.S., Ballester, G.E., Deming, D., Aigrain, S., Desert, J.-M., Gibson, N.P., Henry, G.W., Knutson, H., des Etangs, A.L., Pont, F., Vidal-Madjar, A., Williamson, M.W., Wilson, P.A.: HST hot-Jupiter transmission spectral survey: detection of potassium in WASP-31b along with a cloud deck and Rayleigh scattering. Mon. Not. R. Astron. Soc. 446, 2428-2443 (2015). https://doi.org/10.1093/mnras/stu2279

20. Lacour, S., Nowak, M., Wang, J., Pfuhl, O., Eisenhauer, F., Abuter, R., Amorim, A., Anugu, N., Benisty, M., Berger, J.P., Beust, H., Blind, N., Bonnefoy, M., Bonnet, H., Bourget, P., Brandner, W., Buron, A., Collin, C., Charnay, B., Chapron, F., Clénet, Y., Coudé du Foresto, V., de Zeeuw, P.T., Deen, C., Dembet, R., Dexter, J., Duvert, G., Eckart, A., Förster Schreiber, N.M., Fédou, P., Garcia, P., Garcia Lopez, R., Gao, F., Gendron, E., Genzel, R., Gillessen, S., Gordo, P., Greenbaum, A., Habibi, M., Haubois, X., Hau\ssmann, F., Henning, T., Hippler, S., Horrobin, M., Hubert, Z., Jimenez Rosales, A., Jocou, L., Kendrew, S., Kervella, P., Kolb, J., Lagrange, A.-M., Lapeyrère, V., Le Bouquin, J.-B., Léna, P., Lippa, M., Lenzen, R., Maire, A.-L., Mollière, P., Ott, T., Paumard, T., Perraut, K., Perrin, G., Pueyo, L., Rabien, S., Ram\’\irez, A., Rau, C., Rodr\’'iguezCoira, G., Rousset, G., Sanchez-Bermudez, J., Scheithauer, S., Schuhler, N., Straub, O., Straubmeier, C., Sturm, E., Tacconi, L.J., Vincent, F., van Dishoeck, E.F., von Fellenberg, S., Wank, I., Waisberg, I., Widmann, F., Wieprecht, E., Wiest, M., Wiezorrek, E., Woillez, J., Yazici, S., Ziegler, D., Zins, G.: First direct detection of an exoplanet by optical interferometry Astrometry and K-band spectroscopy of HR 8799 e. A\&A. 623, L11 (2019). https://doi.org/10.1051/0004-6361/201935253

21. Schwieterman, E., Reinhard, C., Olson, S., Lyons, T.: The Importance of UV Capabilities for Identifying Inhabited Exoplanets with Next Generation Space Telescopes. (2018)

22. Powner, M.W., Sutherland, J.D.: Prebiotic chemistry: a new modus operandi. Philos. Trans. R. Soc. B-BIOLOGICAL Sci. 366, 2870-2877 (2011). https://doi.org/10.1098/rstb.2011.0134

23. Oparin, A.I.: The origin of life. New York, Macmillan Company. viii p 2. (1938)

24. Miller, S.L.: A Production of Amino Acids Under Possible Primitive Earth Conditions. Science (80-. ). 117, 528 LP - 529 (1953)

25. Brogan, C.L., Pérez, L.M., Hunter, T.R., Dent, W.R.F., Hales, A.S., Hills, R.E., Corder, S., Fomalont, E.B., Vlahakis, C., Asaki, Y., Barkats, D., Hirota, A., Hodge, J.A., Impellizzeri, C.M. V., Kneissl, R., Liuzzo, E., Lucas, R., Marcelino, N., Matsushita, S., Nakanishi, K., Phillips, N., Richards, A.M.S., Toledo, I., Aladro, R., Broguiere, D., Cortes, J.R., Cortes, P.C., Espada, D., Galarza, F., Appadoo, D.G.-, Ramirez, L.G.-, Humphreys, E.M., Jung, T., Kameno, S., Laing, R.A., Leon, S., Marconi, G., Mignano, A., Nikolic, B., Nyman, L.-A., Radiszcz, M., Remijan, A., Rodón, J.A., Sawada, T., Takahashi, S., Tilanus, R.P.J., Vilaro, B.V., Watson, L.C., Wiklind, T., Akiyama, E., Chapillon, E., Monsalvo, I. de G.-, Francesco, J. Di, Gueth, F., Kawamura, A., Lee, C.-F., Luong, Q.N., Mangum, J., Pietu, V., Sanhueza, P., Saigo, K., Takakuwa, S., Ubach, C., Kempen, T. van, Wootten, A., Carrizo, A.C.-, Francke, H., Gallardo, J., Garcia, J., Gonzalez, S., Hill, T., Kaminski, T., Kurono, Y., 
Liu, H.-Y., Lopez, C., Morales, F., Plarre, K., Schieven, G., Testi, L., Videla, L., Villard, E., Andreani, P., Hibbard, J.E., Tatematsu, K.: The 2014 ALMA long baseline campaign: First results from high angular resolution observations toward the HL Tau region. Astrophys. J. 808, L3 (2015). https://doi.org/10.1088/2041-8205/808/1/L3

26. Canup, R.M., Asphaug, E.: Origin of the Moon in a giant impact near the end of the Earth's formation. Nature. 412, 708-712 (2001). https://doi.org/10.1038/35089010

27. Genda, H., Brasser, R., Mojzsis, S.J.: The terrestrial late veneer from core disruption of a lunarsized impactor. Earth Planet. Sci. Lett. 480, 25-32 (2017).

https://doi.org/10.1016/j.epsl.2017.09.041

28. Koeberl, C., Reimold, W.U., McDonald, I., Rosing, M.: Search for petrographic and geochemical evidence for the late heavy bombardment on Earth in early Archean rocks from Isua, Greenland. In: Gilmour, I. and Koeberl, C. (eds.) Impacts and the early Earth. pp. 73-97. Springer-Verlag Berlin, Heidelberger platz 3, D-14197 Berlin, Germany (2000)

29. Tsiganis, K., Gomes, R., Morbidelli, A., Levison, H.F.: Origin of the orbital architecture of the giant planets of the Solar System. Nature. 435, 459-461 (2005). https://doi.org/10.1038/nature03539

30. Nesvorny, D., Morbidelli, A.: Statistical Study of the Early Solar System's Instability with Four, Five, and Six Giant Planets. Astron. J. 144, (2012). https://doi.org/10.1088/0004$6256 / 144 / 4 / 117$

31. Gomes, R., Levison, H.F., Tsiganis, K., Morbidelli, A.: Origin of the cataclysmic Late Heavy Bombardment period of the terrestrial planets. Nature. 435, 466-469 (2005). https://doi.org/10.1038/nature03676

32. Turner, G., Cadogan, P.H., Yonge, C.J.: Argon selenochronology. Proc. Lunar. Sci. Conf. 4. 18891914 (1973)

33. Tera, F., Papanastassiou, D.A., Wasserburg, G.J.: A lunar cataclysm at $3.95 \mathrm{AE}$ and the systematics of the lunar crust. Lunar Sci. IV., Abstr. Houst. 723-725 (1973)

34. Chyba, C., Sagan, C.: Endogenous Production, Exogenous Delivery and Impact-Shock Synthesis of Organic Molecules - an Inventory for the Origin of Life. Nature. 355, 125-132 (1992). https://doi.org/10.1038/355125a0

35. Morbidelli, A., Marchi, S., Bottke, W.F., Kring, D.A.: A sawtooth-like timeline for the first billion years of lunar bombardment. EARTH Planet. Sci. Lett. 355, 144-151 (2012). https://doi.org/10.1016/j.epsl.2012.07.037

36. Geiss, J., Rossi, A.P.: On the chronology of lunar origin and evolution Implications for Earth, Mars and the Solar System as a whole. Astron. Astrophys. Rev. 21, 1-54 (2013). https://doi.org/10.1007/s00159-013-0068-1

37. Holzheid, A., Sylvester, P., O'Neill, H.S.C., Rubie, D.C., Palme, H.: Evidence for a late chondritic veneer in the Earth's mantle from high-pressure partitioning of palladium and platinum. Nature. 406, 396-399 (2000). https://doi.org/10.1038/35019050

38. Koeberl, C.: Impact processes on the early Earth. Elements. 2, 211-216 (2006). https://doi.org/10.2113/gselements.2.4.211

39. Bottke, W.F., Vokrouhlicky, D., Minton, D., Nesvorny, D., Morbidelli, A., Brasser, R., Simonson, B., Levison, H.F.: An Archaean heavy bombardment from a destabilized extension of the 

asteroid belt. Nature. 485, 78-81 (2012). https://doi.org/10.1038/nature10967

40. Norman, M.D., Duncan, R.A., Huard, J.J.: Imbrium provenance for the Apollo 16 Descartes terrain: Argon ages and geochemistry of lunar breccias 67016 and 67455. Geochim. Cosmochim. Acta. 74, 763-783 (2010). https://doi.org/https://doi.org/10.1016/j.gca.2009.10.024

41. Mann, A.: Bashing holes in the tale of Earth's troubled youth. Nature. 553, 393-395 (2018). https://doi.org/10.1038/d41586-018-01074-6

42. Watson, E.B., Harrison, T.M.: Zircon Thermometer Reveals Minimum Melting Conditions on Earliest Earth. Science (80-. ). 308, 841-844 (2005). https://doi.org/10.1126/science.1110873

43. Ryder, G.: Mass flux in the ancient Earth-Moon system and benign implications for the origin of life on Earth. J. Geophys. Res. Planets. 107, (2002). https://doi.org/https://doi.org/10.1029/2001JE001583

44. Koeberl, C.: The record of impact processes on the early Earth: A review of the first 2.5 billion years. In: Reimold, WU and Gibson, R. (ed.) Processes on the Early Earth. pp. 1-22. Geological Sec Amer Inc., 3300 Penrose PL, PO BOX 9140, Boulder, CO 80301 USA (2006)

45. Kuwahara, H., Sugita, S.: The molecular composition of impact-generated atmospheres on terrestrial planets during the post-accretion stage. Icarus. 257, 290-301 (2015). https://doi.org/10.1016/j.icarus.2015.05.007

46. Lunine, J.I.: Physical conditions on the early Earth. Philos. Trans. R. Soc. B - Biol. Sci. 361, 17211731 (2006). https://doi.org/10.1098/rstb.2006.1900

47. Chyba, C.F., Thomas, P.J., Brookshaw, L., Sagan, C.: Cometary Delivery of Organic Molecules to the Early Earth. Science (80-. ). 249, 366-373 (1990).

https://doi.org/10.1126/science.11538074

48. Martins, Z.: Organic Chemistry of Carbonaceous Meteorites. Elements. 7, 35-40 (2011). https://doi.org/10.2113/gselements.7.1.35

49. Martins, Z., Modica, P., Zanda, B., D'Hendecourt, L.L.S.: The amino acid and hydrocarbon contents of the Paris meteorite: Insights into the most primitive CM chondrite. Meteorit. Planet. Sci. 50, 926-943 (2015). https://doi.org/10.1111/maps.12442

50. Martins, Z., Botta, O., Fogel, M.L., Sephton, M.A., Glavin, D.P., Watson, J.S., Dworkin, J.P., Schwartz, A.W., Ehrenfreund, P.: Extraterrestrial nucleobases in the Murchison meteorite. Earth Planet. Sci. Lett. 270, 130-136 (2008). https://doi.org/10.1016/j.epsl.2008.03.026

51. Sutherland, J.D.: The Origin of Life-Out of the Blue. Angew. Chemie-Internation Ed. 55, 104-121 (2016)

52. Rios, A.C.: Impact synthesis of the RNA bases. Proc. Natl. Acad. Sci. 112, 643-644 (2015)

53. Ferus, M., Nesvorný, D., Šponer, J., Kubelík, P., Michalčíková, R., Shestivská, V., Šponer, J.E., Civiš, S.: High-energy chemistry of formamide: A unified mechanism of nucleobase formation. Proc. Natl. Acad. Sci. U. S. A. 112, 657-662 (2015). https://doi.org/10.1073/pnas.1412072111

54. Morbidelli, A., Chambers, J., Lunine, J.I., Petit, J.M., Robert, F., Valsecchi, G.B., Cyr, K.E.: Source regions and timescales for the delivery of water to the Earth. Meteorit. Planet. Sci. 35, 1309$1320(2000)$

55. de Niem, D., Kuehrt, E., Morbidelli, A., Motschmann, U.: Atmospheric erosion and 
replenishment induced by impacts upon the Earth and Mars during a heavy bombardment. Icarus. 221, 495-507 (2012). https://doi.org/10.1016/j.icarus.2012.07.032

56. Hashimoto, G.L., Abe, Y., Sugita, S.: The chemical composition of the early terrestrial atmosphere: Formation of a reducing atmosphere from Cl-like material. J. Geophys. Res. 112, E05010 (2007). https://doi.org/10.1029/2006JE002844

57. Yang, X., Gaillard, F., Scaillet, B.: A relatively reduced Hadean continental crust and implications for the early atmosphere and crustal rheology. Earth Planet. Sci. Lett. 393, (2014). https://doi.org/10.1016/j.epsl.2014.02.056

58. Zahnle, K., Lupu, R., Catling, D.: Creation and Evolution of Impact-generated Reduced Atmospheres of Early Earth. (2019)

59. Šponer, J.E., Szabla, R., Gora, R.W., Saitta, A.M., Pietrucci, F., Saija, F., Di Mauro, E., Saladino, R., Ferus, M., Civiš, S., Šponer, J.: Prebiotic synthesis of nucleic acids and their building blocks at the atomic level - merging models and mechanisms from advanced computations and experiments. Phys. Chem. Chem. Phys. 18, 20047-20066 (2016). https://doi.org/10.1039/c6cp00670a

60. Babankova, D., Civis, S., Juha, L., Bittner, M., Cihelka, J., Pfeifer, M., Skala, J., Bartnik, A., Fiedorowicz, H., Mikolajczyk, J., Ryc, L., Sedivcova, T.: Optical and X-ray emission spectroscopy of high-power laser-induced dielectric breakdown in molecular gases and their mixtures. J. Phys. Chem. A. 110, 12113-12120 (2006). https://doi.org/10.1021/jp063689o

61. Ferus, M., Pietrucci, F., Saitta, A.M., Knížek, A., Kubelík, P., Ivanek, O., Shestivská, V., Civiš, S., Shestivská, V., Civiš, S.: Formation of nucleobases in a Miller-Urey reducing atmosphere. Proc. Natl. Acad. Sci. 114, 4306-4311 (2017). https://doi.org/10.1073/pnas.1700010114

62. Ferus, M., Michalčíková, R., Shestivská, V., Šponer, J., Šponer, J.E., Civiš, S.: High-Energy Chemistry of Formamide: A simpler way for nucleobase formation. J. Phys. Chem. A. 118, 719736 (2014)

63. Ferus, M., Civis, S., Mladek, A., Sponer, J., Juha, L., Sponer, J.E.: On the Road from Formamide Ices to Nucleobases: IR-Spectroscopic Observation of a Direct Reaction between Cyano Radicals and Formamide in a High-Energy Impact Event. J. Am. Chem. Soc. 134, 20788-20796 (2012). https://doi.org/10.1021/ja310421z

64. Civis, S., Szabla, R., Szyja, B.M., Smykowski, D., Ivanek, O., Knizek, A., Kubelik, P., Sponer, J., Ferus, M., Sponer, J.E.: TiO2-catalyzed synthesis of sugars from formaldehyde in extraterrestrial impacts on the early Earth. Sci. Rep. 6, 23199 (2016). https://doi.org/10.1038/srep27962

65. Civis, S., Juha, L., Babankova, D., Cvacka, J., Frank, O., Jehlicka, J., Kralikova, B., Krasa, J., Kubat, P., Muck, A., Pfeifer, M., Skala, J., Ullschmied, J.: Amino acid formation induced by high-power laser in CO2/CO-N-2-H2O gas mixtures. Chem. Phys. Lett. 386, 169-173 (2004). https://doi.org/10.1016/j.cplett.2004.01.034

66. Ferus, M., Kubelík, P., Knížek, A., Pastorek, A., Sutherland, J., Civiš, S.: High Energy Radical Chemistry Formation of HCN-rich Atmospheres on early Earth. Sci. Rep. 7, (2017). https://doi.org/10.1038/s41598-017-06489-1

67. Civiš, M., Ferus, M., Kní̌ek, A., Kubelík, P., Kamas, M., Španěl, P., Dryahina, K., Shestivska, V., Juha, L., Skřehot, P., Laitl, V., Civiš, S.: Spectroscopic investigations of high-energy-density plasma transformations in a simulated early reducing atmosphere containing methane, nitrogen and water. Phys. Chem. Chem. Phys. 18, 27317-27325 (2016). 
Confidental Revision of the Paper - Ariel consortium WG Astrobiology and Prebiotic Chemistry

Experimental Astronomy: Special issue for Ariel Phase B

https://link.springer.com/journal/10686, the deadline for submission September 14, 2020

https://doi.org/10.1039/c6cp05025e

68. Civiš, S., Knížek, A., Ivanek, O., Kubelík, P., Zukalová, M., Kavan, L., Ferus, M.: Origin of methane and biomolecules from a CO2 cycle on terrestrial planets. Nat. Astron. 1, 721-726 (2017). https://doi.org/10.1038/s41550-017-0260-8

69. Ferus, M., Matulkova, I., Juha, L., Civis, S.: Investigation of laser-plasma chemistry in CO-N-2H2O mixtures using 0-18 labeled water. Chem. Phys. Lett. 472, 14-18 (2009). https://doi.org/10.1016/j.cplett.2009.02.056

70. Civis, S., Babankova, D., Cihelkat, J., Sazama, P., Juha, L.: Spectroscopic investigations of highpower laser-induced dielectric breakdown in gas mixtures containing carbon monoxide. J. Phys. Chem. A. 112, 7162-7169 (2008). https://doi.org/10.1021/jp712011lt

71. Airapetian, V.S., Glocer, A., Gronoff, G., Hebrard, E., Danchi, W.: Prebiotic chemistry and atmospheric warming of early Earth by an active young Sun. Nat. Geosci. 9, 452+ (2016). https://doi.org/10.1038/NGEO2719

72. Lammer, H., Sproß, L., Grenfell, J.L., Scherf, M., Fossati, L., Lendl, M., Cubillos, P.E.: The Role of $\mathrm{N}_{2}$ as a Geo-Biosignature for the Detection and Characterization of Earth-like Habitats.

Astrobiology. 19, 927-950 (2019). https://doi.org/10.1089/ast.2018.1914

73. Lammer, H., Sproß, L., Grenfell, J.L., Scherf, M., Fossati, L., Lendl, M., Cubillos, P.E.: The Role of N2 as a Geo-Biosignature for the Detection and Characterization of Earth-like Habitats. Astrobiology. 19, 927-950 (2019). https://doi.org/10.1089/ast.2018.1914

74. Sproß, L.: Development of the Earth's Nitrogen Atmosphere in the Archean and During the Great Oxidation Event Transition, (2019)

75. Stüeken, E.E., Som, S.M., Claire, M.W., Rugheimer, S., Scherf, M., Sproß, L., Tosi, N.N., Ueno, Y., Lammer, H.: Mission to Planet Earth: The First Two Billion Years. Sp. Sci. Rev. under Rev. (2020)

76. Rimmer, P.B., Ferus, M., Waldmann, I.P., Knížek, A., Kalvaitis, D., Ivanek, O., Kubelík, P., Yurchenko, S.N., Burian, T., Dostál, J., Juha, L., Dudžák, R., Krůs, M., Tennyson, J., Civiš, S., Archibald, A.T., Granville-Willett, A.: Identifiable Acetylene Features Predicted for Young Earthlike Exoplanets with Reducing Atmospheres Undergoing Heavy Bombardment. Astrophys. J. 888, 21 (2019). https://doi.org/10.3847/1538-4357/ab55e8

77. Hazen, R.M., Papineau, D., Leeker, W.B., Downs, R.T., Ferry, J.M., McCoy, T.J., Sverjensky, D.A., Yang, H.: Mineral evolution. Am. Mineral. 93, 1693-1720 (2008). https://doi.org/10.2138/am.2008.2955

78. Hazen, R.M., Downs, R.T., Kah, L., Sverjensky, D.: Carbon Mineral Evolution. In: Hazen, RM and Jones, AP and Baross, J. (ed.) Carbon in Earth. pp. 79-107. Mineralogical soc Amer \& Geochmical soc, 3635 Concorde Pkwy Ste 500, Chantilly, VA 20151-1125 USA (2013)

79. Hazen, R.M., Ferry, J.M.: Mineral Evolution: Mineralogy in the Fourth Dimension. Elements. 6, 9-12 (2010). https://doi.org/10.2113/gselements.6.1.9

80. Góbi, S., Kereszturi, Á.: Role of serpentinization in the thermal and connected mineral evolution of planetesimals - evaluating possible consequences for exoplanetary systems. Mon. Not. R. Astron. Soc. 466, 2099-2110 (2016). https://doi.org/10.1093/mnras/stw3223

81. Lugaro, M., Ott, U., Kereszturi: Radioactive nuclei from cosmochronology to habitability, (2018)

82. Morris, M.A., Desch, S.J.: Phyllosilicate Emission from Protoplanetary Disks: Is the Indirect Detection of Extrasolar Water Possible? Astrobiology. 9, 965-978 (2009). 
Confidental Revision of the Paper - Ariel consortium WG Astrobiology and Prebiotic Chemistry

Experimental Astronomy: Special issue for Ariel Phase B

https://link.springer.com/journal/10686, the deadline for submission September 14, 2020

https://doi.org/10.1089/ast.2008.0316

83. Ertem, G., Steudel, A., Emmerich, K., Lagaly, G., Schuhmann, R.: Correlation Between the Extent of Catalytic Activity and Charge Density of Montmorillonites. Astrobiology. 10, 743-749 (2010). https://doi.org/10.1089/ast.2009.0436

84. Hazen, R.M.: Paleomineralogy of the Hadean Eon: A preliminary species list. Am. J. Sci. 313, 807-843 (2013). https://doi.org/10.2475/09.2013.01

85. Zahnle, K., Arndt, N., Cockell, C.S., Halliday, A.N., Nisbet, E.G., Selsis, F., Sleep, N.H.: Emergence of a Habitable Planet. Sp. Sci Rev. 129, 35-78 (2007)

86. Babankova, D., Civis, S., Juha, L.: Chemical consequences of laser-induced breakdown in molecular gases. Prog. Quantum Electron. 30, 75-88 (2006).

https://doi.org/10.1016/j.pquantelec.2006.09.001

87. Ferus, M., Knížek, A., Civiš, S.: Meteorite-catalyzed synthesis of nucleosides and other prebiotic compounds. Proc. Natl. Acad. Sci. 112, (2015). https://doi.org/10.1073/pnas.1507471112

88. Civiš, S., Szabla, R., Szyja, B.M., Smykowski, D., Ivanek, O., Knížek, A., Kubelík, P., Šponer, J., Ferus, M., Šponer, J.E.: TiO2-catalyzed synthesis of sugars from formaldehyde in extraterrestrial impacts on the early Earth. Sci. Rep. 6, 23199 (2016). https://doi.org/10.1038/srep23199

89. Ferus, M., Kubelik, P., Civis, S.: Laser Spark Formamide Decomposition Studied by FT-IR Spectroscopy. J. Phys. Chem. A. 115, 12132-12141 (2011). https://doi.org/10.1021/jp205413d

90. Ferus, M., Laitl, V., Knizek, A., Kubelik, P., Sponer, J., Kara, J., Sponer, J.E., Lefloch, B., Cassone, G., Civis, S.: HNCO-based synthesis of formamide in planetary atmospheres. Astron. Astrophys. 616, (2018). https://doi.org/10.1051/0004-6361/201833003

91. Ferus, M., Pietrucci, F., Saitta, A.M., Ivanek, O., Knizek, A., Kubel\’ik, P., Krus, M., Juha, L., Dudzak, R., Dostál, J., Pastorek, A., Petera, L., Hrncirova, J., Saeidfirozeh, H., Shestivská, V., Sponer, J., Sponer, J.E., Rimmer, P., Civis, S., Cassone, G.: Prebiotic synthesis initiated in formaldehyde by laser plasma simulating high-velocity impacts. A\&A. 626, A52 (2019). https://doi.org/10.1051/0004-6361/201935435

92. Cassone, G., Saija, F., Sponer, J., Sponer, J.E., Ferus, M., Krus, M., Ciaravella, A., JiménezEscobar, A., Cecchi-Pestellini, C.: Dust Motions in Magnetized Turbulence: Source of Chemical Complexity. Astrophys. J. 866, L23 (2018). https://doi.org/10.3847/2041-8213/aae529

93. Nejdl, L., Zemankova, K., Havlikova, M., Buresova, M., Hynek, D., Xhaxhiu, K., Mravec, F., Matouskova, M., Adam, V., Ferus, M., Kapus, J., Vaculovicova, M.: UV-Induced NanoparticlesFormation, Properties and Their Potential Role in Origin of Life. Nanomaterials. 10, 1529 (2020). https://doi.org/10.3390/nano10081529

94. Fukuhara, M.: Possible generation of heat from nuclear fusion in Earth's inner core. Sci. Rep. 6, 1-7 (2016). https://doi.org/10.1038/srep37740

95. Huang, Y., Chubakov, V., Mantovani, F., Rudnick, R.L., McDonough, W.F.: A reference Earth model for the heat-producing elements and associated geoneutrino flux. Geochemistry, Geophys. Geosystems. 14, 2003-2029 (2013). https://doi.org/10.1002/ggge.20129

96. Davies, J.H., Davies, D.R.: Earth's surface heat flux. Solid Earth. 1, 5-24 (2010)

97. Korenaga, J.: Urey ratio and the structure and evolution of Earth's mantle. Rev. Geophys. 46, RG2007 (2008). https://doi.org/10.1029/2007RG000241 
98. Segura, A., Kasting, J.F., Meadows, V., Cohen, M., Scalo, J., Crisp, D., Butler, R.A.H., Tinetti, G.: Biosignatures from Earth-Like Planets Around M Dwarfs. Astrobiology. 5, 706-725 (2005). https://doi.org/10.1089/ast.2005.5.706

99. Sclater, J.G., Jaupart, C., Galson, D.: The heat flow through oceanic and continental crust and the heat loss of the Earth. Rev. Geophys. 18, 269 (1980). https://doi.org/10.1029/RG018i001p00269

100. Pollack, H.N., Hurter, S.J., Johnson, J.R.: Heat flow from the Earth's interior: Analysis of the global data set. Rev. Geophys. 31, 267 (1993). https://doi.org/10.1029/93RG01249

101. Gando, A., Gando, Y., Ichimura, K., Ikeda, H., Inoue, K., Kibe, Y., Kishimoto, Y., Koga, M., Minekawa, Y., Mitsui, T., Morikawa, T., Nagai, N., Nakajima, K., Nakamura, K., Narita, K., Shimizu, I., Shimizu, Y., Shirai, J., Suekane, F., Suzuki, A., Takahashi, H., Takahashi, N., Takemoto, Y., Tamae, K., Watanabe, H., Xu, B.D., Yabumoto, H., Yoshida, H., Yoshida, S., Enomoto, S., Kozlov, A., Murayama, H., Grant, C., Keefer, G., Piepke, A., Banks, T.I., Bloxham, T., Detwiler, J.A., Freedman, S.J., Fujikawa, B.K., Han, K., Kadel, R., O'Donnell, T., Steiner, H.M., Dwyer, D.A., McKeown, R.D., Zhang, C., Berger, B.E., Lane, C.E., Maricic, J., Miletic, T., Batygov, M., Learned, J.G., Matsuno, S., Sakai, M., Horton-Smith, G.A., Downum, K.E., Gratta, G., Tolich, K., Efremenko, Y., Perevozchikov, O., Karwowski, H.J., Markoff, D.M., Tornow, W., Heeger, K.M., Decowski, M.P.: Partial radiogenic heat model for Earth revealed by geoneutrino measurements. Nat. Geosci. 4, 647-651 (2011). https://doi.org/10.1038/ngeo1205

102. Zagórski, Z.P.: Radiation chemistry and origins of life on earth. Radiat. Phys. Chem. 66, 329-334 (2003). https://doi.org/10.1016/S0969-806X(02)00408-5

103. Zagórski, Z.P., Kornacka, E.M.: Ionizing Radiation : Friend or Foe of the Origins of Life? Orig. LIFE Evol. Biosph. 42, 503-505 (2012). https://doi.org/10.1007/s11084-012-9314-1

104. Turcotte, D.L., Schubert, G.: Geodynamics: Applications of Continuum Physics to Geological Problems. Cambridge University Press (1982)

105. Saladino, R., Bizzarri, B.M., Botta, L., Sponer, J., Sponer, J.E., Georgelin, T., Jaber, M., Rigaud, B., Kapralov, M., Timoshenko, G.N., Rozanov, A., Krasavin, E., Timperio, A.M., Di Mauro, E.: Proton irradiation: a key to the challenge of $\mathrm{N}$-glycosidic bond formation in a prebiotic context. Sci. Rep. 7, (2017). https://doi.org/10.1038/s41598-017-15392-8

106. Saladino, R., Carota, E., Botta, G., Kapralov, M., Timoshenko, G.N., Rozanov, A.Y., Krasavin, E., Di Mauro, E.: Meteorite-catalyzed syntheses of nucleosides and of other prebiotic compounds from formamide under proton irradiation. Proc. Natl. Acad. Sci. 112, E2746-E2755 (2015)

107. Saladino, R., Carota, E., Botta, G., Kapralov, M., Timoshenko, G.N., Rozanov, A., Krasavin, E., Di Mauro, E.: First Evidence on the Role of Heavy Ion Irradiation of Meteorites and Formamide in the Origin of Biomolecules. Orig. Life Evol. Biosph. 1-7 (2016). https://doi.org/10.1007/s11084016-9495-0

108. Adam, Z.R., Hongo, Y., Cleaves II, H.J., Yi, R., Fahrenbach, A.C., Yoda, I., Aono, M.: Estimating the capacity for production of formamide by radioactive minerals on the prebiotic Earth. Sci. Rep. 8, (2018). https://doi.org/10.1038/s41598-017-18483-8

109. Adam, Z.R.R., Hongo, Y., Cleaves, H.J., Yi, R., Fahrenbach, A.C.C., Yoda, I., Aono, M., Cleaves II, H.J., Yi, R., Fahrenbach, A.C.C., Yoda, I., Aono, M.: Estimating the capacity for production of formamide by radioactive minerals on the prebiotic Earth. Sci. Rep. 8, 265 (2018). https://doi.org/10.1038/s41598-017-18483-8 
110. Adam, Z.: Actinides and Life's Origins. Astrobiology. 7, 852-872 (2007). https://doi.org/10.1089/ast.2006.0066

111. Ebisuzaki, T., Maruyama, S.: Nuclear geyser model of the origin of life: Driving force to promote the synthesis of building blocks of life. Geosci. Front. 8, 275-298 (2017). https://doi.org/10.1016/j.gsf.2016.09.005

112. Tu, Lin, Johnstone, Colin P., Güdel, Manuel, Lammer, Helmut: The extreme ultraviolet and X-ray Sun in Time: High-energy evolutionary tracks of a solar-like star. A\&A. 577, L3 (2015). https://doi.org/10.1051/0004-6361/201526146

113. Lammer, H., Zerkle, A.L., Gebauer, S., Tosi, N., Noack, L., Scherf, M., Pilat-Lohinger, E., Güdel, M., Grenfell, J.L., Godolt, M., Nikolaou, A.: Origin and evolution of the atmospheres of early Venus, Earth and Mars, (2018)

114. Ferus, M., Pietrucci, F., Saitta, A.M., Knížek, A., Kubelík, P., Ivanek, O., Shestivska, V., Civiš, S.: Formation of nucleobases in a Miller-Urey reducing atmosphere. Proc. Natl. Acad. Sci. U. S. A. 114, (2017). https://doi.org/10.1073/pnas.1700010114

115. Xu, J., Tsanakopoulou, M., Magnani, C.J., Szabla, R., Sponer, J.E., Sponer, J., Gora, R.W., Sutherland, J.D.: A prebiotically plausible synthesis of pyrimidine beta-ribonucleosides and their phosphate derivatives involving photoanomerization. Nat. Chem. 9, 303-309 (2017). https://doi.org/10.1038/NCHEM.2664

116. Tsai, S.-M., Lyons, J.R., Grosheintz, L., Rimmer, P.B., Kitzmann, D., Heng, K.: VULCAN: An Opensource, Validated Chemical Kinetics Python Code for Exoplanetary Atmospheres. Astrophys. J. Suppl. Ser. 228, (2017). https://doi.org/10.3847/1538-4365/228/2/20

117. Rotelli, L., Trigo-Rodriguez, J.M., Moyano-Cambero, C.E., Carota, E., Botta, L., Di Mauro, E., Saladino, R.: The key role of meteorites in the formation of relevant prebiotic molecules in a formamide/water environment. Sci. Rep. 6, (2016). https://doi.org/10.1038/srep38888

118. Ardaseva, A., Rimmer, P.B., Waldmann, I., Rocchetto, M., Yurchenko, S.N., Helling, C., Tennyson, J.: Lightning chemistry on Earth-like exoplanets. Mon. Not. R. Astron. Soc. 470, 187196 (2017). https://doi.org/10.1093/mnras/stx1012

119. Cassone, G., Sponer, J., Sponer, J.E., Pietrucci, F., Saitta, A.M., Saija, F.: Synthesis of (d)erythrose from glycolaldehyde aqueous solutions under electric field. Chem. Commun. 54, 3211-3214 (2018). https://doi.org/10.1039/c8cc00045j

120. Bourgalais, J., Carrasco, N., Changeat, Q., Venot, O., Jovanović, L., Pernot, P., Tennyson, J., Chubb, K.L., Yurchenko, S.N., Tinetti, G.: lons in the Thermosphere of Exoplanets: Observable Constraints Revealed by Innovative Laboratory Experiments. Astrophys. J. 895, 77 (2020). https://doi.org/10.3847/1538-4357/ab8e2d

121. Le Caër, S.: Water Radiolysis: Influence of Oxide Surfaces on H2 Production under lonizing Radiation. Water. 3, 235-253 (2011). https://doi.org/10.3390/w3010235

122. Buxton, G. V., Greenstock, C.L., Helman, W.P., Ross, A.B.: Critical Review of rate constants for reactions of hydrated electrons, hydrogen atoms and hydroxyl radicals $(\cdot \mathrm{OH} / \cdot \mathrm{O}-$ in Aqueous Solution. J. Phys. Chem. Ref. Data. 17, 513-886 (1988). https://doi.org/10.1063/1.555805

123. Azrague, K., Bonnefille, E., Pradines, V., Pimienta, V., Oliveros, E., Maurette, M.T., BenoitMarquié, F.: Hydrogen peroxide evolution during V-UV photolysis of water. Photochem. Photobiol. Sci. 4, 406-408 (2005). https://doi.org/10.1039/b500162e 
124. Kumar, A., Kołaski, M., Lee, H.M., Kim, K.S.: Photoexcitation and photoionization dynamics of water photolysis. J. Phys. Chem. A. 112, 5502-5508 (2008). https://doi.org/10.1021/jp711485b

125. Tomanová, K., Precek, M., Múčka, V., Vyšín, L., Juha, L., Čuba, V.: At the crossroad of photochemistry and radiation chemistry: Formation of hydroxyl radicals in diluted aqueous solutions exposed to ultraviolet radiation. Phys. Chem. Chem. Phys. 19, 29402-29408 (2017). https://doi.org/10.1039/c7cp05125e

126. Gonzalez, M.G., Oliveros, E., Wörner, M., Braun, A.M.: Vacuum-ultraviolet photolysis of aqueous reaction systems, (2004)

127. Foustoukos, D.I., Houghton, J.L., Seyfried, W.E., Sievert, S.M., Cody, G.D.: Kinetics of H2-O2$\mathrm{H} 2 \mathrm{O}$ redox equilibria and formation of metastable $\mathrm{H} 2 \mathrm{O} 2$ under low temperature hydrothermal conditions. Geochim. Cosmochim. Acta. 75, 1594-1607 (2011). https://doi.org/https://doi.org/10.1016/j.gca.2010.12.020

128. Borda, M.J., Elsetinow, A.R., Schoonen, M.A., Strongin, D.R.: Pyrite-Induced Hydrogen Peroxide Formation as a Driving Force in the Evolution of Photosynthetic Organisms on an Early Earth. Astrobiology. 1, 283-288 (2001). https://doi.org/10.1089/15311070152757474

129. Ball, R., Brindley, J.: The Power Without the Glory: Multiple Roles of Hydrogen Peroxide in Mediating the Origin of Life. Astrobiology. 19, 675-684 (2019).

https://doi.org/10.1089/ast.2018.1886

130. Ball, R., Brindley, J.: Hydrogen peroxide thermochemical oscillator as driver for primordial RNA replication. J. R. Soc. Interface. 11, 20131052 (2014). https://doi.org/10.1098/rsif.2013.1052

131. Johnson, A.P., Cleaves, H.J., Dworkin, J.P., Glavin, D.P., Lazcano, A., Bada, J.L.: The Miller volcanic spark discharge experiment. Science (80-. ). 322, 404 (2008). https://doi.org/10.1126/science.1161527

132. Oberbeck, V.R., Marshall, J., Shen, T.: Prebiotic chemistry in clouds. J. Mol. Evol. 32, 296-303 (1991). https://doi.org/10.1007/BF02102187

133. Schaefer, L., Jr., B.F.: Outgassing of ordinary chondritic material and some of its implications for the chemistry of asteroids, planets, and satellites. Icarus. 186, 462-483 (2007). https://doi.org/http://dx.doi.org/10.1016/j.icarus.2006.09.002

134. Miller, S.L., Schlesinger, G.: The atmosphere of the primitive earth and the prebiotic synthesis of organic compounds. Adv. Sp. Res. 3, 47-53 (1983).

https://doi.org/http://dx.doi.org/10.1016/0273-1177(83)90040-6

135. Yuasa, S., Flory, D., Basile, B., Oró, J.: Abiotic Synthesis of Purines and other heterocyclic compounds by the action of electrical Discharges. J. Mol. Evol. 21, 76-80 (1984). https://doi.org/10.1007/BF02100630

136. Hill, R.D.: An efficient lightning energy-source on the early Earth. Orig. life Evol. Biosph. 22, 277-285 (1992). https://doi.org/10.1007/BF01810857

137. Chyba, C., Sagan, C.: Electrical Energy Sources for Organic Synthesis on the Early Earth. Orig. Life Evol. Biosph. 21, 3-17 (1991). https://doi.org/10.1007/BF01809509

138. Abelson, P.H.: Amino acids formed in primitive atmospheres. Science (80-. ). 124, 935 (1956). https://doi.org/10.1073/pnas.192568299

139. Bahadur, K., Ranganayaki, S., Santamaria, L.: Photosynthesis of amino-acids from paraformaldehyde involving the fixation of nitrogen in the presence of colloidal molybdenum 
Confidental Revision of the Paper - Ariel consortium WG Astrobiology and Prebiotic Chemistry Experimental Astronomy: Special issue for Ariel Phase B

https://link.springer.com/journal/10686, the deadline for submission September 14, 2020

oxide as catalyst. Nature. 182, 1668 (1958)

140. Oparin, A.I., Braunshtein, A.E., Pasynskii, A.G., Pavlovskaya, T.E., Clark, F.: Proceedings of International Symposium on the Origin of Life on the Earth. Pergamon, New York : (1959)

141. Ferus, M., Pietrucci, F., Saitta, A.M., Knížek, A., Kubelik, P., Ivanek, O., Shestivská, V., Civiš, S.: Formation of Nucleobases in a Miller-Urey Reducing Atmosphere. Proc. Natl. Acad. Sci. Wi, (2017)

142. Civis, S., Ferus, M., Chernov, V.E., Zanozina, E.M., Juha, L.: Zn I spectra in the $1300-6500 \mathrm{~cm}(-1)$ range. J. Quant. Spectrosc. Radiat. Transf. 134, 64-73 (2014). https://doi.org/10.1016/j.jqsrt.2013.10.017

143. Hörst, S.M., Yelle, R.V., Buch, A., Carrasco, N., Cernogora, G., Dutuit, O., Quirico, E., SciammaO’Brien, E., Smith, M.A., Somogyi, Á., Szopa, C., Thissen, R., Vuitton, V.: Formation of Amino Acids and Nucleotide Bases in a Titan Atmosphere Simulation Experiment. Astrobiology. 12, 809-817 (2012). https://doi.org/10.1089/ast.2011.0623

144. Jaffe, D.A.: 12 The Nitrogen Cycle. Int. Geophys. 50, 263-284 (1992).

https://doi.org/10.1016/S0074-6142(08)62695-9

145. Jacob, D.J.: Introduction to atmospheric chemistry. Princeton University Press (1999)

146. Galloway, J.N.: The Global Nitrogen Cycle. In: Treatise on Geochemistry. pp. 557-583. Elsevier (2003)

147. Fowler, D., Pyle, J.A., Raven, J.A., Sutton, M.A.: The global nitrogen cycle in the twenty-first century: introduction. Philos. Trans. R. Soc. B Biol. Sci. 368, 20130165-20130165 (2013). https://doi.org/10.1098/rstb.2013.0165

148. Cooray, V.: 19. Interaction of Lightning Flashes with the Earth's Atmosphere. In: An Introduction to Lightning. pp. 1-386. Springer, Dordrecht (2015)

149. Navarro-González, R., Villagrán-Muniz, M., Sobral, H., Molina, L.T., Molina, M.J.: The physical mechanism of nitric oxide formation in simulated lightning. Geophys. Res. Lett. 28, 3867-3870 (2001). https://doi.org/10.1029/2001GL013170

150. Martin, R.S., Mather, T.A., Pyle, D.M.: Volcanic emissions and the early Earth atmosphere. Geochim. Cosmochim. Acta. 71, 3673-3685 (2007)

151. Parkos, D., Pikus, A., Alexeenko, A., Melosh, H.J.: HCN production from impact ejecta on the early earth. AIP Conf. Proc. 1786, (2016). https://doi.org/10.1002/2016JA023638

152. Arumainayagam, C.R., Garrod, R.T., Boyer, M.C., Hay, A.K., Bao, S.T., Campbell, J.S., Wang, J., Nowak, C.M., Arumainayagam, M.R., Hodge, P.J.: Extraterrestrial prebiotic molecules: photochemistry vs. radiation chemistry of interstellar ices. Chem. Soc. Rev. 48, 2293-2314 (2019). https://doi.org/10.1039/C7CS00443E

153. Kundu, S., Prabhudesai, V.S., Krishnakumar, E.: Electron induced reactions in condensed mixtures of methane and ammonia. Phys. Chem. Chem. Phys. 19, 25723-25733 (2017). https://doi.org/10.1039/C7CP04490A

154. Kubelík, P., Civiš, S., Pastorek, A., Zanozina, E. M., Chernov, V. E., Juha, L., Voronina, A. A.: FTIR laboratory measurement of $\mathrm{Ne} \sim\{1\}$ Rydberg states in 1.43--14.3 spectral range. A\&A. 582, A12 (2015). https://doi.org/10.1051/0004-6361/201526442

155. Civiš, S., Kubelík, P., Ferus, M., Zanozina, E.M., Pastorek, A., Naskidashvili, A. V, Chernov, V.E.: 
$\{$ FTIR\} Laboratory Measurement of O $\{1\}$ Spectra in the 0.77\{\textendash $\} 12.5 \sim \$ \mu \$ \mathrm{~m}$ Spectral Range: Rydberg States and Oscillator Strengths. Astrophys. J. Suppl. Ser. 239, 11 (2018). https://doi.org/10.3847/1538-4365/aae5f8

156. Civiš, S., Matulková, I., Cihelka, J., Kubelík, P., Kawaguchi, K., Chernov, V.E.: Low-excited f-, gand $\mathrm{h}$-states in $\mathrm{Au}, \mathrm{Ag}$ and $\mathrm{Cu}$ observed by Fourier-transform infrared spectroscopy in the $1000\{\backslash$ textendash $\} 7500 \mathrm{~cm} \$ \wedge\{-1\} \$$ region. J. Phys. B At. Mol. Opt. Phys. 44, 105002 (2011). https://doi.org/10.1088/0953-4075/44/10/105002

157. Civiš, S., Ferus, M., Kubelík, P., Chernov, V. E., Zanozina, E. M.: Li I spectra in the 4.65-8.33 micron range: high-L states and oscillator strengths. A\&A. 545, A61 (2012). https://doi.org/10.1051/0004-6361/201219852

158. Kobayashi, K., Geppert, W.D., Carrasco, N., Holm, N.G., Mousis, O., Palumbo, M.E., Waite, J.H., Watanabe, N., Ziurys, L.M.: Laboratory Studies of Methane and Its Relationship to Prebiotic Chemistry. Astrobiology. 17, 786-812 (2017). https://doi.org/10.1089/ast.2016.1492

159. Felton, R., Neveu, M., Domagal-Goldman, S.D., Desch, S., Arney, G., Felton, R., Neveu, M., Domagal-Goldman, S.D., Desch, S., Arney, G.: Developing Tighter Constraints on Exoplanet Biosignatures by Modeling Atmospheric Haze. AAS. 231, 439.23 (2018)

160. Zerkle, A., Izon, G.J., Claire, M., Zerkle, A., Izon, G.J., Claire, M.: State of the Haze: The Causes and Consequences of a Hydrocarbon-rich Neoarchean Atmosphere. AGUFM. 2016, PP21D-03 (2016)

161. Khare, B.N., McKay, C., Wilhite, P., Beeler, D., Carter, M., Schurmeier, L., Jagota, S., Kawai, J., Nna-Mvondo, D., Cruikshank, D., Embaye, T.: Organic matter in the Titan lakes, and comparison with primitive Earth. In: AIP Conference Proceedings. pp. 77-88 (2013)

162. Kasting, J.F., Kasting, F., J.: Methane as a Climate Driver During the Precambrian Eon (Invited). AGUFM. 2013, U33A-01 (2013)

163. Maillard, J., Hupin, S., Carrasco, N., Schmitz-Afonso, I., Gautier, T., Afonso, C.: Structural elucidation of soluble organic matter: Application to Titan's haze. Icarus. 340, 113627 (2020). https://doi.org/10.1016/j.icarus.2020.113627

164. Neish, C.D., Somogyi, Á., Smith, M.A.: Titan's primordial soup: Formation of amino acids via low-temperature hydrolysis of tholins. Astrobiology. 10, 337-347 (2010). https://doi.org/10.1089/ast.2009.0402

165. Hörst, S.M., Tolbert, M.A.: In situ measurements of the size and density of titan aerosol analogs. Astrophys. J. Lett. 770, L10 (2013). https://doi.org/10.1088/2041-8205/770/1/L10

166. Arney, G., Meadows, V., Domagal-Goldman, S., Deming, D., Robinson, T.D., Tovar, G., Wolf, E., Schwieterman, E., Arney, G., Meadows, V., Domagal-Goldman, S., Deming, D., Robinson, T.D., Tovar, G., Wolf, E., Schwieterman, E.: Pale Orange Dots: The Impact of Organic Haze on the Habitability and Detectability of Earthlike Exoplanets. DPS. 122.13 (2016)

167. Arney, G., Domagal-Goldman, S.D., Meadows, V.S.: Organic Haze as a Biosignature in Anoxic Earth-like Atmospheres. Astrobiology. 18, 311-329 (2018). https://doi.org/10.1089/ast.2017.1666

168. Arney, G., Domagal-Goldman, S.D., Meadows, V.S., Wolf, E.T., Schwieterman, E., Charnay, B., Claire, M., Hébrard, E., Trainer, M.G.: The Pale Orange Dot: The Spectrum and Habitability of Hazy Archean Earth. Astrobiology. 16, 873-899 (2016). https://doi.org/10.1089/ast.2015.1422 
169. Ugelow, M.S., Haan, D.O. De, Hörst, S.M., Tolbert, M.A.: The Effect of Oxygen on Organic Haze Properties. Astrophys. J. 859, L2 (2018). https://doi.org/10.3847/2041-8213/aac2c7

170. Charnay, B., Sauterey, B., Lefèvre, F., Ferriere, R., Mazevet, S., Affholder, A., Vatant, J., Burgalat, J., Rannou, P., Jaziri, A.: EPSC-DPS Joint Meeting 2019. In: EPSC-DPS Joint Meeting 2019. , geneva (2019)

171. Berry, J.L., Ugelow, M.S., Tolbert, M.A., Browne, E.C.: The Influence of Gas-phase Chemistry on Organic Haze Formation. Astrophys. J. 885, L6 (2019). https://doi.org/10.3847/2041$8213 / a b 4 b 5 b$

172. Hörst, S.M., Tolbert, M.A.: The Effect of Carbon Monoxide on Planetary Haze Formation. ApJ. 781, 53 (2013). https://doi.org/10.1088/0004-637X/781/1/53

173. Zellem, R.T., Swain, M.R., Cowan, N.B., Bryden, G., Komacek, T.D., Colavita, M., Ardila, D., Roudier, G.M., Fortney, J.J., Bean, J., Line, M.R., Griffith, C.A., Shkolnik, E.L., Kreidberg, L., Moses, J.I., Showman, A.P., Stevenson, K.B., Wong, A., Chapman, J.W., Ciardi, D.R., Howard, A.W., Kataria, T., Kempton, E.M.R., Latham, D., Mahadevan, S., Meléndez, J., Parmentier, V.: Constraining exoplanet metallicities and aerosols with the contribution to Ariel spectroscopy of exoplanets (CASE). Publ. Astron. Soc. Pacific. 131, (2019). https://doi.org/10.1088/1538$3873 / a b 2 d 54$

174. Bean, J., Parmentier, V., Mansfield, M., Cowan, N., Kempton, E., Desert, J.-M., Swain, M., Dang, L., Bell, T., Keating, D., Zellem, R., Fortney, J., Line, M., Kreidberg, L., Stevenson, K., Bean, J., Parmentier, V., Mansfield, M., Cowan, N., Kempton, E., Desert, J.-M., Swain, M., Dang, L., Bell, T., Keating, D., Zellem, R., Fortney, J., Line, M., Kreidberg, L., Stevenson, K.: Revealing Fact or Fiction in Spitzer Exoplanet Phase Curve Trends. sptz. 14059 (2018)

175. Miller, S.L.: A Production of Amino Acids Under Possible Primitive Earth Conditions. Science (80-. ). 117, 528-9 (1953). https://doi.org/10.1126/SCIENCE.117.3046.528

176. Saitta, A.M., Saija, F.: Miller experiments in atomistic computer simulations. Proc. Natl. Acad. Sci. U. S. A. 111, 13768-73 (2014). https://doi.org/10.1073/pnas.1402894111

177. Cleaves, H.J., Chalmers, J.H., Lazcano, A., Miller, S.L., Bada, J.L.: A reassessment of prebiotic organic synthesis in neutral planetary atmospheres. Orig. Life Evol. Biosph. 38, 105-115 (2008). https://doi.org/10.1007/s11084-007-9120-3

178. Saladino, R., Botta, G., Delfino, M., Di Mauro, E.: Meteorites as Catalysts for Prebiotic Chemistry. Chem. Eur. J. 19, 16916-16922 (2013). https://doi.org/10.1002/chem.201303690

179. McCollom, T.M.: Miller-Urey and Beyond: What Have We Learned About Prebiotic Organic Synthesis Reactions in the Past 60 Years? In: Annual review of Earth and planetary Sciences. pp. 207-229 (2013)

180. Joyce, G.F.: RNA evolution and the origins of life. Nature. 338, 217-224 (1989). https://doi.org/10.1038/338217a0

181. Gilbert, W.: Origin of life: The RNA world. Nature. 319, 618 (1986)

182. Rich, A.: On the problesm of evolution and biochemical information transfer. In: Kasha, M. and Pullman, B. (eds.) Horizons in Biochemistry. pp. 103-126. Academic Press, New York (1962)

183. Kruger, K., Grabowski, P.J., Zaug, A.J., Sands, J., Gottschling, D.E., Cech, T.R.: Self-splicing RNA Auto-excision and auto-cyclization of the ribosomal-RNA intervening sequence of tetrahymena. Cell. 31, 147-157 (1982). https://doi.org/10.1016/0092-8674(82)90414-7 
184. Crick, F.: On Protein Synthesis. Symp. Soc. Exp. Biol. 12. 12, 138-163 (1958)

185. Kejnovský, E.: Tajemství genů. Academia, Praha (2015)

186. Ferus, M., Kubelik, P., Kawaguchi, K., Dryahina, K., Spanel, P., Civis, S.: HNC/HCN Ratio in Acetonitrile, Formamide, and BrCN Discharge. J. Phys. Chem. A. 115, 1885-1899 (2011). https://doi.org/10.1021/jp1107872

187. Levy, M., Miller, S.L., Oro, J.: Production of guanine from NH4CN polymerizations. J. Mol. Evol. 49, 165-168 (1999). https://doi.org/10.1007/PL00006539

188. Ferris, J.P., Wos, J.D., Nooner, D.W., Oró, J: Chemical Evolution of 21 Aminoacids released on hydrolysis of HCN oligomers. J. Mol. Evol. 3, 225-231 (1974). https://doi.org/10.1007/BF01797455

189. Hoerst, S.M., Yelle, R. V, Buch, A., Carrasco, N., Cernogora, G., Dutuit, O., Quirico, E., SciammaO’Brien, E., Smith, M.A., Somogyi, A., Szopa, C., Thissen, R., Vuitton, V.: Formation of Amino Acids and Nucleotide Bases in a Titan Atmosphere Simulation Experiment. Astrobiology. 12, 809-817 (2012). https://doi.org/10.1089/ast.2011.0623

190. Dezulian, R., Canova, F., Barbanotti, S., Orsenigo, F., Redaelli, R., Vinci, T., Lucchini, G., Batani, D., Rus, B., Polan, J., Kozlová, M., Stupka, M., Praeg, A.R., Homer, P., Havlicek, T., Soukup, M., Krousky, E., Skala, J., Dudzak, R., Pfeifer, M., Nishimura, H., Nagai, K., Ito, F., Norimatsu, T., Kilpio, A., Shashkov, E., Stuchebrukhov, I., Vovchenko, V., Chernomyrdin, V., Krasuyk, I.: Hugoniot data of plastic foams obtained from laser-driven shocks. Phys. Rev. E - Stat. Nonlinear, Soft Matter Phys. 73, (2006). https://doi.org/10.1103/PhysRevE.73.047401

191. Jungwirth, K., Cejnarova, A., Juha, L., Kralikova, B., Krasa, J., Krousky, E., Krupickova, P., Laska, L., Masek, K., Mocek, T., Pfeifer, M., Präg, A., Renner, O., Rohlena, K., Rus, B., Skala, J., Straka, P., Ullschmied, J.: The Prague Asterix Laser System. Phys. Plasmas. 8, 2495-2501 (2001). https://doi.org/10.1063/1.1350569

192. Civiš, S., Juha, L., Babánková, D., Cvačka, J., O, F., Jehlička, J., Králíková, B., Krása, J., Kubát, P., Muck, A., Pfeifer, M., Skála, J., Ullschmied, J.: Amino acid formation induced by high-power laser in CO2/CO-N-2-H2O gas mixtures. Chem. Phys. Lett. 386, 169-173 (2004). https://doi.org/10.1016/j.cplett.2004.01.034

193. Ferus, M., Civis, S., Mladek, A., Sponer, J.E.J., Juha, L., Sponer, J.E.J.: On the Road from Formamide Ices to Nucleobases: IR-Spectroscopic Observation of a Direct Reaction between Cyano Radicals and Formamide in a High-Energy Impact Event. J. Am. Chem. Soc. 134, 2078820796 (2012). https://doi.org/10.1021/ja310421z

194. Civiš, S., Knížek, A., Rimmer, P.B., Ferus, M., Kubelík, P., Zukalová, M., Kavan, L., Chatzitheodoridis, E.: Formation of Methane and (Per)Chlorates on Mars. ACS Earth Sp. Chem. 3, 221-232 (2019). https://doi.org/10.1021/acsearthspacechem.8b00104

195. Civis, S., Kubelik, P., Ferus, M.: Time-Resolved Fourier Transform Emission Spectroscopy of $\mathrm{He} / \mathrm{CH} 4$ in a Positive Column Discharge. J. Phys. Chem. A. 116, 3137-3147 (2012). https://doi.org/10.1021/jp211772d

196. Stehlé, C., Kozlová, M., Larour, J., Nejdl, J., Champion, N., Barroso, P., Suzuki-Vidal, F., Acef, O., Delattre, P.A., Dostál, J., Krus, M., Chièze, J.P.: New probing techniques of radiative shocks. Opt. Commun. 285, 64-69 (2012). https://doi.org/10.1016/j.optcom.2011.09.008

197. Bredereck, H., Gompper, R., Morlock, G.: Neue pyrimidin-synthese aus beta-dicarbonyl verbindungen und formamid. Angew. Chemie - Int. Ed. 68, 151 (1956). 


\section{https://doi.org/10.1002/ange.19560680404}

198. Saladino, R., Crestini, C., Costanzo, G., Negri, R., Di Mauro, E.: A possible prebiotic synthesis of purine, adenine, cytosine, and $4(3 \mathrm{H})$-pyrimidinone from formamide: Implications for the origin of life. Bioorg. Med. Chem. 9, 1249-1253 (2001). https://doi.org/10.1016/S09680896(00)00340-0

199. Knižek, A.: Experimental study of chemical evolution of biomolecules under early Earth conditions, http://hdl.handle.net/20.500.11956/97896, (2018)

200. Ferus, M., Knížek, A., Šponer, J., Šponer, J.E., Civiš, S.: Radical synthesis of nucleic acid bases from formamide in impact plasma. Chem. List. 109, 406-414 (2015)

201. Pastorek, A., Hrnčířová, J., Jankovič, L., Nejdl, L., Civiš, S., Ivanek, O., Shestivska, V., Knížek, A., Kubelík, P., Šponer, J., Petera, L., Křivková, A., Cassone, G., Vaculovičová, M., Šponer, J.E., Ferus, M.: Prebiotic synthesis at impact craters: the role of Fe-clays and iron meteorites. Chem. Commun. 55, 10563-10566 (2019). https://doi.org/10.1039/C9CC04627E

202. Sponer, J.E., Mohammadi, E., Petera, L., Saeidfirozeh, H., Knížek, A., Kubelík, P., Krůs, M., Juha, L., Civiš, S., Coulon, R., Malina, O., Ugolotti, J., Ranc, V., Otyepka, M., Šponer, J., Ferus, M., Dudzak, R.: Formic acid, a ubiquitous but overlooked component of the early Earth atmosphere. Chem. - A Eur. J. (2020). https://doi.org/10.1002/chem.202000323

203. Piast, R.W.: Shannon's information, Bernal's biopoiesis and Bernoulli distribution as pillars for building a definition of life. J. Theor. Biol. 470, 101-107 (2019). https://doi.org/10.1016/j.jtbi.2019.03.009

204. Sasselov, D.D., Grotzinger, J.P., Sutherland, J.D.: The origin of life as a planetary phenomenon. Sci. Adv. 6, eaax3419 (2020). https://doi.org/10.1126/sciadv.aax3419

205. White, L.M., Shibuya, T., Vance, S.D., Christensen, L.E., Bhartia, R., Kidd, R., Hoffmann, A., Stucky, G.D., Kanik, I., Russell, M.J.: Simulating serpentinization as it could apply to the emergence of life using the JPL hydrothermal reactor. Astrobiology. 20, 307-326 (2020). https://doi.org/10.1089/ast.2018.1949

206. Cuéllar-Cruz, M., Schneider, D.K., Stojanoff, V., Islas, S.R., Sánchez-Puig, N., Arreguín-Espinosa, R., Delgado, J.M., Moreno, A.: Formation of Crystalline Silica-Carbonate Biomorphs of Alkaline Earth Metals ( $\mathrm{Ca}, \mathrm{Ba}, \mathrm{Sr}$ ) from Ambient to Low Temperatures: Chemical Implications during the Primitive Earth's Life. Cryst. Growth Des. 20, 1186-1195 (2020). https://doi.org/10.1021/acs.cgd.9b01473

207. Saladino, R., Di Mauro, E., García-Ruiz, J.M.: A Universal Geochemical Scenario for Formamide Condensation and Prebiotic Chemistry. Chem. - A Eur. J. 25, 3181-3189 (2019). https://doi.org/10.1002/chem.201803889

208. Saladino, R., Botta, G., Bizzarri, B.M., Di Mauro, E., Garcia Ruiz, J.M.: A Global Scale Scenario for Prebiotic Chemistry: Silica-Based Self-Assembled Mineral Structures and Formamide. Biochemistry. (2016). https://doi.org/10.1021/acs.biochem.6b00255

209. Sakhno, Y., Battistella, A., Mezzetti, A., Jaber, M., Georgelin, T., Michot, L., Lambert, J.-F.: One Step up the Ladder of Prebiotic Complexity: Formation of Nonrandom Linear Polypeptides from Binary Systems of Amino Acids on Silica. Chem. - A Eur. J. 25, 1275-1285 (2019). https://doi.org/10.1002/chem.201803845

210. Mattia Bizzarri, B., Botta, L., Pérez-Valverde, M.I., Saladino, R., Di Mauro, E., García-Ruiz, J.M.: Silica Metal Oxide Vesicles Catalyze Comprehensive Prebiotic Chemistry. Chem. - A Eur. J. 24, 
8126-8132 (2018). https://doi.org/10.1002/chem.201706162

211. Saladino, R., Šponer, J.E., Šponer, J., Costanzo, G., Pino, S., Mauro, E. Di: Chemomimesis and molecular darwinism in action: From abiotic generation of nucleobases to nucleosides and RNA, http://www.ncbi.nlm.nih.gov/pubmed/29925796, (2018)

212. Saladino, R., Botta, L., Di Mauro, E.: The prevailing catalytic role of meteorites in formamide prebiotic processes, (2018)

213. Rotelli, L., Trigo-Rodríguez, J.M., Moyano-Cambero, C.E., Carota, E., Botta, L., Di Mauro, E., Saladino, R.: The key role of meteorites in the formation of relevant prebiotic molecules in a formamide/water environment. Sci. Rep. 6, 38888-38888 (2016). https://doi.org/10.1038/srep38888

214. Saladino, R., Botta, G., Pino, S., Costanzo, G., Di Mauro, E.: Genetics first or metabolism first? The formamide clue. Chem. Soc. Rev. 41, 5526-5565 (2012).

https://doi.org/10.1039/c2cs35066a

215. Bizzarri, B.M., Šponer, J.E., Šponer, J., Cassone, G., Kapralov, M., Timoshenko, G.N., Krasavin, E., Fanelli, G., Timperio, A.M., Di Mauro, E., Saladino, R.: Meteorite-Assisted Phosphorylation of Adenosine Under Proton Irradiation Conditions. ChemSystemsChem. syst.201900039 (2019). https://doi.org/10.1002/syst.201900039

216. Costanzo, G., Pino, S., Botta, G., Saladino, R., Di Mauro, E.: May Cyclic Nucleotides Be a Source for Abiotic RNA Synthesis? Orig. Life Evol. Biosph. 41, 559-562 (2011). https://doi.org/10.1007/s11084-011-9249-y

217. Sponer, J.E., Sponer, J., Novakova, O., Brabec, V., Sedo, O., Zdrahal, Z., Costanzo, G., Pino, S., Saladino, R., Di Mauro, E.: Emergence of the First Catalytic Oligonucleotides in a FormamideBased Origin Scenario. Chem. Eur. J. 22, 3572-3586 (2016). https://doi.org/10.1002/chem.201503906

218. Chatzitheodoridis, E., Haigh, S., Lyon, I.: A Conspicuous Clay Ovoid in Nakhla: Evidence for Subsurface Hydrothermal Alteration on Mars with Implications for Astrobiology. Astrobiology. 14, 651-693 (2014). https://doi.org/10.1089/ast.2013.1069

219. Menez, B., Pisapia, C., Andreani, M., Jamme, F., Vanbellingen, Q.P., Brunelle, A., Richard, L., Dumas, P., Refregiers, M.: Abiotic synthesis of amino acids in the recesses of the oceanic lithosphere. Nature. 564, 59-63 (2018). https://doi.org/10.1038/s41586-018-0684-z

220. Saladino, R., Neri, V., Crestini, C.: Role of clays in the prebiotic synthesis of sugar derivatives from formamide. In: Philosophical Magazine. pp. 2329-2337. Taylor \& Francis Group (2010)

221. Cairns-Smith, A.G. (Alexander G.: Seven clues to the origin of life. Orion (2000)

222. Wei, H., Wang, E.: Nanomaterials with enzyme-like characteristics (nanozymes): nextgeneration artificial enzymes. Chem. Soc. Rev. 42, 6060-6093 (2013). https://doi.org/10.1039/c3cs35486e

223. Huang, X.-L.: Hydrolysis of Phosphate Esters Catalyzed by Inorganic Iron Oxide Nanoparticles Acting as Biocatalysts. Astrobiology. 18, 294-310 (2018). https://doi.org/10.1089/ast.2016.1628

224. Walther, R., Winther, A.K., Fruergaard, A.S., van den Akker, W., Sørensen, L., Nielsen, S.M., Jarlstad Olesen, M.T., Dai, Y., Jeppesen, H.S., Lamagni, P., Savateev, A., Pedersen, S.L., Frich, C.K., Vigier-Carrière, C., Lock, N., Singh, M., Bansal, V., Meyer, R.L., Zelikin, A.N.: Identification 
and Directed Development of Non-Organic Catalysts with Apparent Pan-Enzymatic Mimicry into Nanozymes for Efficient Prodrug Conversion. Angew. Chemie Int. Ed. 58, 278-282 (2019). https://doi.org/10.1002/anie.201812668

225. Zhang, J., Liu, J.: Light-activated nanozymes: catalytic mechanisms and applications. Nanoscale. 12, 2914-2923 (2020). https://doi.org/10.1039/C9NR10822J

226. Shao, M., Zhang, R., Wang, C., Hu, B., Pang, D., Xie, Z.: Living cell synthesis of CdSe quantum dots: Manipulation based on the transformation mechanism of intracellular Se-precursors. Na1. Shao, M. al. Living cell Synth. CdSe quantum dots Manip. based Transform. Mech. Intracell. Seprecursors. Nano Res. 11, 2498-2511 (2018).no Res. 11, 2498-2511 (2018). https://doi.org/10.1007/s12274-017-1873-z

227. Mota-Morales, J.D., Sánchez-Leija, R.J., Carranza, A., Pojman, J.A., Monte], F. [del, LunaBárcenas, G.: Free-radical polymerizations of and in deep eutectic solvents: Green synthesis of functional materials. Prog. Polym. Sci. 78, 139-153 (2018). https://doi.org/https://doi.org/10.1016/j.progpolymsci.2017.09.005

228. Caetano-Anollés, G., Kim, H.S., Mittenthal, J.E.: The origin of modern metabolic networks inferred from phylogenomic analysis of protein architecture. Proc. Natl. Acad. Sci. U. S. A. 104, 9358-9363 (2007). https://doi.org/10.1073/pnas.0701214104

229. Puzzarini, C., Bloino, J., Tasinato, N., Barone, V.: Accuracy and Interpretability: The Devil and the Holy Grail. New Routes across Old Boundaries in Computational Spectroscopy, (2019)

230. Skouteris, D., Balucani, N., Ceccarelli, C., Faginas Lago, N., Codella, C., Falcinelli, S., Rosi, M.: Interstellar dimethyl ether gas-phase formation: a quantum chemistry and kinetics study. Mon. Not. R. Astron. Soc. 482, 3567-3575 (2018). https://doi.org/10.1093/mnras/sty2903

231. Lefloch, B., Bachiller, R., Ceccarelli, C., Cernicharo, J., Codella, C., Fuente, A., Kahane, C., LópezSepulcre, A., Tafalla, M., Vastel, C., Caux, E., González-García, M., Bianchi, E., Gómez-Ruiz, A., Holdship, J., Mendoza, E., Ospina-Zamudio, J., Podio, L., Quénard, D., Roueff, E., Sakai, N., Viti, S., Yamamoto, S., Yoshida, K., Favre, C., Monfredini, T., Quitián-Lara, H.M., Marcelino, N., Boechat-Roberty, H.M., Cabrit, S.: Astrochemical evolution along star formation: overview of the IRAM Large Program ASAI. Mon. Not. R. Astron. Soc. 477, 4792-4809 (2018). https://doi.org/10.1093/mnras/sty937

232. Kahane, C., Ceccarelli, C., Faure, A., Caux, E.: Detection of formamide, the simplest but crucial amide, in a solar-type protostar. Astrophys. J. Lett. 763, (2013). https://doi.org/10.1088/2041$8205 / 763 / 2 /$ L38

233. Solomon, P.M.: Interstellar molecules. Phys. Today. 26, 32-40 (1973). https://doi.org/10.1063/1.3127983

234. Gottlieb, C.A., Palmer, P., Rickard, L.J., Zuckerman, B.: Studies of interstellar formamide. Astrophys. J. 182, 699-710 (1973). https://doi.org/10.1086/152178

235. Lis, D.C., Mehringer, D.M., Benford, D., Gardner, M., Phillips, T.G., Bockelee-Morvan, D., Biver, N., Colom, P., Crovisier, J., Despois, D., Rauer, H.: New molecular species in comet C/1995 01 (Hale-Bopp) observed with the Caltech Submillimeter Observatory. EARTH MOON PLANETS. 78, 13-20 (1997). https://doi.org/10.1023/A:1006281802554

236. Hudson, R.L., Moore, M.H.: Reactions of nitriles in ices relevant to Titan, comets, and the interstellar medium: Formation of cyanate ion, ketenimines, and isonitriles. Icarus. 172, 466478 (2004). https://doi.org/10.1016/j.icarus.2004.06.011 
237. Adande, G.R., Woolf, N.J., Ziurys, L.M.: Observations of interstellar formamide: Availability of a prebiotic precursor in the galactic habitable zone. Astrobiology. 13, 439-453 (2013). https://doi.org/10.1089/ast.2012.0912

238. López-Sepulcre, A., Jaber, A.A., Mendoza, E., Lefloch, B., Ceccarelli, C., Vastel, C., Bachiller, R., Cernicharo, J., Codella, C., Kahane, C., Kama, M., Tafalla, M.: Shedding light on the formation of the pre-biotic molecule formamide with ASAI. Mon. Not. R. Astron. Soc. 449, 2438-2458 (2015). https://doi.org/10.1093/mnras/stv377

239. Al-Edhari, A.J., Ceccarelli, C., Kahane, C., Viti, S., Balucani, N., Caux, E., Faure, A., Lefloch, B., Lique, F., Mendoza, E., Quenard, D., Wiesenfeld, L.: History of the solar-type protostar IRAS 16293-2422 as told by the cyanopolyynes. Astron. Astrophys. 597, (2017). https://doi.org/10.1051/0004-6361/201629506

240. Jørgensen, J.K., Favre, C., Bisschop, S.E., Bourke, T.L., Van Dishoeck, E.F., Schmalzl, M.: Detection of the simplest sugar, glycolaldehyde, in a solar-type protostar with ALMA. Astrophys. J. Lett. 757, (2012). https://doi.org/10.1088/2041-8205/757/1/L4

241. Lefloch, B., Vastel, C., Viti, S., Jimenez-Serra, I., Codella, C., Podio, L., Ceccarelli, C., Mendoza, E., Lepine, J.R.D., Bachiller, R.: Phosphorus-bearing molecules in solar-type star-forming regions: first PO detection. MNRAS. 462, 3937-3944 (2016). https://doi.org/10.1093/mnras/stw1918

242. Schöier, F.L., Jorgensen, J.K., van Dishoeck, E.F., Blake, G.A.: Does IRAS 16293-2422 have a hot core? Chemical inventory and abundance changes in its protostellar environment. A\&A. 390, 1001-1021 (2002). https://doi.org/10.1051/0004-6361:20020756

243. Walsh, C., Loomis, R.A., Öberg, K.I., Kama, M., Hoff, M.L.R. van 't, Millar, T.J., Aikawa, Y., Herbst, E., Weaver, S.L.W., Nomura, H.: First detection of gas-phase methanol in a protoplanetary disk. Astrophys. J. Lett. 823, L10 (2016). https://doi.org/10.3847/2041-8205/823/1/L10

244. Jheeta, S.: Final frontiers: The hunt for life elsewhere in the Universe, (2013)

245. Afanasiev, V.L., Kalenichenko, V. V., Karachentsev, I.D.: Detection of an intergalactic meteor particle with the 6-m telescope. (2007). https://doi.org/10.1134/s1990341307040013

246. Siraj, A., Loeb, A.: Discovery of a Meteor of Interstellar Origin. (2019)

247. Siraj, A., Loeb, A.: Probing Extrasolar Planetary Systems with Interstellar Meteors. (2019)

248. Team, T. 'Oumuamua I.: The Natural History of 'Oumuamua. (2019). https://doi.org/10.1038/s41550-019-0816-x

249. Gounelle, M., Spurny, P., Bland, P.A.: The orbit and atmospheric trajectory of the Orgueil meteorite from historical records. Meteorit. Planet. Sci. 41, 135-150 (2006). https://doi.org/10.1111/j.1945-5100.2006.tb00198.x

250. List of meteorites with a complete "lineage"

251. Ferus, M., Petera, L., Koukal, J., Lenža, L., Drtinová, B., Haloda, J., Matýsek, D., Pastorek, A., Laitl, V., Poltronieri, R.C., Domingues, M.W., Gonçalves, G., del Olmo Sato, R., Knížek, A., Kubelík, P., Křivková, A., Srba, J., di Pietro, C.A., Bouša, M., Vaculovič, T., Civiš, S.: Elemental composition, mineralogy and orbital parameters of the Porangaba meteorite. Icarus. 341, 113670 (2020). https://doi.org/10.1016/J.ICARUS.2020.113670

252. Gourier, D., Binet, L., Calligaro, T., Cappelli, S., Vezin, H., Bréhéret, J., Hickman-Lewis, K., Gautret, P., Foucher, F., Campbell, K., Westall, F.: Extraterrestrial organic matter preserved in 3.33 Ga sediments from Barberton, South Africa. Geochim. Cosmochim. Acta. 258, 207-225 
(2019). https://doi.org/10.1016/J.GCA.2019.05.009

253. Zahnle, K.J., Sleep, N.H., Thomas, P.J., Hicks, R.D., Chyba, C.F., McKay, C.P.: Comets and the Origin and Evolution of Life. SPRINGER, Berlin (2006)

254. Goesmann, F., Rosenbauer, H., Bredehoeft, J.H., Cabane, M., Ehrenfreund, P., Gautier, T., Giri, C., Krueger, H., Le Roy, L., MacDermott, A.J., McKenna-Lawlor, S., Meierhenrich, U.J., Munoz Caro, G.M., Raulin, F., Roll, R., Steele, A., Steininger, H., Sternberg, R., Szopa, C., Thiemann, W., Ulamec, S.: Organic compounds on comet 67P/Churyumov-Gerasimenko revealed by COSAC mass spectrometry. Science (80-. ). 349, (2015). https://doi.org/10.1126/science.aab0689

255. Benneke, B., Wong, I., Piaulet, C., Knutson, H.A., Lothringer, J., Morley, C. V., Crossfield, I.J.M., Gao, P., Greene, T.P., Dressing, C., Dragomir, D., Howard, A.W., McCullough, P.R., Kempton, E.M.-R., Fortney, J.J., Fraine, J.: Water Vapor and Clouds on the Habitable-zone Sub-Neptune Exoplanet K2-18b. Astrophys. J. 887, L14 (2019). https://doi.org/10.3847/2041-8213/ab59dc

256. Grillmair, C.J., Charbonneau, D., Burrows, A., Armus, L., Stauffer, J., Meadows, V., Van Cleve, J., Levine, D.: A Spitzer Spectrum of the Exoplanet HD 189733b . Astrophys. J. 658, L115-L118 (2007). https://doi.org/10.1086/513741

257. CNES, ESA: COROT, https://corot.cnes.fr/en/COROT/index.htm

258. Johnson, M.: Kepler and K2, https://www.nasa.gov/mission_pages/kepler/main/index.html

259. ESA: Gaia, https://sci.esa.int/web/gaia/

260. Garner, R.: TESS Exoplanet Mission, https://www.nasa.gov/tess-transiting-exoplanet-surveysatellite

261. ESA: CHEOPS, http://www.esa.int/Science_Exploration/Space_Science/Cheops

262. NASA: James Webb Space Telescope, https://www.jwst.nasa.gov/

263. ESA: PLATO, https://sci.esa.int/web/plato/

264. NASA: HabEx, https://www.jpl.nasa.gov/habex/

265. NASA: LUVOIR, 2020-08-18

266. Bottke, W.F., Vokrouhlický, D., Marchi, S., Swindle, T., Scott, E.R.D., Weirich, J.R., Levison, H.: Dating the Moon-forming impact event with asteroidal meteorites. Science (80-. ). 348, 321323 (2015). https://doi.org/10.1126/science.aaa0602

267. Cavosie, A.J., Valley, J.W., Wilde, S.A.: Magmatic delta O-18 in 4400-3900 Ma detrital zircons: A record of the alteration and recycling of crust in the Early Archean. Earth Planet. Sci. Lett. 235, 663-681 (2005). https://doi.org/10.1016/j.epsl.2005.04.028

268. Tinetti, G., Drossart, P., Eccleston, P., Hartogh, P., Leconte, J., Giusi, M., Ollivier, M., Turrini, D., Vandenbussche, B., Wolkenberg, P.: Ariel Atmospheric Remote-sensing Infrared Exoplanet Large-survey. (2017)

269. Mojzsis, S.J., Arrhenius, G., McKeegan, K.D., Harrison, T.M., Nutman, A.P., Friend, C.R.L.: Evidence for life on Earth before 3,800 million years ago. Nature. 384, 55-59 (1996). https://doi.org/10.1038/384055a0

270. Tashiro, T., Ishida, A., Hori, M., Igisu, M., Koike, M., Mejean, P., Takahata, N., Sano, Y., Komiya, T.: Early trace of life from 3.95 Ga sedimentary rocks in Labrador, Canada. Nature. 549, 516+ (2017). https://doi.org/10.1038/nature24019 
271. Bell, E.A., Boehnke, P., Harrison, T.M., Mao, W.L.: Potentially biogenic carbon preserved in a 4.1 billion-year-old zircon. Proc. Natl. Acad. Sci. U. S. A. 112, 14518-21 (2015). https://doi.org/10.1073/pnas.1517557112

272. Dodd, M.S., Papineau, D., Grenne, T., Slack, J.F., Rittner, M., Pirajno, F., O'Neil, J., Little, C.T.S.: Evidence for early life in Earth's oldest hydrothermal vent precipitates. Nature. 543, 60-64 (2017). https://doi.org/10.1038/nature21377

273. Jones, H.: Searching for Alien Life Having Unearthly Biochemistry. Engineering. (2003). https://doi.org/10.1088/1742-6596/234/2/022022

274. Lammer, H., Leitzinger, M., Scherf, M., Odert, P., Burger, C., Kubyshkina, D., Johnstone, C., Maindl, T., Schäfer, C.M., Güdel, M., Tosi, N., Nikolaou, A., Marcq, E., Erkaev, N. V., Noack, L., Kislyakova, K.G., Fossati, L., Pilat-Lohinger, E., Ragossnig, F., Dorfi, E.A.: Constraining the early evolution of Venus and Earth through atmospheric Ar, Ne isotope and bulk K/U ratios. Icarus. 339, 113551 (2020). https://doi.org/10.1016/j.icarus.2019.113551

275. Kaltenegger, L., Selsis, F., Fridlund, M., Lammer, H., Beichman, C., Danchi, W., Eiroa, C., Henning, T., Herbst, T., Leger, A., Liseau, R., Lunine, J., Paresce, F., Penny, A., Quirrenbach, A., Rottgering, H., Schneider, J., Stam, D., Tinetti, G., White, G.J.: Deciphering Spectral Fingerprints of Habitable Exoplanets. Astrobiology. 10, 89-102 (2010). https://doi.org/10.1089/ast.2009.0381

276. Kaltenegger, L., Traub, W.A., Jucks, K.W.: Spectral evolution of an Earth-like planet. Astrophys. J. 658, 598-616 (2007). https://doi.org/10.1086/510996

277. Cataldi, G., Brandeker, A., Thébault, P., Singer, K., Ahmed, E., De Vries, B.L., Neubeck, A., Olofsson, G.: Searching for Biosignatures in Exoplanetary Impact Ejecta. Astrobiology. 17, 721746 (2017). https://doi.org/10.1089/ast.2015.1437

278. Morlok, A., Mason, A.B., Anand, M., Lisse, C.M., Bullock, E.S., Grady, M.M.: Dust from collisions: A way to probe the composition of exo-planets? Icarus. 239, 1-14 (2014). https://doi.org/10.1016/j.icarus.2014.05.024

279. Bochinski, J.J., Haswell, C.A., Marsh, T.R., Dhillon, V.S., Littlefair, S.P.: Direct evidence for an evolving dust cloud from the exoplanet KIC 12557548 b. Astrophys. J. Lett. 800, L21 (2015). https://doi.org/10.1088/2041-8205/800/2/L21

280. Mohon, L.: About Lunar Impact Monitoring, https://www.nasa.gov/centers/marshall/news/lunar/overview.html

281. Brown, D., Webster, G., Zubritsky, E.A., Jones, N.N.: Mars Spacecraft Reveal Comet Flyby Effects on Martian Atmosphere, (2014)

282. Levy, D.H.: The Collision of Comet Shoemaker-Levy 9 with Jupiter. Space Sci. Rev. 85, 523-545 (1998). https://doi.org/10.1023/A:1005079807445

283. Zahnle, K., Low, M.M. Mac: The collision of Jupiter and Comet Shoemaker-Levy 9. Icarus. 108, 1-17 (1994). https://doi.org/10.1006/icar.1994.1038

284. Hammel, H.B., Beebe, R.F., Ingersoll, A.P., Orton, G.S., Mills, J.R., Simon, A.A., Chodas, P., Clarke, J.T., De Jong, E., Dowling, T.E., Harrington, J., Huber, L.F., Karkoschka, E., Santori, C.M., Toigo, A., Yeomans, D., West, R.A.: HST imaging of atmospheric phenomena created by the impact of comet Shoemaker-Levy 9. Science (80-. ). 267, 1288-1296 (1995). https://doi.org/10.1126/science.7871425 
285. Hammel, H.B., Wong, M.H., Clarke, J.T., Pater, I. de, Fletcher, L.N., Hueso, R., Noll, K., Orton, G.S., Pérez-Hoyos, S., Sánchez-Lavega, A., Simon-Miller, A.A., Yanamandra-Fisher, P.A.: Jupiter after the 2009 impact: Hubble Space Telescope imaging of the impact-generated debris and its temporal evolution. Astrophys. J. Lett. 715, L150 (2010). https://doi.org/10.1088/2041$8205 / 715 / 2 /$ L150

286. Paine, M.: Can we detect asteroid impacts with rocky extrasolar planets?

287. Flagg, L., Weinberger, A.J., Matthews, K.: Detectability of planetesimal impacts on giant exoplanets. Icarus. 264, 1-8 (2016). https://doi.org/10.1016/j.icarus.2015.08.024

288. Quintana, E. V., Barclay, T., Borucki, W.J., Rowe, J.F., Chambers, J.E.: The frequency of giant impacts on Earth-like worlds. Astrophys. J. 821, 126 (2016). https://doi.org/10.3847/0004$637 X / 821 / 2 / 126$

289. Edwards, B., Rice, M., Zingales, T., Tessenyi, M., Waldmann, I., Tinetti, G., Pascale, E., Savini, G., Sarkar, S.: Exoplanet spectroscopy and photometry with the Twinkle space telescope. Exp. Astron. 47, 29-63 (2019). https://doi.org/10.1007/s10686-018-9611-4

290. Schwieterman, E.W., Kiang, N.Y., Parenteau, M.N., Harman, C.E., DasSarma, S., Fisher, T.M., Arney, G.N., Hartnett, H.E., Reinhard, C.T., Olson, S.L., Meadows, V.S., Cockell, C.S., Walker, S.I., Grenfell, J.L., Hegde, S., Rugheimer, S., Hu, R., Lyons, T.W.: Exoplanet Biosignatures: A Review of Remotely Detectable Signs of Life. (2017). https://doi.org/10.1089/ast.2017.1729

291. PHL @ UPR Arecibo: Habitable Exoplanets Catalog, Conservative Sample of Potentially Habitable Exoplanets

292. Zechmeister, M., Dreizler, S., Ribas, I., Reiners, A., Caballero, J.A., Bauer, F.F., Béjar, V.J.S., González-Cuesta, L., Herrero, E., Lalitha, S.: The CARMENES search for exoplanets around M dwarfs-Two temperate Earth-mass planet candidates around Teegarden's Star. Astron. Astrophys. 627, A49 (2019)

293. Gillon, M. et al.: Seven temperate terrestrial planets around the nearby ultracool dwarf star TRAPPIST-1. Nature. 7642, 456-460 (2017)

294. Costa, E., Méndez, R.A., Jao, W.-C., Henry, T.J., Subasavage, J.P., lanna, P.A.: The solar neighborhood. XVI. Parallaxes from CTIOPI: final results from the $1.5 \mathrm{~m}$ telescope program. Astron. J. 132, 1234 (2006)

295. Burgasser, A.J., Mamajek, E.E.: On the Age of the TRAPPIST-1 System. Astrophys. J. 845, 110 (2017)

296. exoplanet.eu: Planet GJ 1061 d, http://exoplanet.eu/catalog/gj_1061_b/

297. Anglada-Escudé, G., Tuomi, M., Gerlach, E., Barnes, R., Heller, R., Jenkins, J.S., Wende, S., Vogt, S.S., Butler, R.P., Reiners, A.: A dynamically-packed planetary system around GJ 667C with three super-Earths in its habitable zone. Astron. Astrophys. 556, A126 (2013)

298. Torres, G., Kipping, D.M., Fressin, F., Caldwell, D.A., Twicken, J.D., Ballard, S., Batalha, N.M., Bryson, S.T., Ciardi, D.R., Henze, C.E.: Validation of 12 small Kepler transiting planets in the habitable zone. Astrophys. J. 800, 99 (2015)

299. Astudillo-Defru, N., Forveille, T., Bonfils, X., Ségransan, D., Bouchy, F., Delfosse, X., Lovis, C., Mayor, M., Murgas, F., Pepe, F.: The HARPS search for southern extra-solar planets-XLI. A dozen planets around the M dwarfs GJ 3138, GJ 3323, GJ 273, GJ 628, and GJ 3293. Astron. Astrophys. 602, A88 (2017) 
300. Feng, F., Tuomi, M., Jones, H.R.A., Barnes, J., Anglada-Escudé, G., Vogt, S.S., Butler, R.P.: Color difference makes a difference: four planet candidates around $\tau$ Ceti. Astron. J. 154, 135 (2017)

301. Wright, C.O., Egan, M.P., Kraemer, K.E., Price, S.D.: The Tycho-2 spectral type catalog. Astron. J. 125,359 (2003)

302. Mamajek, E.E., Hillenbrand, L.A.: Improved age estimation for solar-type dwarfs using activityrotation diagnostics. Astrophys. J. 687, 1264 (2008)

303. Brown, A.G.A., Vallenari, A., Prusti, T., De Bruijne, J.H.J., Babusiaux, C., Bailer-Jones, C.A.L., Biermann, M., Evans, D.W., Eyer, L., Jansen, F.: Gaia Data Release 2-Summary of the contents and survey properties. Astron. Astrophys. 616, A1 (2018)

304. Anglada-Escudé, G., Amado, P.J., Barnes, J., Berdiñas, Z.M., Butler, R.P., Coleman, G.A.L., de La Cueva, I., Dreizler, S., Endl, M., Giesers, B.: A terrestrial planet candidate in a temperate orbit around Proxima Centauri. Nature. 536, 437-440 (2016)

305. Karvella, P., Thevenin, F.: A Family Portrait of the Alpha Centauri System

306. Borucki, W.J., Agol, E., Fressin, F., Kaltenegger, L., Rowe, J., Isaacson, H., Fischer, D., Batalha, N., Lissauer, J.J., Marcy, G.W.: Kepler-62: a five-planet system with planets of 1.4 and 1.6 Earth radii in the habitable zone. Science (80-. ). 340, 587-590 (2013)

307. Borucki, W., Thompson, S.E., Agol, E., Hedges, C.: Kepler-62f: Kepler's first small planet in the habitable zone, but is it real? New Astron. Rev. 83, 28-36 (2018)

308. Morton, T.D., Bryson, S.T., Coughlin, J.L., Rowe, J.F., Ravichandran, G., Petigura, E.A., Haas, M.R., Batalha, N.M.: False positive probabilities for all Kepler objects of interest: 1284 newly validated planets and 428 likely false positives. Astrophys. J. 822, 86 (2016)

309. University of Puerto Rico: Kepler 442 b (K-Warm Terran)

310. Torres, G., Kane, S.R., Rowe, J.F., Batalha, N.M., Henze, C.E., Ciardi, D.R., Barclay, T., Borucki, W.J., Buchhave, L.A., Crepp, J.R.: Validation of small Kepler transiting planet candidates in or near the habitable zone. Astron. J. 154, 264 (2017)

311. Berger, T.A., Huber, D., Gaidos, E., van Saders, J.L.: Revised radii of Kepler stars and planets using Gaia Data Release 2. Astrophys. J. 866, 99 (2018)

312. University of Puerto Rico: Kepler 1229 b (M-Warm Terran)

313. Martinez, A.O., Crossfield, I.J.M., Schlieder, J.E., Dressing, C.D., Obermeier, C., Livingston, J., Ciceri, S., Peacock, S., Beichman, C.A., Lépine, S.: Stellar and Planetary Parameters for K2's Latetype Dwarf Systems from C1 to C5. Astrophys. J. 837, 72 (2017)

314. Crossfield, I.J.M., Ciardi, D.R., Petigura, E.A., Sinukoff, E., Schlieder, J.E., Howard, A.W., Beichman, C.A., Isaacson, H., Dressing, C.D., Christiansen, J.L.: 197 candidates and 104 validated planets in K2's first five fields. Astrophys. J. Suppl. Ser. 226, 7 (2016)

315. University of Kyoto: Extrasolar Planets Catalogue- Kepler-1410

316. University of Kyoto: Extrasolar Planets Catalogue - Kepler 1512

317. University of Kyoto: Extrasolar Planets Catalogue - Kepler 560

318. Rodriguez, J.E., Vanderburg, A., Zieba, S., Kreidberg, L., Morley, C. V., Eastman, J.D., Kane, S.R., Spencer, A., Quinn, S.N., Cloutier, R., Huang, C.X., Collins, K.A., Mann, A.W., Gilbert, E., Schlieder, J.E., Quintana, E. V., Barclay, T., Suissa, G., Kopparapu, R. kumar, Dressing, C.D., 
Ricker, G.R., Vanderspek, R.K., Latham, D.W., Seager, S., Winn, J.N., Jenkins, J.M., BertaThompson, Z., Boyd, P.T., Charbonneau, D., Caldwell, D.A., Chiang, E., Christiansen, J.L., Ciardi, D.R., Colón, K.D., Doty, J., Gan, T., Guerrero, N., Günther, M.N., Lee, E.J., Levine, A.M., Lopez, E., Muirhead, P.S., Newton, E., Rose, M.E., Twicken, J.D., Villaseñor, J.N.: The First Habitable Zone Earth-Sized Planet From TESS II: Spitzer Confirms TOI-700 d. (2020)

319. Barclay, T., Quintana, E. V, Adams, F.C., Ciardi, D.R., Huber, D., Foreman-mackey, D., Montet, B.T., Caldwell, D.: THE FIVE PLANETS IN THE KEPLER-296 BINARY SYSTEM ALL ORBIT THE PRIMARY : A STATISTICAL AND ANALYTICAL ANALYSIS. Astrophys. J. 809, 7 (2015). https://doi.org/10.1088/0004-637X/809/1/7

320. Cartier, K.M.S., Gilliland, R.L., Wright, J.T., Ciardi, D.R.: REVISION OF EARTH-SIZED KEPLER PLANET CANDIDATE PROPERTIES WITH HIGH-RESOLUTION IMAGING BY THE HUBBLE SPACE TELESCOPE is. Astrophys. J. 804, 1-16 (2015). https://doi.org/10.1088/0004-637X/804/2/97

321. Muirhead, P.S., Hamren, K., Schlawin, E., Covey, K.R., Lloyd, J.P.: CHARACTERIZING THE COOL KEPLER OBJECTS OF INTERESTS . NEW EFFECTIVE TEMPERATURES, METALLICITIES, MASSES , AND RADII OF LOW-MASS KEPLER PLANET-CANDIDATE HOST STARS. 37, (2012). https://doi.org/10.1088/2041-8205/750/2/L37

322. University of Kyoto: Extrasolar Planets Catalogue - Kepler 438

323. Williams, D.R.: Sun Fact Sheet

324. Rein, H., Fujii, Y., Spiegel, D.S.: Some inconvenient truths about biosignatures involving two chemical species on Earth-like exoplanets. Proc. Natl. Acad. Sci. U. S. A. 111, 6871-5 (2014). https://doi.org/10.1073/pnas.1401816111

325. Bolton, J.R., Strickler, S.J., Connolly, J.S.: Limiting and realizable efficiencies of solar photolysis of water. Nature. 316, 495-500 (1985)

326. Chapman, S.: A theory of upper-atmospheric ozone. In: Memoirs of the Royal meteorological society. pp. 103-125. R. Clark, Ltd., Edinburgh (1929)

327. Hockstad, L.: Inventory of U.S. Greenhouse Gas Emission and Sinks. , 1200 Pennsylvnia Ave, N.W., Washington, DC 20460, U.S.A (2011)

328. Olaya-Abril, A., Hidalgo-Carrillo, J., Luque-Almagro, V.M., Fuentes-Almagro, C., Urbano, F.J., Moreno-Vivián, C., Richardson, D.J., Roldán, M.D.: Exploring the Denitrification Proteome of Paracoccus denitrificans PD1222. Front. Microbiol. 9, 1137 (2018). https://doi.org/10.3389/fmicb.2018.01137

329. Jamieson, C.S., Bennett, C.J., Mebel, A.M., Kaiser, R.I.: Investigating the mechanism for the formation of nitrous oxide [N2O(X1AE+)] in extraterrestrial ices. Astrophys. J. 624, 436-447 (2005). https://doi.org/https://doi.org/10.1086/428933

330. Ravishankara, A.R., Daniel, J.S., Portmann, R.W.: Nitrous oxide (N2O): The dominant ozonedepleting substance emitted in the 21st century. Science (80-. ). 326, 123-125 (2009). https://doi.org/10.1126/science.1176985

331. Leigh, G.J. ed: Nitrogen Fixation at the Millennium. Elsevier science B.V. (2002)

332. Mtaita, T.A.: Food. In: Hazeltine, B. and Bull, C. (eds.) Field Guide to Appropriate Technology. pp. 277-480. Elsevier Inc. (2003)

333. Betz, A.L.: Ammonia in the Giant Planets. In: Amazing Light. pp. 73-78. Springer New York 
Confidental Revision of the Paper - Ariel consortium WG Astrobiology and Prebiotic Chemistry Experimental Astronomy: Special issue for Ariel Phase B

https://link.springer.com/journal/10686, the deadline for submission September 14, 2020

(1996)

334. Oze, C., Sharma, M.: Have olivine, will gas: Serpentinization and the abiogenic production of methane on Mars. Geophys. Res. Lett. 32, L10203 (2005).

https://doi.org/10.1029/2005GL022691

335. Weinstock, B., Niki, H.: Carbon monoxide balance in nature. Science (80-. ). 176, 290-292 (1972). https://doi.org/10.1126/science.176.4032.290

336. Pilcher, C.B.: Biosignatures of Early Earths. Astrobiology. 3, 471-486 (2003). https://doi.org/10.1089/153110703322610582

337. Segura, A., Kasting, J.F., Meadows, V., Cohen, M., Scalo, J., Crisp, D., Butler, R.A.H., Tinetti, G.: Biosignatures from Earth-like planets around M dwarfs. Astrobiology. 5, 706-725 (2005). https://doi.org/10.1089/ast.2005.5.706

338. Kolusu, S.R., Schlünzen, K.H., Grawe, D., Seifert, R.: Determination of chloromethane and dichloromethane in a tropical terrestrial mangrove forest in Brazil by measurements and modelling. Atmos. Environ. 173, 185-197 (2018). https://doi.org/10.1016/j.atmosenv.2017.10.057

339. Roels, J., Verstraete, W.: Biological formation of volatile phosphorus compounds. Bioresour. Technol. 79, 243-250 (2001). https://doi.org/10.1016/S0960-8524(01)00032-3

340. Gassmann, G., Van Beusekom, J.E.E., Glindemann, D.: Offshore atmospheric phosphine. Naturwissenschaften. 83, 129-131 (1996). https://doi.org/10.1007/BF01142178

341. Brucato, J.R., Baratta, G.A., Strazzulla, G.: An infrared study of pure and ion irradiated frozen formamide. Astron. Astrophys. 455, 395-399 (2006). https://doi.org/10.1051/00046361:20065095

342. Khare, B.N., Sagan, C., Thomson, W.R., Arakawa, E.T., Meisse, C., Tuminello, P.S.: Optical Properties of Poly-HCN and their Astronomical Applications. Rev. Can. Chim. 72, 678-694 (1994). https://doi.org/10.1139/v94-093

343. Hazen, R.M., Sverjensky, D.A.: Mineral Surfaces, Geochemical Complexities, and the Origins of Life. Cold Spring Harb. Perspect. Biol. 2, (2010). https://doi.org/10.1101/cshperspect.a002162

344. Rode, B.M.: Peptide and the origin of life. Peptides. 20, 773-786 (1999). https://doi.org/10.1016/S0196-9781(99)00062-5

345. Cleaves, H.J., Chalmers, J.H., Lazcano, A., Miller, S.L., Bada, J.L.: Chemical Evolution across Space \& Time. American Chemical Society, Washington, DC (2008)

346. Wang, Y., Tennyson, J., Yurchenko, S.N.: Empirical Line Lists in the ExoMol Database. (2020). https://doi.org/10.3390/atoms8010007 